\title{
Evaluation of Kitchen Cooking Appliance Efficiency Test Procedures
}

Steven J. Nabinger

U.S. Department of Commerce

National Institute of Standards and Technology

Building and Fire Research Laboratory

Gaithersburg, Maryland 20899

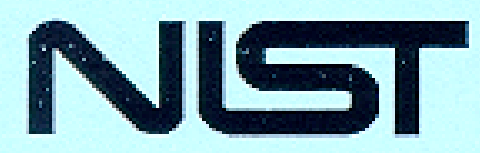

United States Department of Commerce

Technology Administration

National Institute of Standards and Technology 


\section{Evaluation of Kitchen Cooking Appliance Efficiency Test Procedures}

Steven J. Nabinger

U.S. Department of Commerce

National Institute of Standards and Technology

Building and Fire Research Laboratory

Gaithersburg, Maryland 20899

January 1999

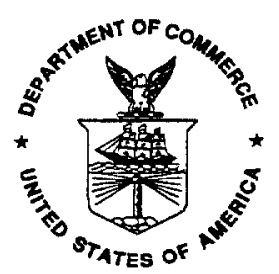

U.S. Department of Commerce

William M. Daley, Secretary

Technology Administration

Gary R. Bachula, Acting Under Secretary for Technology

National Institute of Standards and Technology

Raymond Kammer, Director 


\begin{abstract}
In 1978, the Department of Energy (DOE) published a Final Rule containing test procedures for measuring the efficiency and energy consumption of conventional ranges, ovens, cooking tops, and microwave ovens. Based on a number of technical concerns, including a request from the Association of Home Appliance Manufacturers (AHAM) to adopt the International Electrotechnical Commission's Standard 705 and Amendment 2 as the test method for testing microwave ovens, DOE initiated a revision of the standard in 1993. These efforts resulted in a Proposed Rule that was released for public comment in March of 1995.

In support of the revision process, NIST performed energy efficiency and energy consumption measurements consistent with the Proposed Rule on five household kitchen cooking appliances. The specific appliances tested included an electric oven, a gas oven, an electric cooking top, a gas cooking top, and a microwave oven. A series of tests was performed on each appliance to evaluate the feasibility of implementing the test methods within the Proposed Rule and the accuracy of the results. NIST experienced no significant problems complying with or implementing any of the test procedures. The test results for the ovens and cooking tops were repeatable with good accuracy, while the accuracy and repeatability of the microwave oven tests were dependent on the measurement equipment and details of the test method. This report contains a discussion of the procedures and a summary of the test results.
\end{abstract}

KEY WORDS: cooking appliances, cooking tops, energy consumption, energy efficiency, kitchen appliances, microwave ovens, ovens, ranges, test procedures, testing. 


\section{BLANK PAGE}




\section{TABLE OF CONTENTS}

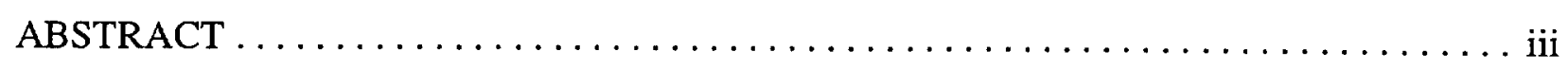

NOMENCLATURE $\ldots \ldots \ldots \ldots \ldots \ldots \ldots \ldots \ldots \ldots \ldots \ldots \ldots \ldots \ldots \ldots \ldots \ldots \ldots$ vii

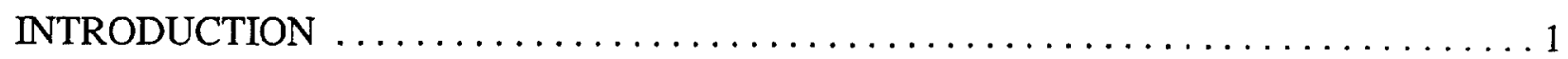

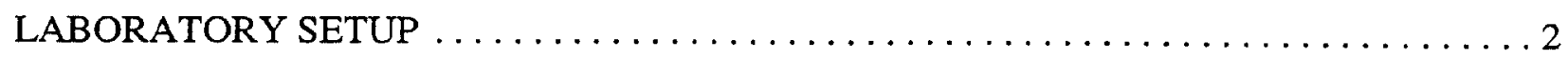

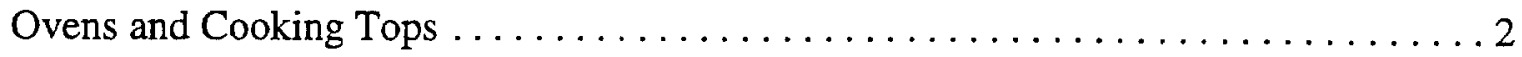

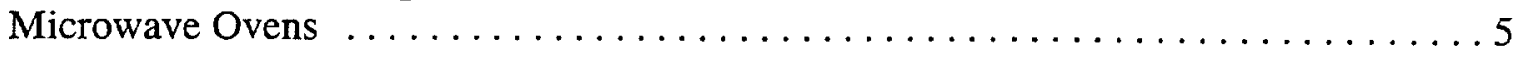

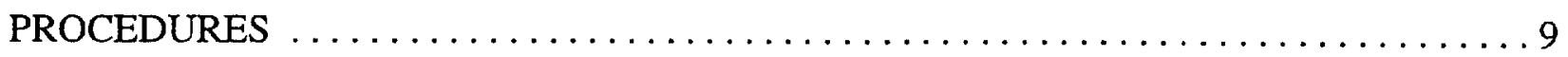

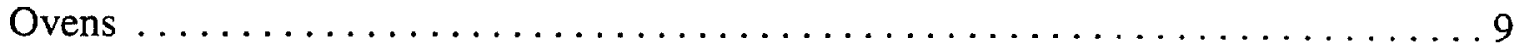

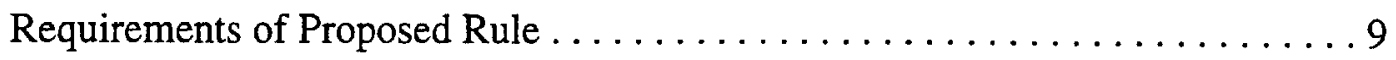

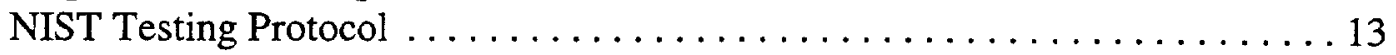

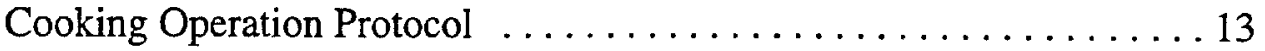

Self-cleaning Operation Protocol $\ldots \ldots \ldots \ldots \ldots \ldots \ldots \ldots \ldots \ldots$

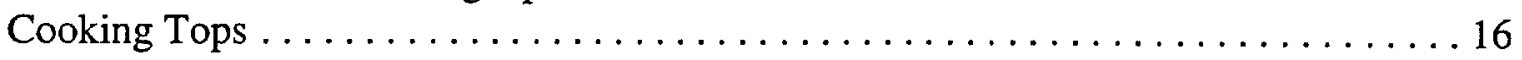

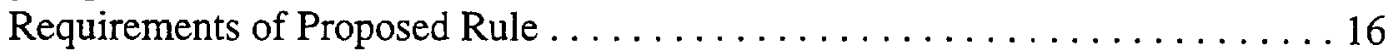

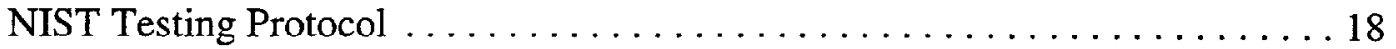

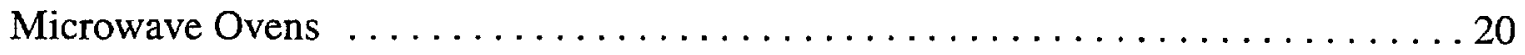

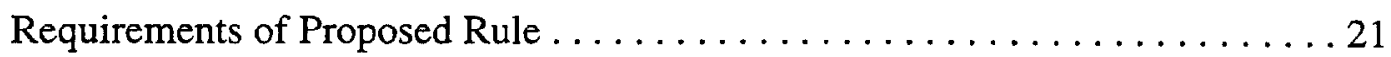

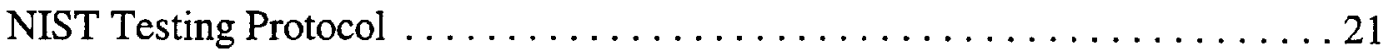

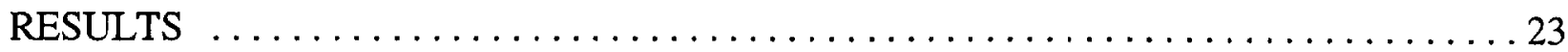

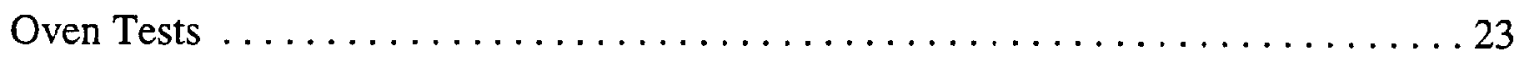

Response of Oven to Energy Consumption Test $\ldots \ldots \ldots \ldots \ldots \ldots \ldots 24$

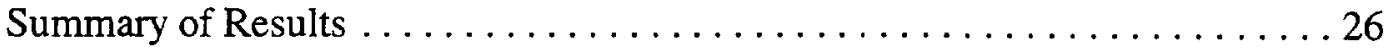

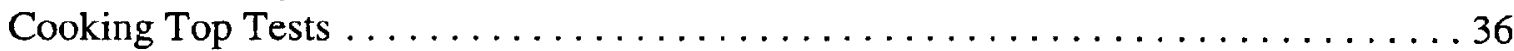

Response of Cooking Top to Energy Consumption Test ............. 36

Summary of Results ................................. 37

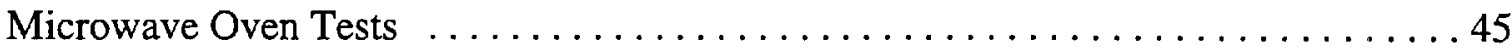

Response of Microwave Oven to Energy Consumption Test $\ldots \ldots \ldots \ldots .45$

Summary of Results ............................. 48

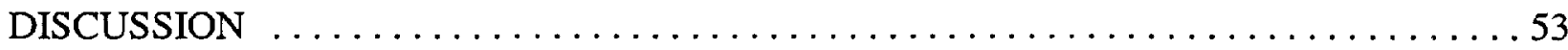

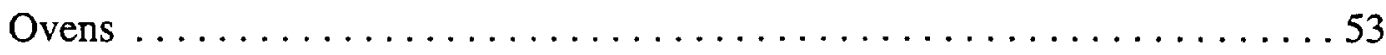

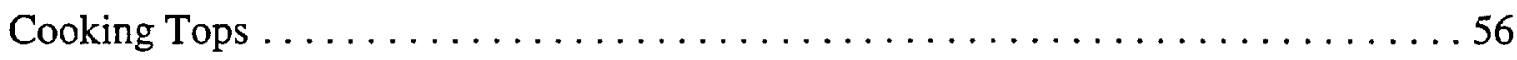

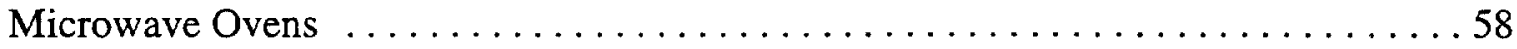

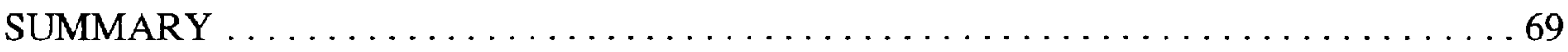


Results

Important Issues

FINAL RULE Issued In 1997

APPENDIX A: Summary of Results of Conventional Electric Oven Tests $\ldots \ldots \ldots \ldots \ldots$

APPENDIX B: Summary of Results of Conventional Gas Oven Tests $\ldots \ldots \ldots \ldots$ 


\section{NOMENCLATURE}

$\mathrm{C}=$ Conversion factor from watts to kilowatts, $0.001 \mathrm{~kW} / \mathrm{W}$.

$\mathrm{C}_{\mathrm{p}}=$ Specific heat of test blocks, $0.23 \mathrm{Btu} / \mathrm{lb}-{ }^{\circ} \mathrm{F}\left(0.96 \mathrm{~kJ} / \mathrm{kg}-{ }^{\circ} \mathrm{C}\right)$.

$\mathrm{C}_{\mathrm{PC}}=$ Specific heat of test load container for microwave oven tests, $0.21 \mathrm{Btu} / \mathrm{lb}-{ }^{\circ} \mathrm{F}$ $\left(0.88 \mathrm{~kJ} / \mathrm{kg}-{ }^{\circ} \mathrm{C}\right)$.

$\mathrm{C}_{\mathrm{PW}}=$ Specific heat of water test load for microwave oven tests, $1.0 \mathrm{Btu} / \mathrm{b}-{ }^{\circ} \mathrm{F}$ $\left(4.187 \mathrm{~kJ} / \mathrm{kg}-{ }^{\circ} \mathrm{C}\right)$.

$\mathrm{E}_{\mathrm{A}} \quad=$ Energy consumed by oven at the end of the last "ON" period before the test block reaches $\mathrm{T}_{\mathrm{O}}$.

$\mathrm{E}_{\mathrm{B}} \quad=$ Energy consumed by oven at the beginning of the "ON" period following the measurement $T_{A}$.

$\mathrm{E}_{\mathrm{C}} \quad=$ Energy consumed by oven at the end of the "ON" period which starts with $\mathrm{T}_{\mathrm{B}}$.

$\mathrm{E}_{\mathrm{D}} \quad=$ Energy consumed by oven at the start of the "ON" period which follows measurement of $\mathrm{T}_{\mathrm{C}}$.

$\mathrm{E}_{\mathrm{AB}}=\left(\mathrm{E}_{\mathrm{A}}+\mathrm{E}_{\mathrm{B}}\right) / 2$

$\mathrm{E}_{\mathrm{CD}}=\left(\mathrm{E}_{\mathrm{C}}+\mathrm{E}_{\mathrm{D}}\right) / 2$

$\mathrm{E}_{\mathrm{AO}}=$ Total annual energy consumption of conventional electric oven.

$\mathrm{E}_{\mathrm{AOE}}=$ Total annual secondary (electric) energy consumption of conventional gas oven.

$\mathrm{E}_{\mathrm{AOG}}=$ Total annual primary (gas) energy consumption of conventional gas oven.

$\mathrm{E}_{\mathrm{CA}}=$ Annual energy consumption of conventional electric cooking top; Total annual energy consumption of conventional gas cooking top.

$\mathrm{E}_{\mathrm{CC}}=$ Annual cooking energy consumption conventional gas cooking top.

$\mathrm{E}_{\mathrm{CL}}=$ Annual clock energy consumption.

$\mathrm{E}_{\mathrm{CO}}=$ Annual primary cooking energy consumption of a conventional oven.

$\mathrm{E}_{\mathrm{CT}}=$ Conventional cooking top surface unit test energy consumption. 
$\mathrm{E}_{\mathrm{IC}}=$ Electrical energy consumption of ignition device during gas cooking top surface unit energy consumption test.

$\mathrm{E}_{\mathrm{IO}}=$ Energy consumption of electrical components required for gas oven operation.

$\left(\mathrm{E}_{\mathrm{IO}}\right)_{1}=$ Energy consumption of electrical components required for gas oven operating in forced convection mode.

$\left(\mathrm{E}_{\mathrm{IO}}\right)_{2}=$ Energy consumption of electrical components required for gas oven operating in natural convection mode.

$\mathrm{E}_{\mathrm{IS}} \quad=$ Secondary (electrical) energy consumed during the self-cleaning operation of a gas oven.

$\mathrm{E}_{\mathrm{M}} \quad=$ Energy consumption during a microwave oven test.

$\mathrm{E}_{\mathrm{MO}}=$ Annual energy consumption of microwave oven.

$\mathrm{E}_{\mathrm{O}} \quad=$ Average test energy consumption of conventional oven.

$\left(E_{\mathrm{O}}\right)_{1}=$ Test energy consumption of conventional oven operating in forced convection mode.

$\left(\mathrm{E}_{\mathrm{O}}\right)_{2}=$ Test energy consumption of conventional oven operating in natural convection mode.

$\mathrm{E}_{\mathrm{PC}} \quad=$ Annual energy consumption of any continuously burning pilot lights of gas cooking top.

$\mathrm{E}_{\mathrm{PO}}=$ Annual pilot light energy consumption of gas oven.

$\mathrm{E}_{\mathrm{S}} \quad=$ Primary energy consumption during self-cleaning oven test.

$\mathrm{E}_{\mathrm{SC}} \quad=$ Annual primary energy consumption of oven self-cleaning operation.

$\mathrm{E}_{\mathrm{SO}} \quad=$ Annual secondary cooking energy consumption of a gas oven.

$\mathrm{E}_{\mathrm{SS}}=$ Annual secondary energy consumption of gas oven self-cleaning operation.

$\mathrm{E}_{\mathrm{T}} \quad=$ Output energy of microwave oven to test load and container.

Eff $_{\mathrm{AO}}=$ Conventional oven cooking efficiency.

Eff $_{\mathrm{CT}}=$ Conventional cooking top efficiency. 


$$
\begin{aligned}
& \mathrm{Eff}_{\mathrm{MO}}=\text { Microwave oven efficiency. } \\
& \mathrm{Eff}_{\mathrm{SU}}=\text { Surface unit cooking efficiency. } \\
& \mathrm{H}=\text { Heating value of the gas used in the test, expressed in Btu per standard cubic } \\
& \text { foot }(\mathrm{kJ} / \mathrm{L}) \text {. } \\
& \mathrm{H}_{\mathrm{e}}=\text { Conversion factor from Wh to Btu }(\mathrm{kJ}), 3.412 \mathrm{Btu} / \mathrm{Wh}(3.6 \mathrm{~kJ} / \mathrm{Wh}) \text {. } \\
& \mathrm{H}_{\mathrm{k}}=\text { Number of hours in a year, } 8,760 \text {. } \\
& \mathrm{H}_{\mathrm{n}} \quad=\text { Heating value of the natural gas. } \\
& \mathrm{H}_{\mathrm{p}} \quad=\text { Heating value of the propane gas. } \\
& \mathrm{L}_{\mathrm{C}}=\text { Test duration of an energy consumption test of cooking top pilot light. } \\
& \mathrm{L}_{\mathrm{O}}=\text { Test duration of an energy consumption test of oven pilot light. } \\
& \mathrm{M}_{\mathrm{C}} \quad=\text { Weight (mass) of the test load container for microwave oven tests. } \\
& \mathrm{M}_{\mathrm{w}} \quad \text { = Weight (mass) of the water test load for microwave oven tests. } \\
& \mathrm{O}_{\mathrm{CT}}=\text { Annual useful cooking energy output of cooking tops, } 209.4 \mathrm{kWh}(753,800 \mathrm{~kJ}) \text { per } \\
& \text { year for electric cooking tops, } 732,500 \mathrm{Btu}(772,800 \mathrm{~kJ}) \text { per year for gas cooking tops. } \\
& \mathrm{O}_{\mathrm{M}}=\text { Annual useful cooking energy output of microwave oven, } 77.3 \mathrm{kWh}(278,300 \mathrm{~kJ}) \text { per } \\
& \mathrm{P}_{\mathrm{MIN}}=\text { Minimum input power during microwave oven energy consumption test. }
\end{aligned}
$$


$\mathrm{P}_{\mathrm{O}} \quad=$ Volume of gas consumed during energy consumption test of oven pilot light.

$\mathrm{P}_{\mathrm{R}} \quad=$ Gas flow rate during energy consumption test for oven pilot light.

$\mathrm{P}_{\mathrm{T}} \quad=$ Output power of microwave oven to the test load and container.

$\mathrm{R}_{\mathrm{CT}}=$ Energy factor of conventional cooking top.

$\mathrm{R}_{\mathrm{M}} \quad=$ Energy factor of microwave oven.

$\mathrm{R}_{\mathrm{O}} \quad=$ Energy factor of conventional oven.

$\mathrm{S}_{\mathrm{e}} \quad=$ Average number of self-cleaning operations of an electric oven per year.

$\mathrm{S}_{\mathrm{g}} \quad=$ Average number of self-cleaning operations of a gas oven per year.

$\mathrm{T}=$ Temperature rise of test block, $234^{\circ} \mathrm{F}\left(112.2^{\circ} \mathrm{C}\right)$.

$\mathrm{T}_{\mathrm{A}}=$ Block temperature at end of last "ON" period of oven before test block reaches $\mathrm{T}_{\mathrm{O}}$.

$T_{B}=$ Block temperature at beginning of "ON" period following measurement of $T_{A}$.

$\mathrm{T}_{\mathrm{C}}=$ Block temperature at end of "ON" period that starts with $\mathrm{T}_{\mathrm{B}}$.

$T_{D}=$ Block temperature at beginning of "ON" period that follows measurement of $T_{C}$.

$\mathrm{T}_{\mathrm{AB}}=\left(\mathrm{T}_{\mathrm{A}}+\mathrm{T}_{\mathrm{B}}\right) / 2$

$\mathrm{T}_{\mathrm{CD}}=\left(\mathrm{T}_{\mathrm{C}}+\mathrm{T}_{\mathrm{D}}\right) / 2$

$\mathrm{T}_{0} \quad=$ Ambient room air temperature for microwave oven test.

$\mathrm{T}_{1} \quad=$ Initial water test load temperature for microwave oven test.

$\mathrm{T}_{2} \quad=$ Final water test load temperature for microwave oven test.

$\mathrm{T}_{\mathrm{CT}}=$ Final test block temperature of cooking top surface unit energy consumption test.

$\mathrm{T}_{\mathrm{I}} \quad=$ Initial test block temperature for oven and cooking top tests.

$\mathrm{T}_{\mathrm{mag}}=$ Temperature of microwave oven magnetron.

$\mathrm{T}_{\mathrm{O}}=\mathrm{T}$ plus the initial test block temperature. 
$T_{R}=$ Ambient room air temperature for oven and cooking top tests.

$\mathrm{T}_{\mathrm{SU}}=$ Increase in test block temperature during cooking top surface unit test, $\mathrm{T}_{\mathrm{CT}}-\mathrm{T}_{\mathrm{I}}$

$\mathrm{T}_{\mathrm{T}} \quad=$ Total test time of cooking top surface unit energy consumption test.

$\mathrm{V}_{\mathrm{A}}=$ Volume of gas consumed at end of last "ON" period before test block reaches $\mathrm{T}_{\mathrm{a}}$.

$V_{B}=$ Volume of gas consumed at beginning of "ON" period following measurement of $T_{A}$.

$V_{C}=$ Volume of gas consumed at end of "ON" period that starts with $T_{B}$.

$V_{D}=$ Volume of gas consumed at start of "ON" period that follows measurement of $T_{C}$.

$\mathrm{W}_{1}=$ Measured weight (mass) of test block used in oven tests.

$\mathrm{W}_{2}=$ Weight (mass) of small test block used with electric surface units less than $7 \mathrm{in}$. $(178 \mathrm{~mm})$ in diameter.

$\mathrm{W}_{3} \quad$ = Weight (mass) of large block used with all gas surface units and electric surface units greater than 7 in. $(178 \mathrm{~mm})$ in diameter. 


\section{INTRODUCTION}

In accordance with requirements of the Energy Policy and Conservation Act, the Department of Energy (DOE) published a Final Rule (43 FR 20120) in 1978 prescribing a test method for measuring the energy efficiency and energy consumption of the kitchen cooking appliances covered under the Act. Included among the kitchen cooking appliances were conventional ranges, ovens, cooking tops, and microwave ovens. When a new energy consumption standard was proposed for these appliances in 1993, concerns about the test methods in the 1978 Rule were expressed by U.S. home appliance manufacturers on the grounds that the method for testing microwave ovens was difficult to use and did not produce repeatable results. DOE therefore initiated efforts to revise the 1978 test procedures for kitchen cooking appliances. During the revision process the Association of Home Appliance Manufacturers (AHAM) requested that DOE adopt the International Electrotechnical Commission (IEC) Standard 705 (1988) and Amendment 2 (1993) as the standard method for testing microwave ovens. DOE took AHAM's request into consideration, and published the Proposed Rule in the Federal Register on March 23, 1995 (43 FR 15330).

To support the revision process, NIST configured two laboratory facilities to test the energy consumption of five kitchen cooking appliances in compliance with the test procedures of the Proposed Rule. The specific appliances tested included a conventional electric oven, a conventional gas oven, a conventional electric cooking top, a conventional gas cooking top, and a microwave oven. A series of tests was performed on each appliance to evaluate the feasibility of implementing the revised test methods and the accuracy of the results. Though multiple ovens and ranges are included within the rule, such combination appliances were not evaluated in this effort. Multiple ovens consist of more than one oven in a single appliance shell, and ranges consist of a combination oven and cooking top. The measurements and calculations in the proposed rule are merely a combination of oven and cooking top measurements and calculations.

This report contains the results of laboratory tests and NIST's determination of the technical accuracy and workability of the 1994 and 1995 versions of Appendix I to Subpart B of the U.S. Department of Energy's 10 CFR part 430 titled "Test Procedures for Kitchen Ranges, Ovens, and Microwave Ovens Proposed Rule." Appendix I to Subpart B is specifically applicable to household cooking appliances and is titled "Uniform Test Method for Measuring the Energy Consumption of Conventional Ranges, Conventional Cooking Tops, Conventional Ovens, and Microwave Ovens." The IEC 705 method, which was adopted by reference in the 1995 version of the Proposed Rule, is known as the International Electrotechnical Commission Publication 705 (IEC 705) and Amendment 2-1993, Section 4, Clauses 12-14, "Methods for Measuring the Performance of Microwave Ovens for Household and Similar Purposes." This method is used for determining the microwave oven power output, electrical power input, and efficiency, and was adopted and included in the Proposed Rule by reference. The Proposed Rule was first published in the Federal Register on March 23, 1995 (43 FR 15330) and remained substantially unchanged until DOE promulgated it into a Final Rule on October 3, 1997. 
Following this introduction, the second section of this report, Laboratory Setup, is presented in two parts. The first discusses the setup used to test ovens and cooking tops, and the second describes the setup used to test microwave ovens. The next section, Procedure, is split into three parts to discuss the procedures and protocols for testing the three appliance types covered by the rule: ovens, cooking tops and microwave ovens. The fourth section, Results, is also split into three parts to present the results of the oven tests, the cooking tops tests, and the microwave oven tests. Next, the Discussion section discusses the workability of the test procedures for the three appliance types. The Summary section contains a summary of the most important results and findings. The last section, Final Rule Issued in 1997, discusses changes made to the Proposed Rule and included in the Final Rule.

\section{LABORATORY SETUP}

The configuration of the laboratory setup for the ovens and cooking tops, and the test equipment, are determined by the regulations found in section 2, "Test Conditions", of the Proposed Rule. Section 2 contains the requirements for setting up the laboratory measurement equipment and apparatus and the energy supply sources associated with testing the appliances. Section 2 also gives instructions on setting up the cooking appliances.

The following two sections describe the two test facilities at NIST for determining the energy usage of conventional kitchen cooking appliances. The first section covers the test setup for ovens and cooking tops; the second covers the test setup for microwave ovens. The laboratory setups included data acquisition and control systems to monitor and record test parameters during the appliance tests. The oven and cooking tops setups also featured triggers to activate alarms for events such as changing temperature set points, power reduction, and test completion.

\section{Ovens and Cooking Tops}

The laboratory equipment specifications and setup of the equipment employed to monitor the performance of ovens and cooking tops is described in this section. All equipment specifications were within the ranges specified in section 2 "Test Conditions" of the Proposed Rule. If the equipment specifications were significantly different from the specifications of the Proposed Rule, a statement to that effect is made in this report. Figure 1 is a schematic of the laboratory setup used to test ovens and cooking tops.

A $240 \mathrm{~V}$ transformer (not shown) was used to elevate and stabilize the laboratory's $208 \mathrm{~V}$ power supply to $240 \mathrm{~V} \pm 2 \%$ as required in section 2.2 , of the Proposed Rule. A solenoid, controlled by the temperature monitoring program, was placed in the power supply line before the oven to reduce the voltage to the electric cooking top from $240 \mathrm{~V}$ to $120 \mathrm{~V}$, and thus lower the power to the cooking tops to one-quarter the maximum power as required in section 3.1 .2 of the Proposed Rule. The gas oven and cooking top required $240 \mathrm{~V} \pm 2 \%$ electrical energy supply and were plugged directly into the $240 \mathrm{~V}$ circuit. A natural gas supply line with approximately 
7.5 inches of water pressure $(1870 \mathrm{~Pa})$ was connected to the gas oven. Natural gas was supplied by a public utility, with a heating value of approximately $1025 \mathrm{Btu} / \mathrm{ft}^{3}\left(38.2 \mathrm{~kJ} / \mathrm{m}^{3}\right)$

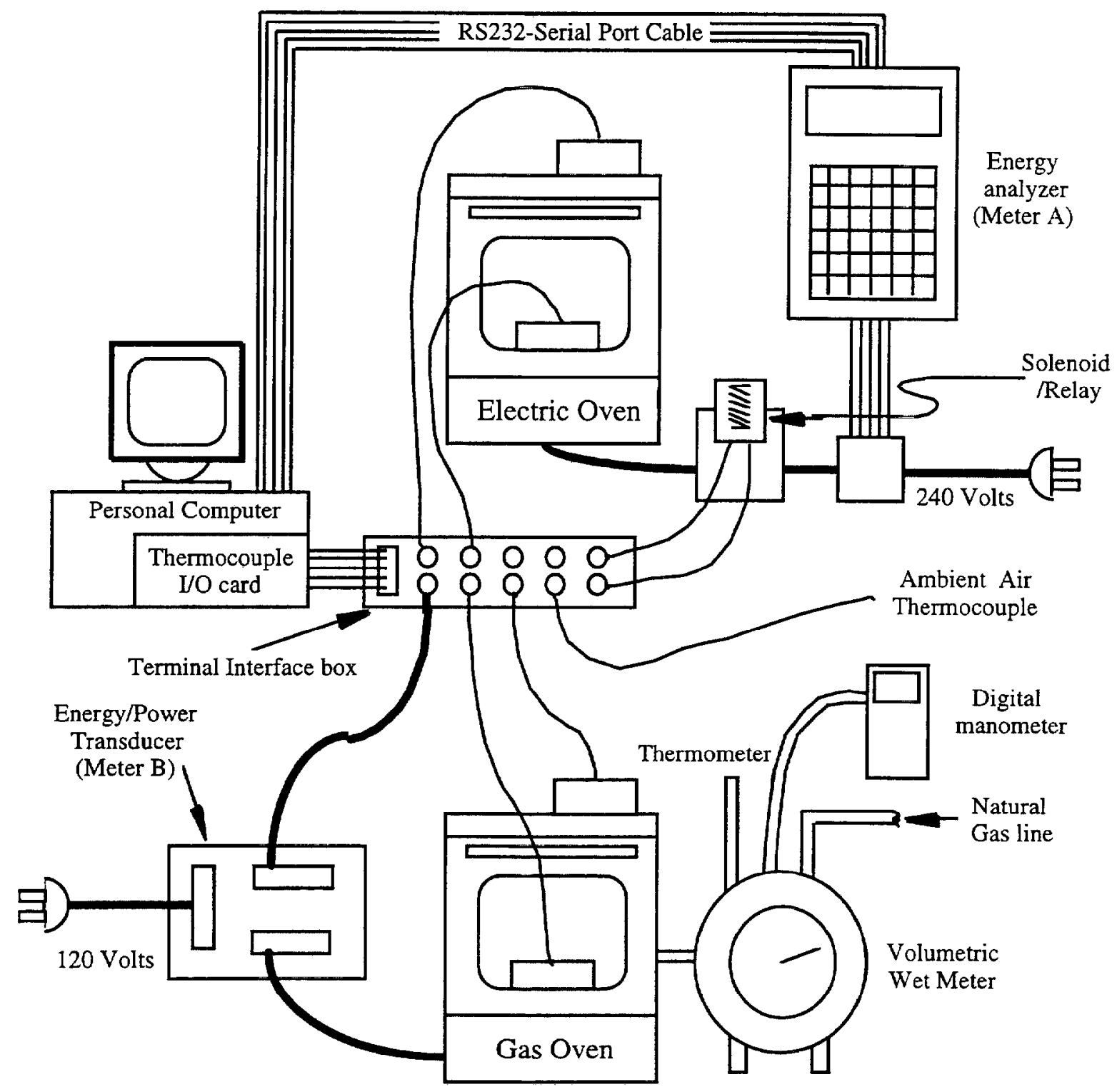

Figure 1: Schematic of Laboratory Setup for Ovens and Cooking Tops 
The electric oven and cooking tops, and the gas oven and cooking tops were part of two free standing ranges, but each one was treated as a separate appliance for the purpose of testing. They were installed and prepared for testing as prescribed by the manufacturers and section 2 of the Proposed Rule. This included connection to the energy supply sources, removal of the broiler pans, and proper insertion of the baking racks. It also included checking and adjusting the oven thermostat's set-point required to provide an average internal oven temperature equal to $325 \pm 5^{\circ} \mathrm{F}\left(180.6^{\circ} \mathrm{C} \pm 2.6^{\circ} \mathrm{C}\right)$ above the ambient room air temperature. All the gas oven burners were inspected to insure the burner adjustment provided sufficient flow to prevent a yellow flame or a flame with yellow tips. The ovens were located in an area of the laboratory where they were not subjected to any direct draft.

A personal computer with an input/output ( $/ / O)$ thermocouple card and a data-collection and instrument-control program was used to continuously monitor and record the test data including time, temperatures, voltages and electric power supplied to the gas and electric ovens and cooking tops. In specific instances, the programs were used to trigger alarms and control temperatures, voltages and electric power supplied to the appliances.

Type "E" thermocouple wire ( 20 gage), with special limits of error of $0.7^{\circ} \mathrm{F}\left(0.4^{\circ} \mathrm{C}\right)$ and a response time of $0.3 \mathrm{~s}$, was connected to the thermocouple card through an interface box and used to monitor the ambient room air temperature, oven interior temperature, oven and cooking tops surface temperature, and the oven and cooking tops load block temperatures. The type "E" thermocouple wires selected met all specifications required in section 2.9.3, "Temperature measurement equipment", of the Proposed Rulc. The junction ends of the thermocouples were either beaded or connected to weighted copper disks and located as prescribed in sections 2.4 through 2.6 of the Proposed Rule. A mercury thermometer with an uncertainty of $0.2^{\circ} \mathrm{F}\left(0.1^{\circ} \mathrm{C}\right)$ over the range of $32{ }^{\circ} \mathrm{F}$ to $122^{\circ} \mathrm{F}\left(0^{\circ} \mathrm{C}\right.$ to $\left.50^{\circ} \mathrm{C}\right)$, and a response time constant of approximately $5 \mathrm{~s}$, was used to measure the initial and final ambient room air temperature and to verify that the thermocouple measurement system was functioning properly. The Proposed Rule and IEC 705 requires that the ambient air temperature measurement device have an uncertainty of $0.45^{\circ} \mathrm{F}$ $\left(0.25^{\circ} \mathrm{C}\right)$.

An energy analyzer meter, designated "Meter A" was used to measure the energy consumption of the electric oven and cooking tops. Meter A recorded the voltage, current, power, power factor, electrical energy and frequency of the energy supply circuit. A second energy/power measurement device, designated "Meter B", was also used to measure the electrical energy consumption of the conventional gas oven and cooking tops. Both Meters $\mathrm{A}$ and $\mathrm{B}$ have maximum errors of no greater than $1 \%$ of the measured value and a resolution of $0.1 \mathrm{Wh}$ and $0.1 \mathrm{~W}$. These accuracies are better than the $1.5 \%$ required by the Proposed Rule for energy measurements and the $5 \%$ accuracy required of a power meter.

The test blocks for the ovens and cooking tops were made as specified in section 2.7 of the proposed rule. The measured weight (mass) of the anodized black test block used in the oven tests was $8.39 \mathrm{lb}(3.81 \mathrm{~kg})$, while its diameter and height were $6.25 \mathrm{in} .(159 \mathrm{~mm})$ and $2.81 \mathrm{in}$. 
(71.4 $\mathrm{mm}$ ) respectively. The small test block used in the cooking top tests had the same weight (mass) and dimensions. The measured weight (mass) of the large test block used in the cooking top tests was $18.49 \mathrm{lb}(8.39 \mathrm{~kg})$, while its diameter was 9 in. $(229 \mathrm{~mm})$ and its height was 3 in. $(76.5 \mathrm{~mm}$ ). Though the measured wcights (masses of the small test blocks indicate that they weigh less than the $8.49 \mathrm{lb} \pm 0.11 \mathrm{lb}(3.86 \mathrm{~kg} \pm 0.05 \mathrm{~kg})$ specified by the Proposed Rule, because the allowable error in the scale is $\pm 0.06 \mathrm{lb}( \pm 28.4 \mathrm{~g}$ ) all test block weights fall within the acceptable range of the Rule.

A volumetric wet meter and a gas flow meter were installed between the natural gas supply line and the gas oven and cooking top to measure the volume and flow rate of natural gas consumed during the tests. The wet meter had an uncertainty of $0.5 \%$ while the gas flow meter (not shown in Figure 1) had an uncertainty of $1.5 \%$. A thermometer and electronic pressure transducer were installed in the wet meter to measure the temperature and pressure of the gas supply to the oven and cooking tops. The thermometer had an uncertainty of $2{ }^{\circ} \mathrm{F}\left(1.1^{\circ} \mathrm{C}\right)$ with a resolution of $0.5^{\circ} \mathrm{F}\left(0.3^{\circ} \mathrm{C}\right)$, and the pressure transducer had an uncertainty of $0.5 \%$ with a resolution of 0.01 in. water column (2.5 Pa). A wall barometer (not shown in Figure 1) with a resolution of 0.27 in. water column ( $67 \mathrm{~Pa}$ ) was used to measure the barometric pressure in the laboratory. These temperature and pressure values were used to convert the measured gas volume to a "standard volume" at standard temperature and pressure.

A calorimeter (not shown in Figure 1) was set up with a sample tube inserted in the gas supply line upstream of all test equipment. The calorimeter was used to measure the heating value of the natural gas supplied to the appliances. It had an uncertainty of $\pm 0.2 \%$ of the measured value and a resolution of $0.1 \mathrm{Btu} / \mathrm{ft}^{3}\left(3.7 \mathrm{~J} / \mathrm{m}^{3}\right)$.

\section{Microwave Ovens}

The equipment and setup employed to monitor the performance of the microwave oven is described in this section. All equipment specifications were within the ranges specified in section 2 "Test Conditions" of the Proposed Rule. If the equipment specifications were significantly different from the specifications of the Proposed Rule, a statement to that effect has been made. Figure 2 is a schematic of the laboratory set up. Four different instruments were used to measure energy and/or power during testing. Meter A and meter B are the same as mentioned in the ovens and cooking tops section. These meters, along with Meter $\mathrm{C}$ and Meter D (not shown in Figure 2), are described below. Three of the four devices, Meters A, B, and C, could measure both energy and power, whereas, Meter D could measure only energy. However, Meter $\mathrm{D}$ could be used to determine the average power during a microwave oven test based on the energy it measured and the test duration. 


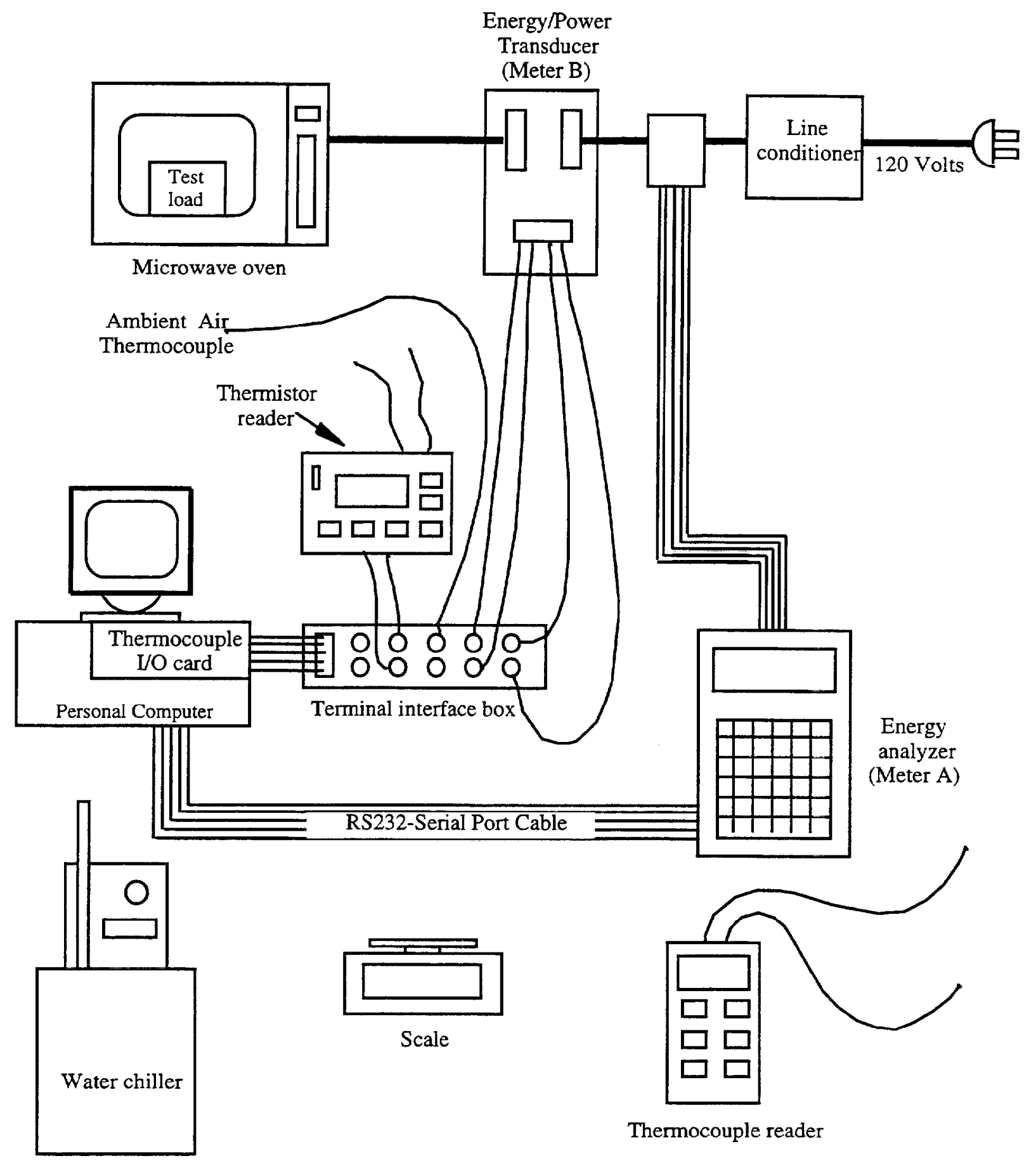

Figure 2: Schematic of Laboratory Setup for Microwave Ovens 
The technical specifications for the microwave oven tests, as published in the operators manual, include a power consumption of $1360 \mathrm{~W}$, an output power of $800 \mathrm{~W}$ (determined by IEC 705-88 test procedures), and an operating frequency of 2,450 MHZ. The test oven also featured a rotating shelf and a digital clock/timer. Utilizing the power consumption and output power factors, the microwave oven efficiency, Eff $\mathrm{MO}_{\mathrm{MO}}$, is $58 \%$.

The data acquisition system used to monitor the microwave oven test parameters consisted of a personal computer with a thermocouple input/output $(\mathrm{I} / \mathrm{O})$ board, a terminal interface box, and a data acquisition and control program. The thermocouple card is capable of reading analog or digital signals from up to eight peripheral devices. The terminal interface box is used to connect thermocouples and other peripheral devices to the I/O board via an RS232serial port cable. A schematic representation of the acquisition system components and connections are shown in Figure 2. The I/O board has a $0.05 \%$ measurement accuracy of voltage and current signals. The data acquisition and control program was written to monitor and record temperatures measured by three type " $E$ " thermocouples, one temperature measured by a thermistor device, and the power and energy measured by Meter B. Meter A was equipped with an internal recording device, and Meter $\mathrm{C}$ and Meter $\mathrm{D}$ were read from meter displays.

A line stabilizer/conditioner was placed immediately after the power supply line and before all other equipment, to provide automatic adjustment of line voltage and to compensate for low voltage. The conditioner is capable of line regulation of $120 \mathrm{~V} \pm 5 \%$ over an input range of $96 \mathrm{~V}$ to $126 \mathrm{~V}$. In all cases, the device was able to maintain the line voltage to within $\pm 1 \mathrm{~V}$ of the measured output value.

Meter A was used to monitor both energy and power consumption at 1-s intervals during each of which the meter recorded the time, true RMS power, Volt-amps power, power factor and frequency. The amount of energy consumed since the start of the test was continuously updated on the instrument's display panel. This manufacturer's calibration was checked at NIST, and the instrument was found to have an uncertainty of $\pm 1 \%$. Meter $A$ is categorized as a "true sampling" device because it samples the line voltage, current, and true RMS power every few $\mu \mathrm{s}$, then calculates the true power factor which it uses to determine the energy consumption during the elapsed time.

A second power/energy transducer, Meter B, was also determined to have an uncertainty of $\pm 1 \%$ of the reading. It outputs an analog signal for power and a pulse signal for the measured energy. The resolution is $0.01 \mathrm{~W}$ and $0.01 \mathrm{Wh}$ for power and energy respectively. The transducer is a time-series multiplierlintegrating device, which measures the true RMS power consumption at discrete time intervals and integrates that power over the time interval to determine the energy consumption. Evaluation of this device showed that it lost less than $0.1 \%$ accuracy due to phase shifts between voltage and current.

The third power/energy meter, Meter $\mathrm{C}$, is a solid-state measurement device, with an uncertainty of $\pm 1 \%$ of the measured value. It featured three digital displays, each of which could 
be set to display the instantaneous voltage, current, power, power factor, or energy measured. The resolution of the instrument was 0.01 in the units of the measured parameter.

The fourth energy meter, Meter D, was an induction energy meter, which is an energy measuring device for $120 \mathrm{~V}$ circuits. It has an uncertainty of $\pm 1.5 \%$ and a digital display with a resolution of 0.1 Wh. This meter measures energy without measuring power; however, the average power consumption during a test can be calculated based on the consumption energy and test duration.

Mercury thermometers were used to measure the ambient air and test load temperatures over a temperature range of $30^{\circ} \mathrm{F}$ to $124^{\circ} \mathrm{F}\left(-1^{\circ} \mathrm{C}\right.$ to $\left.51^{\circ} \mathrm{C}\right)$. Their calibration is certified as traceable to NIST with an uncertainty of $\pm 0.09^{\circ} \mathrm{F}\left( \pm 0.05^{\circ} \mathrm{C}\right)$ and a resolution of $\pm 0.18^{\circ} \mathrm{F}$ $\left( \pm 0.10^{\circ} \mathrm{C}\right)$. This accuracy is one-fifth of that required by the Proposed Rule. It takes approximately $20 \mathrm{~s}$ for the thermometer to reach thermal equilibrium with the test load and accurately measure the temperature of the load.

The beaded thermocouples were used to measure the ambient air, test load and magnetron temperatures. They were made of high performance, type "E" thermocouple wire having special limits of error. The combined thermocouple and acquisition system (without on-site calibration) had an uncertainity of $\pm 1.1^{\circ} \mathrm{F}\left( \pm 0.6^{\circ} \mathrm{C}\right)$ over a range of $-94^{\circ} \mathrm{F}$ to $212^{\circ} \mathrm{F}\left(-70^{\circ} \mathrm{C}\right.$ to $\left.100^{\circ} \mathrm{C}\right)$, and a time constant of approximately $0.5 \mathrm{~s}$. The uncertainty of the individual thermocouples combined with the acquisition system ranged from $\pm 0.05^{\circ} \mathrm{F}$ to $\pm 0.13^{\circ} \mathrm{F}$ $\left( \pm 0.03{ }^{\circ} \mathrm{C}\right.$ to $\left.\pm 0.07^{\circ} \mathrm{C}\right)$ after calibration at NIST, nearly one-tenth of that required by the Rule.

The thermistor system used to measure the ambient air and test load temperatures is capable of measuring and displaying temperatures from five separate thermistor probes over five different channels. The reader can also be set to output the temperature of any one of the 5 channels as an analog signal to be recorded by a personal computer. The thermistor system is certified as NIST traceable, having an uncertainty of $\pm 0.4^{\circ} \mathrm{F}\left( \pm 0.2^{\circ} \mathrm{C}\right)$ over the $32^{\circ} \mathrm{F}$ to $158^{\circ} \mathrm{F}$ $\left(0^{\circ} \mathrm{C}\right.$ to $\left.70^{\circ} \mathrm{C}\right)$ range. The system (combined thermistor reader and probes) has an accuracy of $\pm 0.7^{\circ} \mathrm{F}\left( \pm 0.4^{\circ} \mathrm{C}\right)$ over the same range. The time constant for the air/gas probe is $10 \mathrm{~s}$, and the time constant for the liquid immersion probe is $3.5 \mathrm{~s}$.

The chiller used to chill the test water prior to testing has a stainless steel reservoir with a $3.25 \mathrm{gal}(12.3 \mathrm{~L})$ capacity. It is equipped with a $2,730 \mathrm{Btu} / \mathrm{h}(800 \mathrm{~W})$ heater and has a nominal cooling capacity of $1,705 \mathrm{Btu} / \mathrm{h}(500 \mathrm{~W})$. The temperature range of the chiller is from $-13^{\circ} \mathrm{F}$ to $302^{\circ} \mathrm{F}\left(-25^{\circ} \mathrm{C}\right.$ to $\left.150^{\circ} \mathrm{C}\right)$. The unit has a temperature stability of $0.02{ }^{\circ} \mathrm{F}\left(0.01{ }^{\circ} \mathrm{C}\right)$ and a digital controller read out with a resolution of $0.2^{\circ} \mathrm{F}\left(0.1^{\circ} \mathrm{C}\right)$.

The glass vessel used to hold the test load is a borosilicate glass container of $0.1 \mathrm{in}$. $(3 \mathrm{~mm})$ thickness with an outside diameter of $6.7 \mathrm{in}(170 \mathrm{~mm})$ and a height of 3.1 in $(80 \mathrm{~mm})$. The test load consisted of $2.2 \mathrm{lb} \pm 0.01 \mathrm{lb}(1000 \mathrm{~g} \pm 5 \mathrm{~g})$ of distilled water. The scale used to measure the weight (mass) to the test load has an uncertainty of $\pm 0.5 \mathrm{~g}$. 


\section{PROCEDURES}

This section describes the procedures in the Proposed Rule used to determine the annual energy consumption, energy efficiency, and energy factor of conventional ovens, cooking tops, and microwave ovens. For each appliance, a description of the Proposed Rule is presented first, followed by a summary of the test protocol used by NIST. Certain phrases have been underlined within the sections titled "Requirements of Proposed Rule." The underlined phrases are the titles given to calculated parameters. All section numbers in this section refer to the Proposed Rule, unless stated otherwise. All procedures of the "Ovens" and "Cooking tops" sections pertain to both electric and gas appliances unless stated as applying to either electric or gas appliances.

\section{Ovens}

The objective of the oven test method in DOE's Proposed Rule is to determine the total annual energy consumption, the energy efficiency, and the energy factor of conventional electric and gas ovens. The determination of these factors requires the determination of a number of intermediate parameters, which are in turn obtained by performing a self-cleaning oven test, a pilot light energy consumption measurement, and a measurement of clock power (when these functions are available on the test oven). A summary of these methods are included below along with those of the basic oven test.

\section{Requirements of Proposed Rule}

This section provides a description of the DOE Proposed Rule test procedures for determining the annual energy consumption, energy efficiency and energy factor for conventional electric and gas ovens.

Before the start of oven tests, the conditions of section 2, Test Conditions, of the Proposed Rule must be met. Section 2 contains specifications for the laboratory equipment and conditions imposed on the laboratory environment and the electrical and natural gas supply sources. These equipment specifications have already been presented; the environmental and energy supply requirements of section 2 are presented here. The ambient room air temperature must be between $68^{\circ} \mathrm{F}$ and $86^{\circ} \mathrm{F}\left(20^{\circ} \mathrm{C}\right.$ and $\left.30^{\circ} \mathrm{C}\right)$ and the appliance and test block at the normal non-operating temperature as defined in section 1.6 and described in section 2.5 of the Proposed Rule. The oven racks must be properly in place, the broiler pans removed as instructed by the manufacturer, and the supply voltage within the acceptable range of $240 \mathrm{~V} / 120 \mathrm{~V} \pm 2 \%$ based on the manufacturer's specified voltage. The clock is disconnected if not an integral part of the temperature control circuit. The conventional oven thermostat setting required to provide an average internal temperature rise of $325^{\circ} \mathrm{F} \pm 5^{\circ} \mathrm{F}\left(162.8^{\circ} \mathrm{C} \pm 2.8^{\circ} \mathrm{C}\right)$ above the room ambient air temperature is determined. 
In the case of conventional gas ovens, the pressure in the supply gas line must be between 7 in. water column and $10 \mathrm{in}$. water column (1700 Pa and $2500 \mathrm{~Pa}$ ) for natural gas, or if the oven is convertible and propane is used, the pressure must be between $11 \mathrm{in}$. water column and 13 in. water column $(2700 \mathrm{~Pa}$ and $3200 \mathrm{~Pa})$. The heating value of the natural gas, $\mathrm{H}_{\mathrm{n}}$, or propane, $\mathrm{H}_{\mathrm{p}}$, (whichever is applicable) is determined, and the flames from the oven burners are adjusted to insure that they do not appear yellow or with yellow tips. If yellow flames or flame tips appear, the airflow to the burners is adjusted so that the entire flame is blue. Also, any pilot lights are adjusted per the manufacturer's instructions and the gas flow to the cooking tops, if present is turned off. For gas or electric model oven tests, if there is a switch for setting the mode of operation of the oven, it is set to normal. If the oven permits baking with or without forced convection, it is tested in both the forced and non-forced convention modes and the results are averaged together.

Before an oven test, the weight of the test block, $W_{1}$, the room ambient air temperature, $\mathrm{T}_{\mathrm{R}}$, and the initial test block temperature, $\mathrm{T}_{\mathrm{I}}$ are measured and recorded. The test is started by setting the oven thermostat at $325^{\circ} \mathrm{F}\left(262^{\circ} \mathrm{C}\right)$. If the oven thermostat controls the temperature without cycling on and off, the energy consumed, $E_{0}$, when the block reaches $T_{0}=T_{1}+234^{\circ} \mathrm{F}$ $\left(130^{\circ} \mathrm{C}\right)$ is measured and recorded. If the oven thermostat controls the oven temperature by cycling on and off, the series of temperatures $T_{A}, T_{B}, T_{C}$, and $T_{D}$ and the corresponding energy consumption values $\mathrm{E}_{\mathrm{A}}, \mathrm{E}_{\mathrm{B}}, \mathrm{E}_{\mathrm{C}}$, and $\mathrm{E}_{\mathrm{D}}$ are measured and recorded as prescribed in section 3.2 .1 and defined in section 4.1.1 of the Proposed Rule. These temperatures and energy values are associated with the cyclic periods mentioned below and the reference temperature $T_{O} . T_{A}$, and $E_{A}$ are associated with the temperature and energy consumption measurements at the end of the last "on" period prior to the test block reaching $\mathrm{T}_{\mathrm{O}}$, while subscripts $\mathrm{B}$ and $\mathrm{C}$ are associated with the beginning and end of the next "on" period. D is associated with the start of the next "on" period. Based on these values and $T_{0}$, the value of $E_{0}$ is calculated as prescribed in section 4.1.1 of the Proposed Rule. If the oven permits baking with and without forced convection, the oven is tested in each mode to determine the test energies $\left(\mathrm{E}_{0}\right)_{1}$ and $\left(\mathrm{E}_{0}\right)_{2}$. These two test energies $\left(\mathrm{E}_{0}\right)_{1}$ and $\left(\mathrm{E}_{0}\right)_{2}$ are averaged to determine the average test energy consumption of the oven as specified in section 4.1.1.1 of the rule.

For a gas oven, the electrical energy, $\mathrm{E}_{\mathrm{IO}}$, consumed by an electronic ignition device or by other electrical components required for operation of the oven while heating the block to $\mathrm{T}_{\mathrm{O}}$ are measured and recorded. If the gas oven permits baking with and without forced convection, $\left(\mathrm{E}_{\mathrm{TO}}\right)_{1}$ and $\left(\mathrm{E}_{\mathrm{TO}}\right)_{2}$ for the electrical device are measured and averaged to obtain the average electrical energy, $\mathrm{E}_{\mathrm{IO}}$, consumed by the gas oven during the test as prescribed in section 4.1.1.1 of the rule. If the clock is an integral part of the temperature control circuit of the oven, the energy consumed by the clock during the oven test may be subtracted from the energy consumption measured for the oven test.

Once the energy consumption during a single oven test is determined, the annual primary cooking energy consumption, $\mathrm{E}_{\mathrm{CO}}$, of the oven is calculated. The annual primary cooking energy consumption of the oven is either the electrical or gas energy consumed for cooking. The 
primary cooking energy therefore excludes the clock and pilot light energy. For an electric oven, $\mathrm{E}_{\mathrm{co}}$ is the product of the oven test energy, the estimated amount of energy used by the oven to cook food on an annual basis, (hereafter known as annual useful cooking energy output) and a conversion factor, divided by the product of the weight (mass), specific heat, and temperature rise of the test block as specified in section 4.1.2.1.1 of the Proposed Rule. For a gas oven, one also calculates the annual secondary cooking energy consumption, $\mathrm{E}_{\mathrm{so}}$. The secondary energy consumption is any electrical energy consumed by a gas oven other than clock energy. The annual primary cooking energy consumption for gas ovens is calculated as the same ratio of parameters as the electric oven, but without the conversion factor (section 4.1.2.1.1).

Next, a self-cleaning operation is performed to measure the primary and secondary energy usage in order to determine the annual primary and secondary self-cleaning energy. The selfcleaning operation is performed by first establishing the conditions of section 2 . During the selfcleaning operation, the electric or gas energy consumption, that is, the primary self-cleaning energy consumption, $\mathrm{E}_{S}$, is measured. For gas ovens, any pilot lights are adjusted as prescribed by the manufacturer's instructions and the gas flow to the cooking tops is turned off (if applicable). Also the heating value of the natural gas, $H_{n}$, or propane, $H_{p}$, is determined. The oven is set at its normal non-operating temperature as prescribed in section 2.6 of the rule, and the self-cleaning process is started in accordance with the manufacturer's instructions. For a gas oven, any secondary self-cleaning electrical energy, $\mathrm{E}_{\mathrm{IS}}$, consumed by an ignition device or any other electrical component necessary for completion of the self-cleaning test is measured.

For gas ovens, the energy consumption of any continuously-burning pilot light(s) is measured in order to calculate their annual energy consumption. The test conditions for a pilot light energy consumption measurement are set forth in section 2, "Test Conditions" of Appendix I. The oven is set at the normal non-operation temperature as defined in section 1.6 and in section 2.5. The heating value of the natural gas, $\mathrm{H}_{\mathrm{n}}$, or propane, $\mathrm{H}_{\mathrm{p}}$, is determined. If a positive displacement meter is used, the test duration should be sufficient to measure gas consumption of at least 200 times the resolution of the gas meter. Prior to testing, the pilot light(s) of the oven is adjusted as specified in the manufacturer's instruction manual and the gas flow to the cooking top is turned off. To obtain the energy consumption of the oven's pilot light(s), the gas consumption volume, $P_{O}$, and test duration, $L_{O}$, or the gas flow rate, $P_{R}$, during the test are measured.

After performing the self-cleaning oven operation and the pilot light energy consumption measurement, the annual energy consumption of any continuously burning pilot light (s), $\mathrm{E}_{\mathrm{PO}}$, is calculated as the product of the measured flow rate (or the measured volume divided by the test duration), the heating value of the supply gas and the estimated amount of time the pilot light burns per year while the oven is not used for cooking, as prescribed in section 4.1.2.2. With the measurements obtained from the self-cleaning operation, the annual conventional primary and secondary self-cleaning energy, $E_{S C}$ and $E_{S S}$, are calculated as described in section 4.1.2.3. The annual primary self-cleaning energy, $\mathrm{E}_{\mathrm{SC}}$, is calculated as the product of the individual selfcleaning test energy and the number of self-cleaning operations per year as specified in section 
4.1.2.3.1 of the Proposed Rule. The annual secondary self-cleaning energy, $\mathrm{E}_{\mathrm{SS}}$, of a conventional gas oven is the product of the measured electric energy consumption of an electric ignition device (or other electrical device required to complete the self-cleaning test) and the number of self-cleaning operations per year as specified in section 4.1.2.3.2 of the Proposed Rule.

The clock power, $\mathrm{P}_{\mathrm{CL}}$, is measured if the power rating is not known from the manufacturer's literature. After determining the clock power, it is multiplied by the number of hours in a year to obtain the annual energy consumption of the clock, $\mathrm{E}_{\mathrm{CL}}$ as specified in section 4.1.2.4.

Having determined the annual pilot light, self-cleaning and clock energy consumption, the total annual energy consumption of a single conventional oven is calculated using these values as prescribed in section 4.1.2.5. The total annual energy consumption of a single conventional electric oven, $E_{A O}$, is calculated as the sum of the annual energy consumption of the oven, the annual cooking energy consumption from the self-cleaning operations and the annual clock energy consumption. The total annual energy consumption of a single conventional gas oven is determined in two parts, $\mathrm{E}_{\mathrm{AOG}}$, and $\mathrm{E}_{\mathrm{AOE}}$. $\mathrm{E}_{\mathrm{AOG}}$, is the total annual primary energy consumption of the gas oven, calculated as the sum of the annual energy consumption of the oven, the annual primary self-cleaning energy consumption from the self-cleaning operations and the annual energy consumption of any continuously burning pilot lights. $\mathrm{E}_{\mathrm{AOE}}$, is the total annual secondary energy consumption of the gas oven calculated as the sum of the annual secondary cooking energy consumption of the oven, the annual secondary self-cleaning energy consumption of the oven and the annual clock energy consumption of the oven as designated in section 4.1.2.5.2.

The conventional oven cooking efficiency, Eff $_{\mathrm{AO}}$, is calculated as described in Section 4.1.3. It is defined as the ratio of the product of the weight (mass), specific heat, and temperature rise of the test block divided by the oven test energy. For electric ovens, the test energy is the electrical energy consumed during the cooking energy consumption test, whereas, for the gas oven, the test energy includes the primary gas energy plus any secondary (electrical) energy required to complete the cooking energy consumption test. The secondary energy is converted to an equivalent gas energy and added to the primary energy before being divided into the numerator described above. Finally, the conventional oven energy factor, $R_{0}$, is as the ratio of the annual useful cooking energy output to the total annual energy consumption of the oven as described in section 4.1.4. For conventional electric ovens, the total annual energy consumption of the oven is the electrical energy, $\mathrm{E}_{\mathrm{AO}}$. For conventional gas ovens, the total annual energy consumption of the oven is the sum of the total primary gas energy, $E_{A O G}$, and the total secondary energy, $\mathrm{E}_{\mathrm{AOE}}$, (if present) converted to equivalent units of gas energy. 


\section{NIST Testing Protocol}

This section contains the protocols followed by NIST to perform the oven tests required by the Proposed Rule to determine the energy consumption, energy efficiency and the energy factor of the conventional electric and conventional gas ovens. Two protocols were followed. The first is for the cooking operation of the oven, and the second is for the self-cleaning operation of the oven. Since the bumers of the gas oven were electronically ignited, no protocol for determining the energy consumption of pilot lights is documented below. Also, since the energy input to the ovens was continuously monitored during and after the tests, there was no need for a protocol to independently determine the secondary energy consumption of the electronic ignition devices associated with the gas oven or the annual clock energy consumption for either oven. The clock and ignition device energy consumption was available from the raw data and were determined in the data reduction process.

\section{Cooking Operation Protocol}

The following protocol was used to perform the oven tests for determining the annual cooking energy consumption and energy efficiency of the conventional electric and conventional gas ovens. The results of this test were combined with the self-cleaning operation test results to determine the total annual energy consumption and energy factor for the ovens. The steps involved in implementing the oven test protocol are:

- Fulfill the conditions of section 2 of the Proposed Rule for testing conventional ovens.

- Check the following:

Temperature distribution of lab air

Voltage $=240 \mathrm{~V}+1-2 \%$

Voltage $=120 \mathrm{~V}+/-2 \%$

Heating value of natural gas

Barometric pressure in laboratory

Open gas supply line to oven
Electric and Gas ovens

Electric ovens

Gas ovens

Gas ovens

Gas ovens

Gas ovens

- Set the iodized black test block in the center of the oven cavity.

For electric ovens,

- Set the PC's data logging system to collect data every $5 \mathrm{~s}$ to $10 \mathrm{~s}$.

- Set up Meter A's data logging system and synchronize the clock with the internal PC clock. Set Meter A's logging interval for $5 \mathrm{~s}$ or $10 \mathrm{~s}$.

For electric and gas ovens,

- Synchronize the oven clock with the PC clock to within $2 \mathrm{~s}$.

- Enter the PC-based data acquisition and equipment control programming environment to input test parameters and check the ambient air, oven surface, and test block temperatures.

- Compare the ambient temperature of the thermocouple reading displayed on the PC to that of the mercury thermometer, and the oven surface and test block temperatures displayed on the PC to the ambient air temperature to insure the thermocouples are 
operating correctly.

- Enter the sample logging rate (5 s or $10 \mathrm{~s}$ ) and a name for the data acquisition file.

- Enter the temperature rise required of the test block, $W_{1}$, during the oven tests, $234^{\circ} \mathrm{F}$ $\left(130^{\circ} \mathrm{C}\right)$. This value is added to the initial block temperature, $\mathrm{T}_{\mathrm{I}}$, to determine the final "setpoint" temperature of the test block.

- Start the oven by setting the oven thermostat at $325^{\circ} \mathrm{F}\left(181^{\circ} \mathrm{C}\right)$ above the ambient room air temperature (approximately $400^{\circ} \mathrm{F}\left(204^{\circ} \mathrm{C}\right)$ ).

For electric ovens,

- Start both the PC and Meter A's automated data acquisition and control programs within $5 \mathrm{~s}$ after starting the oven thermostat.

For gas ovens,

- Start the PC-based data acquisition and control program within $5 \mathrm{~s}$ after setting the oven thermostat. Meter B, which is connected between the $120 \mathrm{~V}$ electrical supply outlet and the oven's electrical plug, monitors the electrical energy consumption of the gas oven upon starting the program. The energy consumption values from Meter B are recorded by the PC data acquisition and control program.

For electric and gas ovens,

- Record test type (i.e., electric or gas oven test), file name of the PC-acquired data file, name of file to be downloaded from Meter A (contains energy consumption data for electric ovens), date, test start and finish times, initial ambient air, oven surface, test block and final ambient air temperatures.

For gas ovens,

- Record initial flow rate from flow meter, initial and final volumetric meter readings, barometric pressure, pressure of supply gas from electronic manometer display, and temperature of supply gas from volumetric meter thermometer.

- Calculate and record the elapsed test time and total gas volume consumed from the test start and finish times and initial and final volumes, the gas flow rate for the test from the elapsed test time, and the total gas volume consumed.

For electric and gas ovens,

- When the test block setpoint temperature is reached, the control program will trip audible and visual alarms on the PC. After the alarms are activated, allow the test to run for three more "on/off" cycles of the oven and then turn the oven off.

- Rename and save the raw data files for import into the data reduction spreadsheet template.

- Reduce data to obtain the test results of a single oven test.

Self-cleaning Operation Protocol

The following protocol was used to perform the self-cleaning operation on conventional electric and gas ovens to determine the energy consumption associated with a single self-cleaning operation. The results of this test are combined with the oven cooking energy consumption test results to determine the total annual energy consumption and the energy factor for the ovens. The steps involved in implementing the oven self-cleaning test protocol are: 
- Fulfill the conditions of section 2 of the Proposed Rule for testing conventional ovens.

- Check the following:

Temperature distribution of lab air

Voltage $=240 \mathrm{~V}+/-2 \%$

Electric and Gas ovens

Voltage $=120 \mathrm{~V}+/-2 \%$

Electric ovens

Heating value of natural gas

Gas ovens

Barometric pressure in laboratory

Gas ovens

Open gas supply line to oven

Gas ovens

Gas ovens

\section{For electric ovens,}

- Set the PC's data logging system to collect data every $5 \mathrm{~s}$ to $10 \mathrm{~s}$.

- Set up Meter A's data logging system and synchronize the clock with the internal PC clock. Set Meter A's logging interval for $5 \mathrm{~s}$ or $10 \mathrm{~s}$.

For electric and gas ovens,

- Synchronize the oven clock with the PC clock to within $2 \mathrm{~s}$.

- Enter the PC-based data acquisition and equipment control programming environment to input test parameters and check the ambient air, oven surface, and test block temperatures.

- Compare the ambient temperature of the thermocouple reading displayed on the PC to that of the mercury thermometer, and the oven surface and test block temperatures displayed on the PC to the ambient air temperature to insure the thermocouples are operating correctly.

- Start the self-cleaning operation by pressing the "clean" button of the oven's control keypad and set the self-cleaning time to 3 hours.

For electric ovens,

- Start the PC-based data acquisition and control program and Meter A within $5 \mathrm{~s}$ after setting the self-clean temperature.

For gas ovens,

- Start the PC-based data acquisition and control program within $5 \mathrm{~s}$ after setting the selfcleaning temperature. Meter B, which is connected between the $120 \mathrm{~V}$ electrical supply outlet and the oven's electrical plug, automatically monitors the energy consumption of the gas oven upon starting the self-cleaning test program. The energy consumption values from Meter B are automatically recorded by the PC data acquisition program.

For electric and gas ovens,

- Record test type (i.e., electric or gas self-cleaning operation), file name of the PC acquired raw data file, name of the file to be downloaded from Meter A (contains energy consumption data for electric ovens), date, test start and finish times, initial ambient air, oven surface, internal oven and final ambient air temperatures.

\section{For gas ovens,}

- Record initial flow rate from flow meter, initial and final volumetric meter readings, barometric pressure, pressure of gas supply from electronic manometer display, and temperature of gas supply from volumetric meter thermometer.

- Calculate and record the elapsed test time and total gas volume consumed from the test start and finish times and the initial and final volumes, the gas flow rate for the test 
from the elapsed test time, and the total gas volume consumed

- During the first $30 \mathrm{~min}$ of the test, measure the elapsed time required for the oven to consume a volume of $2 \mathrm{ft}^{3}\left(0.06 \mathrm{~m}^{3}\right)$ then calculate and record the gas flow rate and compare this flow rate to that of the flow meter. Repeat this process during the last half hour of the test to determine if any change in the gas flow rate has occurred.

For electric and gas ovens,

- Monitor the energy consumption and temperature parameters until the $3 \mathrm{~h}$ self-cleaning operation is over.

\section{Cooking Tops}

The objective of DOE's Proposed Rule regarding the cooking top test methods is to determine the total annual energy consumption, the energy efficiency, and the energy factor of conventional electric and gas cooking tops. The determination of these factors include only surface unit tests and other calculations for electric cooking tops. For gas cooking tops, the annual energy consumption of pilot lights and/or electronic ignition devices is also required. To obtain these intermediate parameters the rule requires a pilot light energy consumption measurement or electronic ignition device energy consumption measurement as applicable. The sections below cover procedural requirements of the Proposed Rule and the protocol used at NIST for testing both electric and gas cooking tops.

\section{Requirements of Proposed Rule}

This section describes the requirements of the Proposed Rule for obtaining the energy consumption for a single surface unit of a cooking top. The requirements for the measurement of the energy consumption of pilot light(s) of gas cooking tops are also presented. Finally, the procedures for the determination of the test results are outlined.

To perform an energy consumption test on either an electric or gas cooking top, the conditions of section 2, Test Conditions, of the Proposed Rule must be fulfilled. Section 2 of the rule contains the specifications required of the laboratory equipment, and the conditions imposed on the laboratory environment and the electrical and natural gas supply sources. The more important environmental and energy source requirements of section 2 follow.

Prior to testing either electric or gas cooking tops, the ambient room air temperature must be between $68{ }^{\circ} \mathrm{F}$ and $86^{\circ} \mathrm{F}\left(20^{\circ} \mathrm{C}\right.$ and $\left.30^{\circ} \mathrm{C}\right)$, the cooking tops and test block at the normal non-operating temperature as defined in section 1.6 and described in section 2.5 of the Proposed Rule, and the supply voltage within the acceptable $240 \mathrm{~V} / 120 \mathrm{~V} \pm 2 \%$ range for the cooking tops as specified by the manufacturer. The clock must be disconnected if it is not an integral part of the temperature control circuit. If the clock is an integral part of the temperature control circuit and can not be disconnected, then the clock energy may be subtracted from the surface unit energy at the end of the energy consumption test. 
When conventional gas cooking tops are tested, the pressure in the gas supply line must be between 7 in. water column and 10 in. water column (1700 Pa and $2500 \mathrm{~Pa}$ ) for natural gas, or if the cooking tops are convertible and propane is used, between 11 in. water column and 13 in. water column (2700 Pa and $3200 \mathrm{~Pa}$ ). The heating value of the natural gas, $\mathrm{H}_{\mathrm{n}}$, or propane, $\mathrm{H}_{\mathrm{p}}$, (whichever is applicable) is determined, and the flames from the cooking tops's surface unit burners are adjusted to ensure that they do not appear yellow or with yellow tips. If yellow flames or flame tips appear, the airflow to the burners is adjusted so that the entire flame is blue. Next, any pilot lights are adjusted and the gas flow to the oven, if present, is turned off.

For either gas or electric cooking top tests, section 3.2.2 of the Proposed Rule requires the following. The test block is set in the center of the surface unit being tested. The small test block, $\mathrm{W}_{2}$, is used with electric surface units less than 7 in. $(178 \mathrm{~mm})$ in diameter. The large test block, $\mathrm{W}_{3}$, is used on electric surface units greater than 7 in. $(178 \mathrm{~mm})$ in diameter and on all gas surface units of any size. The weight (mass) of the test block, $\mathrm{W}_{2}$, or $\mathrm{W}_{3}$, the room ambient air temperature, $T_{R}$, and the initial block temperature, $T_{I}$ are measured and recorded. The cooking top turned on and the energy input rate of the surface unit under test is set at the maximum setting. When the test block reaches $144^{\circ} \mathrm{F}\left(80^{\circ} \mathrm{C}\right)$ above the initial block temperature, the energy input rate is reduced to $25 \% \pm 5 \%$ of the maximum input rate for 15 minutes. After 15 minutes at the reduced energy input setting, the surface unit test energy consumption, $\mathrm{E}_{\mathrm{CT}}$, the final test block temperature, $T_{C T}$, and the total test time, $T_{T}$ are measured and recorded. If the unit under test is a gas cooking top, any electrical energy, $\mathrm{E}_{\mathrm{TC}}$, consumed by an electric ignition device is measured and recorded.

After collecting all the raw data required for the electric cooking top, the surface unit cooking efficiency, Eff ${ }_{\mathrm{SU}}$, is calculated as the product of the weight (mass), specific heat, and temperature rise of the test block during the test divided by the measured energy consumption of the surface unit during the test, as shown in section 4.2.1.1 of the Proposed Rule. After calculating the efficiency of each surface unit of the cooking top, the conventional cooking top cooking efficiency, Eff $\mathrm{CT}_{\mathrm{C}}$, is calculated as the average efficiency of the surface units as prescribed in section 4.2.1.3. Next, the conventional electric cooking top annual encrgy consumption, $\mathrm{E}_{\mathrm{CA}}$, is calculated as specified in section 4.2.2.1 of the rule, as the ratio of the annual useful electric cooking energy output to the efficiency of the cooking top. Finally, the conventional cooking top energy factor, $R_{C T}$, is calculated as the ratio of useful cooking energy output for cooking to the total energy input as in section 4.2.3.

For gas cooking tops with pilot lights, determination of the surface unit efficiency requires knowledge of the energy consumption of the pilot lights. The procedure for determining the annual energy consumption of any continuously-burning pilot light is as follows. Before measuring the energy consumption of a pilot light, the test conditions are established as set forth in section 2, "Test Conditions" of Appendix I. The cooking top starts at the normal nonoperating temperature as defined in section 1.6 and described in section 2.5 of the Proposed Rule. The heating value of the natural gas, $H_{n}$, or propane, $H_{p}$, is determined. If a positive displacement meter is used, the test duration should be sufficient to measure a gas consumption 
of at least 200 times the resolution of the gas meter. Prior to testing, the pilot light(s) of the cooking top are adjusted as specified in the manufacturer's instruction manual and the gas flow to the oven, if present, is turned off. To obtain the energy consumption rate of the cooking top's pilot light(s), the gas consumption volume, $\mathrm{P}_{\mathrm{C}}$, and duration, $\mathrm{L}_{\mathrm{C}}$, or the gas flow rate, $\mathrm{P}$, are measured. If the volume and test duration were measured, the flow rate is calculated by dividing the test duration into the volume.

Having determined the flow rate of the pilot lights for gas cooking tops, (if applicable), the energy consumption of the pilot light during the surface unit test is the product of the gas flow rate, the duration of the test, and the heating value of the gas. For gas cooking tops, the surface unit cooking efficiency, Eff ${ }_{\mathrm{SU}}$, is specified in section 4.2.1.2 of the Proposed Rule as the product of the weight (mass), specific heat, and temperature rise of the test block, divided by the energy consumption of the surface unit minus any energy consumption of the pilot light plus any energy consumption of an electronic ignition device (converted to equivalent units of gas energy) during the test. After calculating the efficiency of each surface unit of the cooking top, the conventional cooking top cooking efficiency, Eff $\mathrm{CT}_{\mathrm{CT}}$, is calculated as the average efficiency of the surface units as prescribed in section 4.2.1.3. The conventional gas cooking top annual cooking energy consumption, $\mathrm{E}_{\mathrm{CC}}$, is then calculated as in section 4.2.2.2, as the ratio of the annual useful gas cooking energy output to the efficiency of the cooking top. After which, the annual energy consumption of any continuously buming gas pilots of the gas cooking top, $\mathrm{E}_{\mathrm{pC}}$, is calculated as described in section 4.2.2.2.2 of the Proposed Rule as the product of the gas flow rate of the pilot light, the number of hours per year and the heating value of the gas, $\mathrm{H}_{\mathrm{n}}$ or $\mathrm{H}_{\mathrm{p}}$. The total annual energy consumption of a conventional gas cooking top, $\mathrm{E}_{\mathrm{CA}}$ is then calculated as the sum of the annual cooking energy consumption and the annual pilot light energy consumption as in section 4.2.2.2.3. Finally, the conventional cooking top energy factor, $\mathrm{R}_{\mathrm{CT}}$, is calculated as the ratio of useful cooking energy output for cooking to the total energy input as in section 4.2.3.

\section{NIST Testing Protocol}

The following protocol was employed to perform the conventional electric and gas cooking top tests. The results of these tests were used to calculate the individual surface unit cooking efficiency, the efficiency of the cooking tops, the annual cooking energy consumption, the total annual energy consumption, and the energy factor for the conventional electric and gas cooking tops as required by the Proposed Rule. The steps in the protocol are:

- Fulfill the conditions of section 2 of the Proposed Rule for testing conventional cooking tops.

- Set the test block, $\mathrm{W}_{2}$ or $\mathrm{W}_{3}$, in the center of the surface unit under test. Use the small block, $W_{2}$, for electric surface units 7 in. $(17.8 \mathrm{~cm})$ or less in diameter and the large block, $W_{3}$, for electric surface units greater than 7 in. $(17.8 \mathrm{~cm})$ and all gas surface units.

- Check the following:

Temperature distribution of lab air

Electric and Gas cooking tops 
Voltage $=240 \mathrm{~V}+/-2 \%$

Voltage $=120 \mathrm{~V}+1-2 \%$

Heating value of natural gas

Barometric pressure in laboratory

Open gas supply line to cooking tops
Electric cooking tops

Gas cooking tops

Gas cooking tops

Gas cooking tops

Gas cooking tops

\section{For electric cooking tops,}

- Set the data logging system to collect data every 5 to 10 seconds and synchronize Meter A's clock with the internal PC clock.

For electric and gas cooking tops,

- Synchronize the oven clock with the PC clock to within $2 \mathrm{~s}$.

- Enter the PC-based data acquisition and equipment control programming environment to input test parameters and check the ambient air, cooking top surface, and test block temperatures.

- Compare the ambient temperature of the thermocouple reading displayed on the PC to that of the mercury thermometer, and the cooking top surface and test block temperatures displayed on the PC to the ambient air temperature to insure the thermocouples are operating correctly.

- Enter the sample logging rate ( $5 \mathrm{~s}$ or $10 \mathrm{~s})$ and a name for the data acquisition file.

- Enter the temperature rise required of the test block, as $144^{\circ} \mathrm{F}\left(80^{\circ} \mathrm{C}\right)$. This value is added to the initial block temperature, $T_{\mathrm{I}}$, to determine an intermediate setpoint temperature required of the block for testing as instructed in the Proposed Rule. The setpoint is used by the program to activate an alarm, signifying the test block has reached the required temperature and mark the beginning of a 15 minute reduced energy input period, after which the test is complete.

For electric cooking tops,

- Simultaneously start the PC data monitoring and control program (to record the date, time and temperature data) and energy Meter A (to record the energy data).

For gas cooking tops,

- Start the PC data monitoring and control program (energy Meter B will automatically monitor the electric energy input to the gas cooking top while the PC program monitors and records the date, time, temperature and energy data).

For electric and gas cooking tops,

- Start the cooking top by setting the control knob for the surface unit under test to the highest setting.

For electric and gas cooking tops,

- Record test type (i.e., electric or gas cooking top), file name of the PC-acquired data file to be downloaded from energy Meter A, date, test start and finish times, and initial ambient air, cooking top surface, test block and final ambient air temperatures.

For gas cooking tops,

- Record initial flow rate from flow meter, initial and final volumetric meter readings, barometric pressure, pressure of gas supply from electronic manometer display, and temperature of gas supply from volumetric meter thermometer.

- Calculate and record the elapsed test time and total gas volume consumed from the test 
start and finish times and initial and final volumes. Calculate/record the average gas flow rate for the test from the elapsed test time, and the total gas volume consumed. For gas cooking tops,

- Start a stopwatch when the cooking top gas flow begins and record the gas flow rate from the flow meter. After $2 \mathrm{ft}^{3}\left(0.06 \mathrm{~m}^{3}\right)$ of gas consumption, record the elapsed time from the stopwatch, and calculate and record the gas flow rate to compare with the flow meter. When the test block reaches the setpoint temperature, the PC alarm will be triggered and a timer will start the 15-minute reduced energy input countdown. When the alarm goes off, adjust the gas flow rate to $1 / 4$ of the maximum rate. Next, record the volume reading of the volumetric meter and start a stopwatch. After $2 \mathrm{ft}^{3}\left(0.06 \mathrm{~m}^{3}\right)$ of gas volume is consumed, stop the stopwatch, and calculate and record the gas flow rate.

For electric and gas cooking tops,

- Monitor the energy consumption and temperature parameters until the 15-minute reduced energy input period is over. An audible alarm sounds and the block temperature flashes on the PC screen when the 15-minute period is complete.

- When the alarm is activated, the test is finished. Turn off the cooking top.

After completion of all cooking tops surface unit tests, the results of each surface unit are used as specified in the Proposed Rule to determine the efficiency, annual cooking energy consumption, total annual energy consumption and the energy factor of the cooking tops.

\section{Microwave Ovens}

The objective of the Proposed Rule regarding the microwave oven test method is to determine the energy efficiency, the annual energy consumption, and the energy factor of microwave ovens. Due to uncertainties regarding technical issues, DOE had not included the IEC 705, Amendment 2 (1993) by reference at the time of the tests at NIST. However, the procedures of the IEC 705, Amendment 2 (1993) were written into the Proposed Rule with minor deviations and an additional temperature and encrgy measurement requirement. One of the primary purposes of testing the microwave oven was to determine the appropriateness of including the IEC 705 by reference within the Proposed Rule.

This section is made up of two subsections. The first part contains the procedural requirements of the 1994-draft Proposed Rule to determine energy consumption values and procedural requirements contained in the IEC 705, Amendment 2, which DOE adopted for determining the efficiency of microwave ovens. The second part provides a description of the test protocol used at NIST to implement the test procedures. 


\section{Requirements of Proposed Rule}

A microwave oven test begins by establishing the applicable "Test Conditions" set forth in section 2 of appendix I of the Proposed Rulc and the procedures of section 4, paragraph 12 of the IEC 705, Amendment 2. A summary of the IEC 705 test method is as follows. At the start of test, the test load container and microwave oven are to be at normal non-operating temperature and the ambient air temperature is to be between $64^{\circ} \mathrm{F}$ and $72{ }^{\circ} \mathrm{F}\left(18^{\circ} \mathrm{C}\right.$ and $\left.22^{\circ} \mathrm{C}\right)$. The voltage is to be supplied at the rated voltage $\pm 1 \%$ and the oven operated at its maximum power setting. Place the test load container in the microwave oven as described in paragraph 12.2. The water temperature is initially below the ambient temperature and raised to the ambient temperature by heating it in the microwave oven. The initial ambient room air temperature, $\mathrm{T}_{0}$, and the mass of the container, $\mathrm{M}_{\mathrm{C}}$ are measured at the beginning of the test. Immediately before pouring the test water into the test container, the initial water temperature, $\mathrm{T}_{1}$, is measured and should be $18^{\circ} \mathrm{F} \pm 1.8^{\circ} \mathrm{F}\left(10^{\circ} \mathrm{C} \pm 1{ }^{\circ} \mathrm{C}\right)$ below $\mathrm{T}_{0} .0 .45 \pm 0.01 \mathrm{lb}(1000 \mathrm{~g} \pm 5 \mathrm{~g})$ of water are measured into the load container, the microwave test time is set, and the test load is placed in the center of the useable shelf space at the lowest position in the oven. The microwave oven is started, and then the stopwatch is started when the input current to the magnetron reaches $90 \%$ of its final value. (As discussed later, the determination of when the current attains this $90 \%$ value is problematic). The input power to the microwave oven is measured with an induction type watt meter as prescribed in paragraph 13. At the end of the test, the stopwatch is turned off, the elapsed test time is recorded, the water is stirred to obtain a uniform temperature, and the final water temperature, $T_{2}$ is measured and recorded. The final temperature is to be measured within $60 \mathrm{~s}$ after the oven has switched off. Next, the microwave output power, $\mathrm{P}$, in watts is calculated as prescribed in paragraph 12.5 of the IEC 705 Procedure. The test is performed three times, unless the results from the second test are within $1.5 \%$ of the first. The results are averaged together to obtain the microwave oven power output. Measurements are to be separated by a period of at least 6 hours, or until the magnetron and its supply main circuit falls within $9^{\circ} \mathrm{F}\left(5^{\circ} \mathrm{C}\right)$ of the ambient temperature. After calculating the power output, the energy efficiency of the microwave oven is calculated using the measured input and calculated output power.

Though DOE adopted the IEC 705 and Amendment 2 by reference, the Proposed Rule adds a measurement of the electrical input energy, $\mathrm{E}_{\mathrm{M}}$, with a watt-hour meter and states that the supply voltage is to be at $120 \mathrm{~V} \pm 1 \mathrm{~V}$. The input energy to the microwave oven is measured by a watt-hour meter and includes the magnetron warmup time, rather than calculated by the watt meter and elapsed test time defined in note 1 of paragraph 12.5 of the IEC 705 . The temperatures $\mathrm{T}_{0}, \mathrm{~T}_{1}$, and $\mathrm{T}_{2}$, and the mass of the container and test load are used to calculate the microwave oven output energy consumption, annual energy consumption, and the energy factor. The energy factor is the ratio of the useful cooking energy output to the total energy input on a yearly basis.

\section{NIST Testing Protocol}

The following protocol was employed at NIST to perform the microwave oven tests. The microwave oven ambient air conditions imposed by Section 2 of the Proposed Rule and IEC 705, 
Amendment 2 are fulfilled by insuring there is no direct draft on the microwave oven and the ambient air temperature is between $65^{\circ} \mathrm{F}$ and $72^{\circ} \mathrm{F}\left(18^{\circ} \mathrm{C}\right.$ and $\left.22^{\circ} \mathrm{C}\right)$ measured at a distance at least $5 \mathrm{ft}(1.5 \mathrm{~m})$ and no more than $8 \mathrm{ft}(2.4 \mathrm{~m})$ from the nearest surface of the microwave oven. Also prior to testing, the chiller bath has an adequate supply of chilled water and the bath temperature set point is adjusted to $18^{\circ} \mathrm{F} \pm 1.8^{\circ} \mathrm{F}\left(10^{\circ} \mathrm{C} \pm 1{ }^{\circ} \mathrm{C}\right)$ below the ambient air temperature. After this, at least $0.45 \mathrm{lb}(1000 \mathrm{~g})$ of distilled water is poured into a vessel and placed into the chiller bath water for cooling to $18^{\circ} \mathrm{F} \pm 1.8^{\circ} \mathrm{F}\left(10^{\circ} \mathrm{C} \pm 1{ }^{\circ} \mathrm{C}\right)$ below the ambient air temperature. When ready to perform a test, the following are checked:

Temperature distribution of laboratory air is uniform, $\pm 1.8^{\circ} \mathrm{F}\left(1^{\circ} \mathrm{C}\right)$,

Temperature of room air, $\mathrm{T}_{\mathrm{o}}$, is $68^{\circ} \mathrm{F} \pm 3.6^{\circ} \mathrm{F}\left(20^{\circ} \mathrm{C} \pm 2{ }^{\circ} \mathrm{C}\right)$,

Voltage supply is $120 \mathrm{~V} \pm 1 \%$

Magnetron temperature is within $9{ }^{\circ} \mathrm{F}\left(5^{\circ} \mathrm{C}\right)$ of the ambient air temperature,

To begin the data acquisition process and perform the microwave oven test, the following steps are completed.

- If Meter $A$ is being used to record the input power and energy consumption of the microwave oven, access energy Meter A via the personal computer (PC) and set the data logging interval of Meter A to $1 \mathrm{~s}$.

- Start the PC-based data acquisition system so that the ambient room air and magnetron temperatures are displayed on the monitor.

- Compare the temperatures displayed on the PC screen from all temperature measurement devices to that of the mercury thermometer to insure the thermocouples and thermistors are operating correctly.

- Enter a sample recording rate of $0.1 \mathrm{~s}$ to $0.2 \mathrm{~s}$ and a name for the data acquisition file of the PC data acquisition system.

- Record the date, time, data file names, magnetron temperature, and ambient air temperature as displayed by the mercury thermometer and thermocouple, or the mercury thermometer and the thermistor.

- Prepare to start the microwave oven by setting the power level on high and the cooking time for $60 \mathrm{~s}$ or other appropriate time to produce the desired temperature rise in the test load.

- Measure and record the temperature of the water in the storage vessel in the chiller.

- Place the test load container on the scale and pour $0.45 \mathrm{lb} \pm 0.01 \mathrm{lb}(1000 \mathrm{~g} \pm 5 \mathrm{~g})$ into the container.

- Measure and record the temperature of the water with the thermometer and thermocouple or the thermometer and thermistor (make the measurement within $30 \mathrm{~s}$ after pouring the water into the container).

- Immediately place the water test load at the center of the lowest position in the microwave oven.

- Simultaneously start the microwave oven and the power/energy meters used to monitor the input energy to the microwave oven. Since Meter A and Meter B record the data, they can be started before the starting the microwave oven. Meter $C$ and Meter D may also be started prior to the microwave oven, however, they must be reset to zero watthours at the start of the microwave oven test. If only a single power reading is used, as 
in the IEC 705, these meters do not require resetting.

- After starting the microwave oven, start a stopwatch immediately after the magnetron warm-up period.

- During the test, energy consumption data monitored by Meters $A$ and $B$ is recorded by a data logger and the automated PC monitoring system. For Meters $\mathrm{C}$ and $\mathrm{D}$, as applicable, record the volts, current, true rms power, volt amp power, power factor, and frequency from the meters' displays. Also, record the test energy consumption as registered on Meter C's or Meter D's display at the end of the test.

- At the end of the test, stop the stopwatch and immediately remove the test load container from the microwave oven.

- Within $60 \mathrm{~s}$ of the oven switching off, measure and record the water temperature with the same temperature measurement devices used prior to the test, then record the time of testing from the stopwatch.

- If the resulting water test load temperature is not within $1.8^{\circ} \mathrm{F}\left(1^{\circ} \mathrm{C}\right)$ of the ambient air temperature, the test is unacceptable. Wait six hours, or until the magnetron is within $9^{\circ} \mathrm{F}\left(5^{\circ} \mathrm{C}\right)$ of the room ambient air temperature, and restart the test.

- Record date, time, name of the PC raw data file, name of the file from the energy Meter A (if applicable), initial ambient air, oven magnetron and test load temperatures, and elapsed time as determined by the stopwatch (the total time of energy consumption, including the magnetron warm-up period, will be determined by the raw data files of Meter A and/or B).

\section{RESULTS}

This section presents the results of testing conventional ovens, conventional cooking tops and microwave ovens in accordance with the procedures set forth in the Proposed Rule. The first section presents the results from conventional electric and gas oven tests. The second section presents the results of testing conventional gas and electric cooking tops, and the third section presents the results from the microwave oven tests. The microwave tests were performed in compliance with the 1994 proposed test procedure and are compared to results obtained when utilizing specified conditions as prescribed in the IEC 705 Amendment 2 (1993).

\section{Oven Tests}

This section presents the individual test results and a summary of the seven electric oven tests of the primary cooking energy consumption and the seven self-cleaning tests. It also includes the results of five conventional gas oven energy consumption tests and five self-cleaning tests of the gas oven. These tests were performed, and the results determined, in compliance with the 1995 version of DOE's Proposed Rule.

The first section describes the oven's response to the primary cooking energy consumption test for the electric ovens. In the next section, the individual electric and gas oven test results are given. 


\section{Response of Oven to Energy Consumption Test}

This section describes the response of a conventional electric oven to the energy consumption test. Figure 3 is a plot of the temperature data collected during an electric oven energy consumption test. The plot contains the oven interior, test block, oven surface and the room air temperatures during an oven test conducted to determine the primary energy consumption of a conventional oven for cooking. Figure 4 is a graph of the temperature profiles for the same locations during the cooling of the oven after testing. Prior to testing, the oven and test block are at the normal non-operating temperature. At the beginning of the oven test, the oven thermostat is set to a temperature $325^{\circ} \mathrm{F} \pm 5^{\circ} \mathrm{F}\left(180.6^{\circ} \mathrm{C} \pm 2.8^{\circ} \mathrm{C}\right)$ above the ambient room air temperature, $T_{R}$, usually about $400^{\circ} \mathrm{F}\left(204^{\circ} \mathrm{C}\right)$. The uppermost trace of Figure 3 represents the interior temperature of the oven over the test period. When the oven test is started, power is applied to the heating element which causes a steady increase in the interior temperature of the oven from its normal non-operating temperature to the set point temperature. When the oven temperature reaches the set point, its thermostat cycles the energy supply on and off to maintain an average temperature at the set point. When testing the electric oven, the initial ramping period lasted about $12 \mathrm{~min}$., and each cycle lasted about $7 \mathrm{~min}$., roughly $2 \mathrm{~min}$. of which are the "on" portion of the cycle. While the time periods are not the same, temperature measurements on the gas oven produce similar data.

Figure 3: Energy Consumption Test Typical Plot of Time versus Temperature

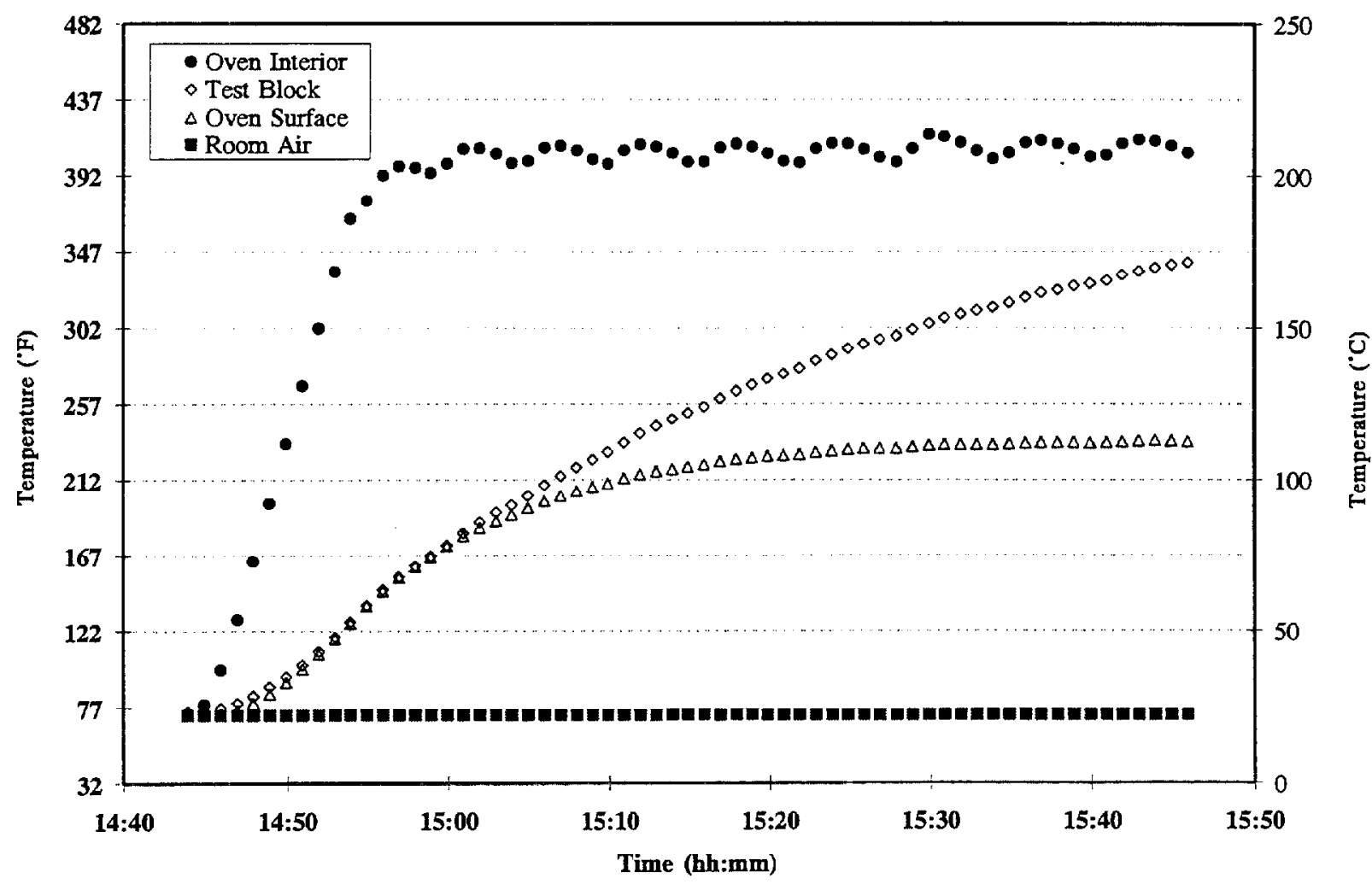


While the oven temperature rises and fluctuates about $\mathrm{T}_{\mathrm{R}}+375^{\circ} \mathrm{F}\left(\mathrm{T}_{\mathrm{R}}+180.6^{\circ} \mathrm{C}\right)$, the test block is heated to the target temperature of $\mathrm{T}_{\mathrm{o}}$, which is $202^{\circ} \mathrm{F}\left(112.2^{\circ} \mathrm{C}\right)$ above the initial test block temperature, $T_{\mathrm{I}}$, measured at the start of the test. The initial temperature must be, and was in all cases, within $4{ }^{\circ} \mathrm{F}\left( \pm 2.2^{\circ} \mathrm{C}\right)$ of the ambient room air temperature. As illustrated in Figure 3 , the test block temperature rises steadily to the target temperature, $\mathrm{T}_{\mathrm{O}}=\mathrm{T}_{\mathrm{I}}+20{ }^{\circ} \mathrm{F}$ $\left(\mathrm{T}_{\mathrm{I}}+112^{\circ} \mathrm{C}\right)$. For this particular example, the ambient air temperature was $72^{\circ} \mathrm{F}\left(22^{\circ} \mathrm{C}\right)$, the initial block temperature, $\mathrm{T}_{\mathrm{I}}$, was $73^{\circ} \mathrm{F}\left(23^{\circ} \mathrm{C}\right)$, and the block target temperature, $\mathrm{T}_{\mathrm{O}}$, was $275^{\circ} \mathrm{F}$ $\left(135^{\circ} \mathrm{C}\right)$. It took approximately $30 \mathrm{~min}$. to reach the temperature $\mathrm{T}_{\mathrm{O}}$, and another $10 \mathrm{~min}$. to finish the test.

The oven surface temperature essentially coincides with that of the test block for the first eight or nine minutes of the test, and then begins to level off and asymptotically approach an equilibrium temperature of roughly $230^{\circ} \mathrm{F}\left(110^{\circ} \mathrm{C}\right)$, while the test block temperature continues to increase at a relatively constant rate. The surface temperature measurement was made near the exhaust vent of the oven to observe the greatest temperature increase of the oven surface during the test and to determine the minimum time between tests.

The ambient room air temperature remains constant throughout the test, showing that the room air temperature is stable and not influenced by the heat from the stove. The initial room air temperature typically ranged from $71.6^{\circ} \mathrm{F}\left(22^{\circ} \mathrm{C}\right)$ to $75.2^{\circ} \mathrm{F}\left(24^{\circ} \mathrm{C}\right)$ for the 12 tests, and typically increased less than $1.8^{\circ} \mathrm{F}\left(1^{\circ} \mathrm{C}\right)$ during the tests. These values are well within the conditions required in section 2.5 of the rule.

Figure 4 is a plot of the temperature profiles of the test block, interior oven, oven surface and ambient room air temperatures after an oven test is over and the oven is switched off. As seen in Figure 4, it takes about nine hours for the oven and test block to cool to within a few degrees of the ambient temperature. The data in Figure 4 were collected with the oven door closed after testing. Data was also collected with the oven door open and a fan blowing into the oven cavity to increase the rate of cooling. Under the latter conditions, it took three hours to cool the test block and one and one-half hours to cool the oven. Since it is acceptable to water cool the test block, it appears that the time between oven tests could easily be reduced to two hours. 
Figure 4: Typical Cooling Curve after Oven Test: Temperature versus Time

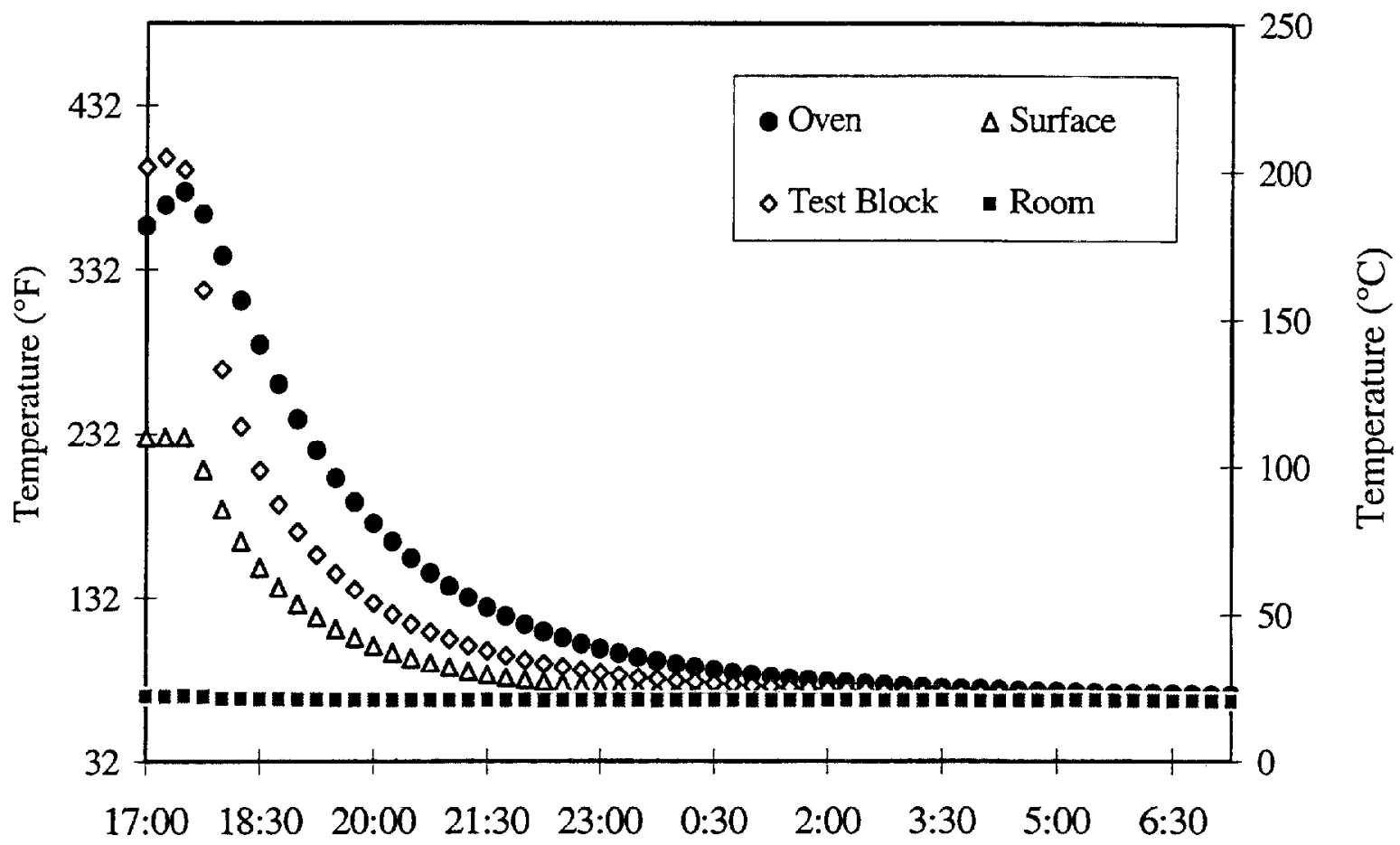

Time (hh:mm)

\section{Summary of Results}

Figure 5 summarizes the results of a typical electric oven test, and Figure 6 summarizes the results of a typical gas oven test. Appendix A contains summary sheets for all seven electric oven tests, and Appendix B contains summary sheets for all five gas oven tests. An explanation of the parameters listed in Figure 5 and Figure 6, and in Appendix A and Appendix B, is given in the Nomenclature section of this report. Figure 5 lists the measured temperatures $T_{A}, T_{B}, T_{C}$, and $T_{D}$, and energy consumption values $E_{A}, E_{B}, E_{C}$, and $E_{D}$, along with the constants and initial values pertinent to the tests. In addition, the figure contains the required temperature rise $T$ of the test block, the block target temperature $T_{O}$ after adding the initial block temperature $T_{I}$ to $T$, the average clock power measured throughout the test, $\mathrm{P}_{\mathrm{CL}}$, the average temperatures $\mathrm{T}_{\mathrm{AB}}$ and $\mathrm{T}_{\mathrm{CD}}$, and the average energy consumption values $E_{A B}$ and $E_{C D}$ used along with $T_{O}$ to extrapolate the test energy $E_{0}$.

Figure 5 then presents the steps within the oven test procedure. The first line in each step is the descriptive name of the result described in the Proposed Rule. The second line is the equation used to calculate the value or a description of how the value was obtained. The third line provides the value of the parameter. 
FIGURE 5: Results of Conventional Electric Oven Test \#1

\begin{tabular}{|c|c|c|c|c|}
\hline \multicolumn{3}{|c|}{ Temperature } & \multirow{2}{*}{$\frac{\text { Energy Consumption (Wh) }}{E_{\mathrm{A}}=850.0}$} & \multirow{2}{*}{$\begin{array}{c}\text { Constants, and Initial Values } \\
\mathrm{P}_{\mathrm{CL}}=3.1 \mathrm{~W}\end{array}$} \\
\hline $\mathrm{T}_{\mathrm{A}}$ & $256.3^{\circ} \mathrm{F}$ & $124.6^{\circ} \mathrm{C}$ & & \\
\hline $\mathrm{T}_{\mathrm{B}}$ & $275.1^{\circ} \mathrm{F}$ & $135.1^{\circ} \mathrm{C}$ & $E_{B}=850.2$ & $\mathrm{O}_{\mathrm{o}}=35.5 \mathrm{kWh} / \mathrm{yr}$ \\
\hline $\mathrm{T}_{\mathrm{c}}$ & $279.1^{\circ} \mathrm{F}$ & $137.3^{\circ} \mathrm{C}$ & $E_{C}=920.5$ & $\mathrm{~W}_{1}=8.38 \mathrm{lb}(3.81 \mathrm{~kg})$ \\
\hline $\mathrm{T}_{\mathrm{D}}$ & $295.9^{\circ} \mathrm{F}$ & $146.6^{\circ} \mathrm{C}$ & $E_{D}=920.7$ & $\mathrm{C}_{\mathrm{p}}=0.23 \mathrm{Btu} / \mathrm{hb}{ }^{\circ} \mathrm{F}\left(0.96 \mathrm{~kJ} / \mathrm{kg}^{\circ} \mathrm{C}\right)$ \\
\hline & & & & $\mathrm{T}=202.0^{\circ} \mathrm{F}\left(112.2^{\circ} \mathrm{C}\right)$ \\
\hline $\mathrm{T}_{\mathrm{AB}}$ & $257.8^{\circ} \mathrm{F}$ & $129.9^{\circ} \mathrm{C}$ & $\mathrm{E}_{\mathrm{AB}}=850.1$ & $\mathrm{H}_{\mathrm{e}}=3.6 \mathrm{~kJ} / \mathrm{Wh}$ \\
\hline $\mathrm{T}_{\mathrm{CD}}$ & $287.6^{\circ} \mathrm{F}$ & $142.0^{\circ} \mathrm{C}$ & $E_{C D}=920.6$ & $\mathrm{H}_{\mathrm{k}}=8760 \mathrm{hr} / \mathrm{yr}$ \\
\hline$T_{0}$ & $276.6^{\circ} \mathrm{F}$ & $135.9^{\circ} \mathrm{C}$ & & $\mathrm{C}=0.001 \mathrm{~kW} / \mathrm{w}$ \\
\hline
\end{tabular}

Test energy consumption for conventional electric oven

$$
\begin{aligned}
& \mathrm{E}_{\mathrm{O}}=\left\{\mathrm{E}_{\mathrm{AB}}+\left[\left(\left(\mathrm{T}_{\mathrm{O}}-\mathrm{T}_{\mathrm{AB}}\right) /\left(\mathrm{T}_{\mathrm{CD}}-\mathrm{T}_{\mathrm{AB}}\right)\right) \times\left(\mathrm{E}_{\mathrm{CD}}-\mathrm{E}_{\mathrm{AB}}\right)\right]\right\} \\
& \mathrm{E}_{\mathrm{O}}=885.3 \mathrm{Wh}
\end{aligned}
$$

Annual primary energy consumption

$$
\begin{aligned}
& \mathrm{E}_{\mathrm{co}}=\left(\mathrm{E}_{\mathrm{o}} \times \mathrm{H}_{\mathrm{e}} \times \mathrm{O}_{\mathrm{o}}\right) /\left(\mathrm{W}_{1} \times \mathrm{C}_{\mathrm{p}} \times \mathrm{T}\right) \\
& \mathrm{E}_{\mathrm{co}}=275.3 \mathrm{kWh} / \mathrm{yr}
\end{aligned}
$$

Energy consumption of self-cleaning operation

$$
\begin{aligned}
& E_{\mathrm{s}}=\text { Direct measurement of electric consumption } \\
& E_{\mathrm{S}}=6.80 \mathrm{kWh}
\end{aligned}
$$

Annual self-cleaning energy consumption for electric oven

$$
\begin{aligned}
& E_{S C}=E_{S} \times S_{E}, S_{E}=11 \\
& E_{S C}=74.8 \mathrm{kWh} / \mathrm{yr}
\end{aligned}
$$

Annual clock energy consumption

$$
\begin{aligned}
& \mathrm{E}_{\mathrm{CL}}=\mathrm{P}_{\mathrm{CL}} \times \mathrm{H}_{\mathrm{k}} \times \mathrm{C} \\
& \mathrm{E}_{\mathrm{CL}}=27.2 \mathrm{kWh} / \mathrm{yr}
\end{aligned}
$$

Total annual energy consumption of single electric oven

$$
\begin{aligned}
& \mathrm{E}_{\mathrm{AO}}=\mathrm{E}_{\mathrm{CO}}+\mathrm{E}_{\mathrm{SC}}+\mathrm{E}_{\mathrm{CL}} \\
& \mathrm{E}_{\mathrm{AO}}=377.9 \mathrm{kWh} / \mathrm{yr}
\end{aligned}
$$

Annual conventional oven cooking efficiency

$$
\begin{aligned}
& \text { Eff }_{A O}=\left(W_{1} \times C_{p} \times T\right) /\left(E_{O} \times H_{e}\right) \\
& \text { Eff }_{A O}=12.9 \%
\end{aligned}
$$

Energy factor

$$
\begin{aligned}
& R_{o}=O_{O} / E_{A O} \\
& R_{O}=0.094
\end{aligned}
$$


Figure 6 and the summaries in Appendix B, contain the same data as in Figure 5 with the addition of the gas volume consumed and the heating value of the natural gas used during testing. Figure 7 summarizes the results of the seven electric oven tests. Figure 8 summarizes the results of the five gas oven tests.

The first parameter determined from an oven test is the energy consumption, $\mathrm{E}_{\mathrm{O}}$, which is the primary energy consumed by the oven for heating the test block during the test. For the electric oven tested, this value includes the clock energy since the clock could not be disconnected during the measurement. The range of $E_{O}$ from the electric oven tests was $862 \mathrm{Wh}$ to $898 \mathrm{Wh}$, while the range of $E_{\mathrm{o}}$ for the gas oven tests was from $5.55 \times 10^{3} \mathrm{Btu}$ to $5.74 \times 10^{3} \mathrm{Btu}$ $(1.63 \mathrm{kWh}$ to $1.68 \mathrm{kWh})$. The average primary cooking energy, along with the standard deviation and coefficient of variance (C.V.), were calculated from the results of the seven electric oven tests and the five gas oven tests. The electric oven consumed an average of $880 \mathrm{Wh}$ per test with a standard deviation of $14.0 \mathrm{Wh}$ and a C.V. of $1.6 \%$. The gas oven consumed an average of $5.63 \times 10^{3} \mathrm{Btu}(1.65 \mathrm{kWh})$ per test with a standard deviation of $72 \mathrm{Btu}(0.2 \mathrm{kWh})$ and a C.V. of $1.3 \%$.

The next step, which only applies to the gas oven, is to determine the energy consumption of electrical components required for its operation, $\mathrm{E}_{\mathrm{IO}}$. The gas oven employed an electric ignition device, commonly referred to as a "glow plug", which consumes electric power whenever the gas flow is cycled on. The electric energy consumed by the glow plug, is included in $\mathrm{E}_{\mathrm{IO}}$. The secondary energy, $\mathrm{E}_{\mathrm{IO}}$, used during the gas oven tests ranged from 116 to $119 \mathrm{Wh}$. The glow plug was monitored throughout each test and its power load ranged from about $380 \mathrm{~W}$ to $405 \mathrm{~W}$ with an average of about $390 \mathrm{~W}$. The average glow plug energy consumption was 118 Wh per test with a standard deviation of $1.5 \mathrm{Wh}$ and a coefficient of variance of $1.3 \%$. 
Figure 6: Results of Conventional Gas Oven Test

\begin{tabular}{|c|c|c|c|c|c|c|c|c|c|c|c|}
\hline \multicolumn{3}{|c|}{ Temperature } & \multicolumn{3}{|c|}{ Energy Consumption } & \multicolumn{3}{|c|}{ Gas Volume } & \multicolumn{3}{|c|}{ Constants, and Initial Values } \\
\hline & $\left({ }^{\circ} \mathrm{F}\right)$ & $\left({ }^{\circ} \mathrm{C}\right)$ & & (Btu) & (Wh) & & $\left(\mathrm{ft}^{3}\right)$ & (L) & & & \\
\hline$T_{A}$ & 269.4 & 131.9 & $\mathrm{E}_{\mathrm{A}}$ & 5653 & 1657 & $\mathrm{~V}_{\mathrm{A}}$ & 5.50 & 155.9 & $\mathrm{P}_{\mathrm{CL}}$ & $0.9 \mathrm{Btu}$ & $3.1 \mathrm{~W}$ \\
\hline$T_{B}$ & 278.7 & 137.1 & $E_{B}$ & 5653 & 1657 & $\mathrm{~V}_{\mathrm{B}}$ & 5.50 & 155.9 & $\mathrm{O}_{0}$ & $124,200 \mathrm{Btu} / \mathrm{yr}$ & $36.4 \mathrm{kWh} / \mathrm{yr}$ \\
\hline $\mathrm{T}_{\mathrm{c}}$ & 281.9 & 138.8 & $\mathrm{E}_{\mathrm{C}}$ & 6044 & 1771 & $\mathrm{~V}_{\mathrm{c}}$ & 5.88 & 166.7 & $W_{1}$ & $8.38 \mathrm{lb}$ & $3.81 \mathrm{~kg}$ \\
\hline$T_{D}$ & 290.7 & 143.7 & $E_{D}$ & 6044 & 1771 & $\mathrm{~V}_{\mathrm{D}}$ & 5.88 & 166.7 & $C_{p}$ & $0.23 \mathrm{Btu} / \mathrm{b}^{\circ} \mathrm{F}$ & $0.96 \mathrm{~kJ} / \mathrm{kg}^{\circ} \mathrm{C}$ \\
\hline & & & & & & & & & $\mathrm{T}$ & $202.0^{\circ} \mathrm{F}$ & $112.2^{\circ} \mathrm{C}$ \\
\hline$T_{\mathrm{AB}}$ & 274.0 & 134.5 & $E_{\mathrm{AB}}$ & 5653 & 1657 & $V_{A B}$ & 5.50 & 155.9 & $\mathrm{H}_{\mathbf{E}}$ & $3.41 \mathrm{Btu} / \mathrm{Wh}$ & $3.6 \mathrm{~kJ} / \mathrm{Wh}$ \\
\hline$T_{C D}$ & 286.3 & 141.3 & $\mathrm{E}_{\mathrm{CD}}$ & 6044 & 1771 & $\mathrm{~V}_{\mathrm{CD}}$ & 5.88 & 166.7 & $\mathrm{H}_{\mathrm{n}}$ & $1027 \mathrm{Btu} / \mathrm{ft}^{3}$ & $10.6 \mathrm{Wh} / \mathrm{L}$ \\
\hline$T_{0}$ & 276.6 & 276.6 & & & & & & & $\mathrm{H}_{\mathrm{k}}$ & $8760 \mathrm{hr} / \mathrm{yr}$ & $\mathrm{C}=0.001 \mathrm{~kW} / \mathrm{W}$ \\
\hline
\end{tabular}

Conventional gas oven test energy consumption

$$
\begin{aligned}
& E_{O}=E_{A B}+\left[\left(\left(T_{O}-T_{A B}\right) /\left(T_{C D}=T_{A B}\right)\right) \times\left(E_{C D}-E_{A B}\right)\right] \\
& \mathrm{E}_{\mathrm{O}}=5,735 \mathrm{Btu} \quad 1.681 \mathrm{kWh} / \mathrm{yr}
\end{aligned}
$$

Energy consumption of electrical components required for operation of gas oven

Direct measurement of gas ignition device

$\mathrm{E}_{\mathrm{IO}}=118.7 \mathrm{Wh}$

Annual primary energy consumption

$$
\begin{aligned}
& \left.\mathrm{E}_{\mathrm{co}}=\left(\mathrm{E}_{\mathrm{O}} \times \mathrm{O}_{\mathrm{O}}\right) / \mathrm{W}_{1} \times \mathrm{C}_{\mathrm{p}} \times \mathrm{T}\right) \\
& \mathrm{E}_{\mathrm{CO}}=1.83 \times 10^{6} \mathrm{Btu} / \mathrm{yr}
\end{aligned}
$$

Annual secondary energy for gas ovens

(from glow plug)

$$
\begin{aligned}
& \mathrm{E}_{\mathrm{so}}=\left(\mathrm{E}_{\mathrm{IO}} \times \mathrm{H}_{\mathrm{e}} \times \mathrm{O}_{\mathrm{O}}\right) /\left(\mathrm{W}_{1} \times \mathrm{C}_{\mathrm{P}} \times \mathrm{T}\right) \\
& \mathrm{E}_{\mathrm{so}}=36.9 \mathrm{kWh} / \mathrm{yT}
\end{aligned}
$$

Energy consumption of self-cleaning operation of gas oven

Direct measurement of gas consumption

$$
\mathrm{E}_{\mathrm{S}}=46.2 \times 10^{3} \mathrm{Btu} \quad 13.5 \mathrm{kWh}
$$

Annual energy consumption of self-cleaning operation for conventional gas oven

$$
\begin{aligned}
& E_{s c}=E_{s} \times E_{s s}, E_{s s}=7 \\
& E_{s c}=323 \times 10^{3} \mathrm{Btu} / \mathrm{yr}
\end{aligned}
$$

Annual secondary energy consumption for self-cleaning gas oven

$$
\begin{aligned}
& \mathrm{E}_{\mathrm{ss}}=\mathrm{E}_{\mathrm{IS}} \times \mathrm{S}_{\mathrm{g}} \times \mathrm{C} \\
& \mathrm{E}_{\mathrm{ss}}=6.99 \mathrm{kWh} / \mathrm{yr}
\end{aligned}
$$

Annual clock energy consumption

$$
\begin{aligned}
& E_{\mathrm{CL}}=\mathrm{P}_{\mathrm{CL}} \times \mathrm{H}_{\mathrm{k}} \times \mathrm{C} \\
& \mathrm{E}_{\mathrm{CL}}=27.2 \mathrm{kWh} / \mathrm{yr}
\end{aligned}
$$

Total annual energy consumption of single conventional gas oven

$$
\begin{aligned}
& E_{\mathrm{AOG}}=E_{\mathrm{CO}}+\mathrm{E}_{\mathrm{SC}} \\
& E_{\mathrm{AOG}}=2.15 \times 10^{6} \mathrm{Btu} / \mathrm{yr} \quad 630.6 \mathrm{kWh} / \mathrm{yr}
\end{aligned}
$$

Total annual electrical energy consumption of gas oven

$$
\begin{aligned}
& E_{A O E}=E_{S O}+E_{S S}+E_{C L} \\
& E_{A O E}=71.1 \mathrm{kWh} / \mathrm{yr}
\end{aligned}
$$

Annual conventional oven cooking efficiency

$$
\begin{aligned}
& \operatorname{Eff}_{A O}=\left(W_{1} \times C_{p} \times T\right) /\left(E_{O} \times\left(E_{10} \times H_{c}\right)\right) \\
& \operatorname{Eff}_{A O}=6.3 \%
\end{aligned}
$$

Energy factor

$$
\begin{aligned}
& \mathrm{R}_{\mathrm{o}}=\mathrm{O}_{\mathrm{O}} / \mathrm{E}_{\mathrm{AO}} \\
& \mathrm{R}_{\mathrm{o}}=0.052
\end{aligned}
$$


Figure 7: Summary of Results of Electric Oven Tests

\begin{tabular}{|c|cccccccc|}
\hline $\begin{array}{c}\text { Test } \\
\text { Number }\end{array}$ & $\begin{array}{c}\mathrm{E}_{\mathrm{O}} \\
(\mathrm{Wh})\end{array}$ & $\begin{array}{c}\mathrm{E}_{\mathrm{CO}} \\
(\mathrm{kWh} / \mathrm{yr})\end{array}$ & $\begin{array}{c}\mathrm{E}_{\mathrm{S}} \\
(\mathrm{kWh})\end{array}$ & $\begin{array}{c}\mathrm{E}_{\mathrm{SC}} \\
(\mathrm{kWh} / \mathrm{yr})\end{array}$ & $\begin{array}{c}\mathrm{E}_{\mathrm{CL}} \\
(\mathrm{kWh} / \mathrm{yr})\end{array}$ & $\begin{array}{c}\mathrm{E}_{\mathrm{AO}} \\
(\mathrm{kWh} / \mathrm{yr})\end{array}$ & $\begin{array}{c}\mathrm{Eff}_{\mathrm{AO}} \\
(\%)\end{array}$ & $\begin{array}{c}\mathrm{R}_{\mathrm{O}} \\
(---)\end{array}$ \\
\hline 1 & 885 & 276 & 6.80 & 74.8 & 27.2 & 378 & $12.9 \%$ & 0.094 \\
2 & 885 & 276 & 6.79 & 74.7 & 25.7 & 376 & $12.9 \%$ & 0.094 \\
3 & 893 & 278 & 6.97 & 76.7 & 26.3 & 381 & $12.8 \%$ & 0.093 \\
4 & 898 & 280 & 6.80 & 74.8 & 24.3 & 379 & $12.7 \%$ & 0.094 \\
5 & 862 & 269 & 6.97 & 76.7 & 24.4 & 370 & $13.2 \%$ & 0.096 \\
6 & 868 & 271 & 6.98 & 76.8 & 26.3 & 374 & $13.1 \%$ & 0.095 \\
7 & 867 & 270 & 7.01 & 77.1 & 25.9 & 373 & $13.1 \%$ & 0.095 \\
\hline \hline Average & 880 & 274 & 6.90 & 75.9 & 25.7 & 376 & $13.0 \%$ & 0.094 \\
Stdev. & 14.0 & 4.38 & 0.10 & 1.10 & 1.04 & 3.92 & $0.21 \%$ & 0.001 \\
C.V. & $1.60 \%$ & $1.60 \%$ & $1.45 \%$ & $1.45 \%$ & $4.06 \%$ & $1.04 \%$ & $1.60 \%$ & $1.04 \%$ \\
\hline
\end{tabular}

The annual primary energy consumption, $\mathrm{E}_{\mathrm{CO}}$, is the electric energy consumed by an electric oven for cooking per year and the gas energy consumed by a gas oven for cooking per year. Its value is based on the oven test primary energy multiplied by the annual useful cooking energy $\mathrm{O}_{\mathrm{O}}$ and divided by the test block weight (mass) $\mathrm{W}_{1}$, specific heat $\mathrm{C}_{\mathrm{p}}$ and temperature rise, $T$. The annual primary energy consumption, $\mathrm{E}_{\mathrm{CO}}$, ranged from $269 \mathrm{kWh} / \mathrm{yr}$ to $280 \mathrm{kWh} / \mathrm{yr}$ for the electric oven and from $1.77 \times 10^{6} \mathrm{Btu} / \mathrm{yr}$ to $1.83 \times 10^{6} \mathrm{Btu} / \mathrm{yr}(518 \mathrm{kWh} / \mathrm{yr}$ to $536 \mathrm{kWh} / \mathrm{yr})$ for the gas oven. The average annual primary energy consumption for the electric oven was $274 \mathrm{kWh} / \mathrm{yr}$ with a standard deviation of $4.38 \mathrm{kWh} / \mathrm{yr}$ and a C.V. of $1.6 \%$. The average annual primary energy consumption for the gas oven was $1.79 \times 10^{6} \mathrm{Btu} / \mathrm{yr}(526 \mathrm{kWh} / \mathrm{yr})$ with a standard deviation of $22.7 \times 10^{3} \mathrm{Btu} / \mathrm{yr}(6.7 \mathrm{kWh} / \mathrm{yr})$ and a C.V. of $1.3 \%$.

The next step, for gas ovens only, is to determine the annual secondary energy consumption $\mathrm{E}_{\mathrm{sO}}$, of the gas oven's glow plug, $\mathrm{E}_{\mathrm{so}}$ ranged from $35.9 \mathrm{kWh} / \mathrm{yr}$ to $37.1 \mathrm{kWh} / \mathrm{yr}$. The average annual secondary energy consumption for the five gas oven tests is $36.6 \mathrm{kWh} / \mathrm{yr}$, while the standard deviation and C.V. is $0.48 \mathrm{kWh} / \mathrm{yr}$ and $1.3 \%$ respectively. For the model oven tested, the annual secondary energy consumption was entirely due to the glow plug, and is $7.0 \%$ of the annual primary energy used by a gas oven. It is $6.5 \%$ of the total annual cooking energy, $\mathrm{E}_{\mathrm{CO}}+\mathrm{E}_{\mathrm{SO}}$.

The next step for both ovens is to determine the energy consumption associated with selfcleaning. The manufacturer of the ovens tested recommends a self-cleaning operation time between $2 \mathrm{~h}$ and $4 \mathrm{~h}$, depending on the soiling of the oven. The self-cleaning operations were set to clean for $3 \mathrm{~h}$, the time recommended for moderate soiling. Though the Proposed Rule uses the 
symbol $E_{S}$ to represent both the electric energy consumed by an electric oven and the volume of gas consumed by a gas oven during testing, the gas volume has been multiplied by the heating value of the gas and the symbol $E_{S}$ is used to represent the primary energy consumption in units of $\mathrm{kWh}$ for electric and Btu for gas ovens. The self-cleaning energy consumption measurements ranged from $6.79 \mathrm{kWh}$ to $7.01 \mathrm{kWh}$ and from $45.2 \times 10^{3}$ Btu to $47.1 \times 10^{3} \mathrm{Btu}(13.3 \mathrm{kWh}$ to 13.8 $\mathrm{kWh}$ ) for the electric and gas ovens respectively. The average self-cleaning energy consumption of the electric and gas ovens was $6.90 \mathrm{kWh}$ and $46.1 \times 10^{3}$ Btu $(13.5 \mathrm{kWh})$ respectively, while the standard deviation and C.V. was $0.10 \mathrm{kWh}$ and $1.5 \%$ for the electric oven, and $704 \mathrm{Btu}$ $(0.21 \mathrm{kWh})$ and $1.5 \%$ for the gas oven.

The secondary (electric) energy consumption during the self-cleaning gas oven operation is solely determined by the energy consumption of the glow plug for the oven tested. Since the oven clock could not be disconnected, the secondary energy was obtained by monitoring the total energy consumption throughout the test, then extracting the clock energy. The clock energy was determined by multiplying the average clock power during the test by the test duration. The secondary energy consumption of the self-cleaning gas oven operation, $\mathrm{E}_{\mathrm{IS}}$, was between $999 \mathrm{Wh}$ and 1041 Wh for the gas oven. The secondary energy consumption of the five self-cleaning energy consumption tests averaged $1021 \mathrm{Wh}$, with a standard deviation of $20.5 \mathrm{Wh}$ and a C.V. of $2.0 \%$. The average secondary energy consumption of the five tests is equivalent to $3,506 \mathrm{Btu}$. The total combined gas and electric energy consumed per conventional gas oven self-cleaning test is equivalent to $49.6 \times 10^{3} \mathrm{Btu}(14.5 \mathrm{kWh})$. The secondary energy consumption per test makes up $7.0 \%$ of the total energy consumed per test.

The annual primary self-cleaning energy consumption, $\mathrm{E}_{\mathrm{SC}}$, for electric and gas ovens and the annual secondary self-cleaning energy consumption, $\mathrm{E}_{S S}$, for a gas oven were calculated next, as prescribed in the Proposed Rule. $E_{S C}$ is dependent only on the energy consumption test results and a usage factor, which is the number of times the oven is operated in the self-cleaning mode per year. At the time of testing, the usage factors, $S_{c}$ and $S_{g}$, for electric and gas self-cleaning operations, were 11 and 7 respectively. Due to re-evaluation of these factors by DOE, $S_{e}$ and $S_{g}$, have been changed to 4 self-cleaning operations per year in the Final Rule. The results published in this report were determined with $S_{e}$ equal to 11 and $S_{g}$ equal to 7 unless stated otherwise.

The annual primary self-cleaning energy consumption, $\mathrm{E}_{\mathrm{SC}}$, during the electric and gas tests ranged from $74.7 \mathrm{kWh} / \mathrm{yr}$ to $77.1 \mathrm{kWh} / \mathrm{yr}$ and $317 \times 10^{3} \mathrm{Btu} / \mathrm{yr}$ to $330 \mathrm{x} 10^{3} \mathrm{Btu} / \mathrm{yr}(92.8$ $\mathrm{kWh} / \mathrm{yr}$ to $96.2 \mathrm{kWh} / \mathrm{yr}$ ) respectively. The average annual primary self-cleaning energy consumption and standard deviation for the seven electric self-cleaning oven operations was 75.9 $\mathrm{kWh} / \mathrm{yr} \pm 1.10 \mathrm{kWh} / \mathrm{yr}$. The average annual primary energy consumed and standard deviation of the five gas self-cleaning oven operations was $323 \times 10^{3} \mathrm{Btu} / \mathrm{yr} \pm 4.90 \times 10^{3} \mathrm{Btu} / \mathrm{yr}(94.6 \mathrm{kWh} / \mathrm{yr}$ $\pm 1.4 \mathrm{kWh} / \mathrm{yr}$ ). The C.V. of the annual primary energy consumption of the electric and gas selfcleaning tests were both $1.5 \%$. The annual secondary energy consumption, $\mathrm{E}_{\mathrm{SS}}$, ranged from 6.99 $\mathrm{kWh} / \mathrm{yr}$ to $7.28 \mathrm{kWh} / \mathrm{yr}$, while the average annual secondary energy consumption and standard deviation based on the five tests was $7.15 \mathrm{kWh} / \mathrm{yr} \pm 0.14 \mathrm{kWh} / \mathrm{yr}$ with a C.V. of $2.0 \%$. 
An estimate of the clock power $\mathrm{P}_{\mathrm{CL}}$ was calculated for each test as the average of all power measurements recorded while all other energy consuming devices were off. Based on the average test power and the number of hours in a year, the annual energy consumption of the clock, $\mathrm{E}_{\mathrm{CL}}$, was determined on a per test basis for both the electric and gas ovens. Based on the seven electric oven tests, the average electric oven clock power was $2.9 \mathrm{~W}$ and the average gas oven clock power was $3.2 \mathrm{~W}$. The average of the seven annual clock energy consumption values of the electric oven was $25.7 \mathrm{kWh} / \mathrm{yr}$ with a standard deviation of $1.04 \mathrm{kWh} / \mathrm{yr}$, and a C.V. of $4.1 \%$. The annual energy consumption of the gas oven's clock was $27.9 \mathrm{kWh} / \mathrm{yr}$ with a standard deviation of $1.05 \mathrm{kWh} / \mathrm{yr}$ and a C.V. of 3.8\%. It is notable that the coefficient of variance related to the clock power of both ovens are two to three times greater than the C.V.'s of the other test parameters measured with the same instrument. This larger C.V. of the clock power measurements is not surprising given that it is difficult to measure such low levels of power with a great degree of accuracy. This is the most logical reason for the original $5 \%$ accuracy specification for a watt meter when measuring in the range below $10 \mathrm{~W}$. Since it is not difficult to obtain relatively accurate measurements (within about $1 \%$ ) down to about $10 \mathrm{~W}$ with current watt meters, the $5 \%$ accuracy specification for watt meters could be changed to $1 \%$ for measured values above 100 watts.

Since the clock of both test ovens was an integral part of the temperature control circuit, the oven test energy consumption values, $\mathrm{E}_{\mathrm{A}}, \mathrm{E}_{\mathrm{B}}, \mathrm{E}_{\mathrm{C}}$, and $\mathrm{E}_{\mathrm{D}}$, included the clock energy recorded in the raw data files. However, the energy consumed by the clock is already accounted for in the annual clock energy consumption. Oven test energy consumption results were determined with the clock energy included and with the clock energy subtracted from the energy consumption measurements of the tests to determine the corrected results and the error associated with including the clock energy in the original calculations of the oven energy consumption test results. The uncorrected and corrected results are presented in Figure 9 for oven test \#1. The difference in the final values for total annual energy consumption and the energy factor for a single oven is approximately $0.05 \%$. This demonstrates that the effect of including the clock power in the calculation of the oven efficiency, annual energy consumption and energy factor is negligible for the oven tested at NIST. However, the annual clock energy is roughly $7 \%$ of the total annual energy consumption for the oven tests, and can not be neglected.

The total annual primary energy consumption, $\mathrm{E}_{\mathrm{AO}}$, of the seven electric oven tests ranged from $373 \mathrm{kWh} / \mathrm{yr}$ to $381 \mathrm{kWh} / \mathrm{yr}$ with an average value of $376 \mathrm{kWh} / \mathrm{yr}$, a standard deviation of $3.92 \mathrm{kWh} / \mathrm{yr}$ and a coefficient of variance of $1.0 \%$. The total annual primary energy consumption, $\mathrm{E}_{\mathrm{AOG}}$, of the five gas oven tests ranged from $2.09 \times 10^{6} \mathrm{Btu} / \mathrm{yr}$ to $2.15 \times 10^{6} \mathrm{Btu} / \mathrm{yr}$ $(613 \mathrm{kWh} / \mathrm{yr}$ to $630 \mathrm{kWh} / \mathrm{yr})$ with an average value of $2.12 \times 10^{6} \mathrm{Btu} / \mathrm{yr}(620 \mathrm{kWh} / \mathrm{yr})$, a standard deviation of $22.4 \times 10^{3} \mathrm{Btu} / \mathrm{yr}(6.6 \mathrm{kWh} / \mathrm{yr})$ and a coefficient of variance of $1.1 \%$. The annual secondary energy, $\mathrm{E}_{\mathrm{AOE}}$, of the gas oven tests was ranged from $70.6 \mathrm{kWh} / \mathrm{yr}$ to $73.6 \mathrm{kWh} / \mathrm{yr}(6.6$ $\mathrm{kWh} / \mathrm{yr}$ ) with an average of $71.6 \mathrm{kWh} / \mathrm{yr}$, a standard deviation of $1.14 \mathrm{kWh} / \mathrm{yr}$ and a coefficient of variance of $1.6 \%$. 
The annual conventional electric oven cooking efficiency, Eff $_{\mathrm{AO}}$, is determined by the oven test block weight, specific heat, and temperature rise during the oven test divided by the energy consumption input during the oven test and a conversion factor. The efficiencies of the electric oven tests, ranged form $12.7 \%$ to $13.1 \%$ with an average value of $13.0 \%$, a standard deviation of $0.21 \%$, and a coefficient of variance of $1.6 \%$. The efficiency of the five gas oven tests ranged from approximately $6.3 \%$ to $6.5 \%$ with and average of $6.5 \%$, a standard deviation of $0.08 \%$ and a coefficient of variance of $1.2 \%$.

The conventional electric oven energy factor, $R_{\mathrm{O}}$, calculated as the annual useful cooking energy divided by the total annual energy consumption, ranged from 0.093 to 0.096 with an average value of 0.094 , a standard deviation of 0.001 , and a coefficient of variance of $1.0 \%$. The energy factor of the five gas oven tests ranged from 0.052 to 0.053 with an average value of 0.053 , a standard deviation of less than 0.001 and a coefficient of variance of $0.9 \%$. 
Figure 8a: Summary of Results of Gas Oven Tests

\begin{tabular}{|c|c|c|c|c|c|c|c|c|c|c|c|c|c|}
\hline $\begin{array}{c}\text { Test } \\
\text { Number }\end{array}$ & $\begin{array}{c}\mathbf{E}_{\mathbf{0}} \\
\text { (Btu) }\end{array}$ & $\begin{array}{c}\mathbf{E}_{\text {lo }} \\
\text { (Wh) }\end{array}$ & $\begin{array}{c}\mathbf{E}_{\mathrm{CO}} \\
(\mathbf{B t u} / \mathbf{y r})\end{array}$ & $\begin{array}{c}\text { Eso }_{\mathrm{SO}} \\
(\mathbf{k W h} / \mathbf{y r})\end{array}$ & $\begin{array}{c}\mathbf{E}_{\mathrm{S}} \\
\text { (Btu) }\end{array}$ & $\begin{array}{c}\mathbf{E}_{\mathbf{T S}} \\
(\mathbf{W h})\end{array}$ & $\begin{array}{c}\mathbf{E}_{\mathrm{SC}} \\
(\mathbf{B t u} / \mathbf{y r})\end{array}$ & $\begin{array}{c}\mathbf{E}_{\mathrm{SS}} \\
(\mathrm{kWh} / \mathbf{y r})\end{array}$ & $\begin{array}{c}\mathbf{E}_{\mathrm{Cr}} \\
(\mathrm{kWh} / \mathrm{yr})\end{array}$ & $\begin{array}{c}\mathbf{E}_{\mathrm{AOG}} \\
(\mathrm{Btu} / \mathrm{yr}) \\
\end{array}$ & $\begin{array}{c}\mathbf{E}_{\mathrm{AOE}} \\
(\mathbf{k W h} / \mathbf{y r})\end{array}$ & $\begin{array}{c}\mathrm{Eff}_{\mathrm{AO}} \\
(\%)\end{array}$ & $\begin{array}{l}\mathbf{R}_{\mathbf{O}} \\
(--\cdot)\end{array}$ \\
\hline 1 & $5.74 \mathrm{E}+03$ & 119 & $1.83 \mathrm{E}+06$ & 36.9 & $4.62 \mathrm{E}+04$ & 999 & $3.23 \mathrm{E}+05$ & 6.99 & 27.17 & $2.15 \mathrm{E}+06$ & 71.06 & $6.34 \%$ & 0.052 \\
\hline 2 & $5.65 \mathrm{E}+03$ & 118 & $1.80 \mathrm{E}+06$ & 36.8 & $4.52 \mathrm{E}+04$ & 1038 & $3.17 E+05$ & 7.2 & 29.49 & $2.12 \mathrm{E}$ & 13.5 & & 0.052 \\
\hline 3 & $5.60 \mathrm{E}+03$ & 117 & $1.78 \mathrm{E}+06$ & 36.3 & 4.71E+04 & 1028 & $3.30 \mathrm{E}+05$ & 7.20 & 27.06 & $2.11 \mathrm{E}$ & 70.59 & & 0.053 \\
\hline 4 & $5.55 \mathrm{E}+03$ & 119 & $1.77 \mathrm{E}+06$ & 37.1 & $4.63 \mathrm{E}+04$ & 999 & $3.24 \mathrm{E}+05$ & 6.99 & 27.19 & $2.09 \mathrm{E}$ & 71.28 & $54 \%$ & 0.053 \\
\hline 5 & $5.60 \mathrm{E}+03$ & 116 & $1.78 \mathrm{E}+06$ & 35.9 & 4.57E+04 & 1041 & $3.20 \mathrm{E}+05$ & 7.28 & 28.32 & $2.10 \mathrm{E}+06$ & 71.51 & $6.51 \%$ & 0.053 \\
\hline erage & $63 \mathrm{E}+03$ & 1 & & 36.6 & $4.61 E+04$ & 1021 & $3.23 E+05$ & 7.1 & 27.85 & $2.12 \mathrm{E}+06$ & 71.60 & $6.46 \%$ & 0.053 \\
\hline Stdev. & 72.2 & 1.51 & $2.27 \mathrm{E}+04$ & 0.48 & & 20.5 & $4.90 \mathrm{E}-$ & & 1.05 & $2.24 \mathrm{E}+04$ & 1.14 & $0.08 \%$ & 0.0005 \\
\hline C.V. & $1.28 \%$ & $1.29 \%$ & $1.27 \%$ & $1.32 \%$ & $1.53 \%$ & $2.01 \%$ & $1.52 \%$ & $2.01 \%$ & $3.79 \%$ & $1.06 \%$ & $1.60 \%$ & $1.20 \%$ & $0.94 \%$ \\
\hline
\end{tabular}

Figure 8b: Summary of Results of Gas Oven Tests

\begin{tabular}{|c|c|c|c|c|c|c|c|c|c|c|c|c|c|}
\hline $\begin{array}{c}\text { Test } \\
\text { Number }\end{array}$ & $\begin{array}{c}\mathbf{E}_{\mathbf{0}} \\
(\mathbf{k W h})\end{array}$ & $\begin{array}{c}\mathbf{E}_{\text {Yo }} \\
\text { (Wh) } \\
\end{array}$ & $\begin{array}{c}\mathbf{E}_{\mathrm{CO}} \\
(\mathrm{kWh} / \mathbf{y r})\end{array}$ & $\begin{array}{c}\text { Eso } \\
(\mathrm{kWh} / \mathrm{yr})\end{array}$ & $\begin{array}{c}\mathbf{E}_{S} \\
(\mathbf{k W h})\end{array}$ & $\begin{array}{c}\mathbf{E}_{\mathbf{S}} \\
(\mathbf{W h}) \\
\end{array}$ & $\begin{array}{c}\begin{array}{c}\mathbf{E}_{\mathrm{SC}} \\
(\mathbf{k W h} / \mathbf{y r})\end{array} \\
\end{array}$ & $\begin{array}{c}\begin{array}{c}\mathbf{E}_{\mathrm{SS}} \\
(\mathrm{kWh} / \mathbf{y r})\end{array} \\
\end{array}$ & $\begin{array}{c}\mathbf{E}_{\mathrm{CL}} \\
(\mathbf{k W h} / \mathbf{y r})\end{array}$ & $\begin{array}{c}\mathbf{E}_{\mathrm{AOG}} \\
(\mathbf{k W h} / \mathbf{y r})\end{array}$ & $\begin{array}{c}\begin{array}{c}\mathbf{E}_{\mathrm{AOE}} \\
(\mathbf{k W h} / \mathbf{y r})\end{array} \\
\end{array}$ & $\begin{array}{c}\mathbf{E f f}_{A O} \\
(\%) \\
\end{array}$ & $\begin{array}{l}\mathbf{R}_{\mathbf{O}} \\
(-) \\
\end{array}$ \\
\hline 1 & 1.68 & 119 & 535.8 & 36.9 & 13.53 & 999 & 94.7 & 6.99 & 27.17 & 630.7 & 71.06 & $6.34 \%$ & 0.052 \\
\hline 2 & 1.66 & 118 & 528.1 & 36.8 & 13.26 & 1038 & 92.8 & 7.26 & 29.49 & 620.8 & 73.55 & $6.43 \%$ & 0.052 \\
\hline 3 & 1.64 & 117 & 522.9 & 36.3 & 13.81 & 1028 & 96.7 & 7.20 & 27.06 & 619.6 & 70.59 & $6.50 \%$ & 0.053 \\
\hline 4 & 1.63 & 119 & 518.5 & 37.1 & 13.57 & 999 & 95.0 & 6.99 & 27.19 & 613.4 & 71.28 & $6.54 \%$ & 0.053 \\
\hline 5 & 1.64 & 116 & 522.6 & 35.9 & 13.40 & 1041 & 93.8 & 7.28 & 28.32 & 616.4 & 71.51 & $6.51 \%$ & 0.053 \\
\hline Average & 1.65 & 118 & 525.5 & 36.6 & 13.5 & 1021 & 94.6 & 7.15 & 27.85 & 620.2 & 71.60 & $6.46 \%$ & 0.053 \\
\hline Stdev. & 0.02 & 1.51 & 6.7 & 0.48 & 0.21 & 20.5 & 1.4 & 0.14 & 1.05 & 6.6 & 1.14 & $0.08 \%$ & 0.0005 \\
\hline C. $V$. & $1.28 \%$ & $1.29 \%$ & $1.27 \%$ & $1.32 \%$ & $1.53 \%$ & $2.01 \%$ & $1.52 \%$ & $2.01 \%$ & $3.79 \%$ & $1.06 \%$ & $1.60 \%$ & $1.20 \%$ & $0.94 \%$ \\
\hline
\end{tabular}


Figure 9: Results of Conventional Electric Oven Test \#1

\begin{tabular}{|c|c|c|c|c|c|}
\hline & \multirow{2}{*}{\multicolumn{2}{|c|}{ Temperature }} & \multicolumn{2}{|c|}{ Energy Consumption (Wh) } & \multirow{2}{*}{ Constants, and Initial Values } \\
\hline & & & measured & corrected & \\
\hline $\mathrm{T}_{\mathrm{A}}=$ & $256.3^{\circ} \mathrm{F}$ & $124.6^{\circ} \mathrm{C}$ & $E_{A}=850.0$ & 848.3 & $P_{C L}=3.1 \mathrm{~W}$ \\
\hline $\mathrm{T}_{\mathrm{B}}=$ & $275.2^{\circ} \mathrm{F}$ & $135.1^{\circ} \mathrm{C}$ & $E_{B}=850.2$ & 848.3 & $\mathrm{O}_{\mathrm{O}}=35.5 \mathrm{kWh} / \mathrm{yr}$ \\
\hline $\mathrm{T}_{\mathrm{c}}=$ & $279.1^{\circ} \mathrm{F}$ & $137.3^{\circ} \mathrm{C}$ & $\mathrm{E}_{\mathrm{C}}=920.5$ & 918.6 & $\mathrm{~W}_{1}=8.38 \mathrm{lb}(3.81 \mathrm{~kg})$ \\
\hline \multirow[t]{2}{*}{$\mathrm{T}_{\mathrm{D}}=$} & $295.1^{\circ} \mathrm{F}$ & $146.6^{\circ} \mathrm{C}$ & $E_{D}=920.7$ & 918.5 & $\mathrm{C}_{\mathrm{p}}=0.23 \mathrm{Btu} / 16^{\circ} \mathrm{F}\left(0.96 \mathrm{~kJ} / \mathrm{kg}^{\circ} \mathrm{C}\right)$ \\
\hline & & & & & $\mathrm{T}=202.0^{\circ} \mathrm{F}\left(112.2^{\circ} \mathrm{C}\right)$ \\
\hline $\mathrm{T}_{\mathrm{AB}}=$ & $265.8^{\circ} \mathrm{F}$ & $129.9^{\circ} \mathrm{C}$ & $\mathrm{E}_{\mathrm{AB}}=850.1$ & 848.3 & $\mathrm{H}_{\mathrm{e}}=3.6 \mathrm{~kJ} / \mathrm{Wh}$ \\
\hline $\mathrm{T}_{\mathrm{CD}}=$ & $287.6^{\circ} \mathrm{F}$ & $142.0^{\circ} \mathrm{C}$ & $\mathrm{E}_{\mathrm{CD}}=920.6$ & 918.5 & $\mathrm{H}_{\mathrm{k}}=8760 \mathrm{~h} / \mathrm{yr}$ \\
\hline $\mathrm{T}_{0}=$ & $276.6^{\circ} \mathrm{F}$ & $135.9^{\circ} \mathrm{C}$ & & & $\mathrm{C}=0.001 \mathrm{~kW} / \mathrm{W}$ \\
\hline
\end{tabular}

Test energy consumption for conventional electric oven

$$
\begin{aligned}
& \mathrm{E}_{\mathrm{O}}=\left\{\mathrm{E}_{\mathrm{AB}}+\left[\left(\left(\mathrm{T}_{\mathrm{O}}-\mathrm{T}_{\mathrm{AB}}\right) /\left(\mathrm{T}_{\mathrm{CD}}-\mathrm{T}_{\mathrm{AB}}\right)\right) \times\left(\mathrm{E}_{\mathrm{CD}}-\mathrm{E}_{\mathrm{AB}}\right)\right]\right\} \\
& \mathrm{E}_{\mathrm{O}}=885.3 \mathrm{Wh}
\end{aligned}
$$

Annual primary energy consumption

$$
\begin{aligned}
& \mathrm{E}_{\mathrm{CO}}=\left(\mathrm{E}_{\mathrm{o}} \times \mathrm{H}_{\mathrm{e}} \times \mathrm{O}_{\mathrm{o}}\right) /\left(\mathrm{W}_{1} \times \mathrm{C}_{\mathrm{p}} \times \mathrm{T}\right) \\
& \mathrm{E}_{\mathrm{CO}}=275.9 \mathrm{kWh} / \mathrm{yr}
\end{aligned}
$$

$\mathrm{E}_{\mathrm{COcorr}}=275.3 \mathrm{Wh} / \mathrm{yr}$

Energy consumption of self-cleaning operation

$E_{S}=$ Direct measurement of electric consumption

$E_{S}=6.80 \mathrm{kWh}$

$\mathrm{E}_{\mathrm{Scorr}}=6.8 \mathrm{kWh}$

Annual self-cleaning energy consumption for electric oven

$$
\begin{aligned}
& E_{S C}=E_{S} \times S_{c}, S_{c}=11 \\
& E_{s C}=74.7 \mathrm{kWh} / \mathrm{yr}
\end{aligned}
$$

$\mathrm{E}_{\mathrm{SCcorr}}=74.6 \mathrm{KWh} / \mathrm{yr}$

Annual clock energy consumption

$$
\begin{aligned}
& \mathrm{E}_{\mathrm{CL}}=\mathrm{P}_{\mathrm{CL}} \times \mathrm{H}_{\mathrm{k}} \times \mathrm{C} \\
& \mathrm{E}_{\mathrm{CL}}=26.3 \mathrm{kWh} / \mathrm{yr}
\end{aligned}
$$

$$
E_{\text {CLeor }}=26.3 \mathrm{kWh} / \mathrm{yr}
$$

Total annual energy consumption of single electric oven

$$
\begin{aligned}
& E_{A O}=E_{C O}+E_{S C}+E_{C L} \\
& E_{A O}=376.9 \mathrm{kWh} / \mathrm{yr}
\end{aligned}
$$

$\mathrm{E}_{\mathrm{AOCorr}}=376.2 \mathrm{kWh} / \mathrm{yr}$

Annual conventional oven cooking efficiency

$$
\begin{array}{ll}
\mathrm{E}_{\mathrm{AO}}=\left(\mathrm{W}_{1} \times \mathrm{C}_{\mathrm{p}} \times \mathrm{T}\right) /\left(\mathrm{E}_{\mathrm{O}} \times \mathrm{H}_{\mathrm{e}}\right) & \\
\mathrm{Eff}_{\mathrm{AO}}=12.9 \% & \mathrm{Eff}_{\mathrm{AOCOO}}=12.9 \%
\end{array}
$$

Energy factor

$$
\begin{aligned}
& \mathrm{R}_{\mathrm{O}}=\mathrm{O}_{\mathrm{O}} / \mathrm{E}_{\mathrm{AO}} \\
& \mathrm{R}_{\mathrm{O}}=0.094
\end{aligned}
$$

$R_{\text {Ocorr }}=0.094$ 


\section{Cooking Top Tests}

This section presents the test results for both the gas and electric cooking tops. These tests were performed, and the results determined, in compliance with the Proposed Rule. The first section describes the gas cooking top's response to the energy consumption test. The next section summarizes the results of the individual gas and electric cooking top surface unit tests.

\section{Response of Cooking Top to Energy Consumption Test}

Figure 10 is a time-series plot of temperature data acquired during a large surface unit test performed on the gas cooking top with the large test block. The upper curve is a plot of the test block temperature, while the center and lower curves are the cooking top surface temperature and the ambient room air respectively. The curves in Figure 10 are also typical of tests with the small gas burner test and the large test block, and with the electric burners. The most pronounced difference between electric and gas cooking top surface unit tests is the amount of time and energy required to elevate the test block to $144^{\circ} \mathrm{F}\left(80^{\circ} \mathrm{C}\right)$ above its initial temperature and the temperature at the end of the test. The test block is initially at room temperature. About $30 \mathrm{~s}$ into the test, the temperature of the block begins to rise at a constant rate of about $16^{\circ} \mathrm{F} / \mathrm{min}$. $\left(9^{\circ} \mathrm{C} / \mathrm{min}\right.$.). The load reaches its set point temperature $144^{\circ} \mathrm{F}\left(80^{\circ} \mathrm{C}\right)$ above its initial temperature, about $210^{\circ} \mathrm{F}\left(102^{\circ} \mathrm{C}\right)$, about 9 min. into the test, but the temperature increases for another minute due to the thermal inertia of the test load. It takes approximately $11 \mathrm{~min}$. to reach the set point using the small gas burner and the large test block. In contrast, the electric cooking top requires only about $4 \mathrm{~min}$. to $5 \mathrm{~min}$. to raise the temperatures of the small block on the small burner and the large block on the large burner. After the set point is reached, the energy input to the surface unit is reduced to one-quarter of its full power. After the thermal inertia effects die out, the rate of temperature increase changes to about $9^{\circ} \mathrm{F} / \mathrm{min} .\left(5^{\circ} \mathrm{C} / \mathrm{min}\right.$.) for the remainder of the $15 \mathrm{~min}$. reduced input energy period. The complete surface unit test takes about $25 \mathrm{~min}$. for the gas cooking top and $20 \mathrm{~min}$. for the electric cooking top. The final temperatures of the test block on the large and small surface units of the gas cooking tops for the entire test period is roughly $250^{\circ} \mathrm{F}$ and $275^{\circ} \mathrm{F}\left(120^{\circ} \mathrm{C}\right.$ and $\left.135^{\circ} \mathrm{C}\right)$, while the final temperatures of the test block on the large and small surface units of the electric cooking top is roughly $332^{\circ} \mathrm{F}$ and $356^{\circ} \mathrm{F}\left(170^{\circ} \mathrm{C}\right.$ and $180^{\circ} \mathrm{C}$ ). These correspond to overall temperature rises in the large and small burner test load of approximately $205^{\circ} \mathrm{F}$ and $180^{\circ} \mathrm{F}\left(115^{\circ} \mathrm{C}\right.$ and $\left.100^{\circ} \mathrm{C}\right)$, and $260^{\circ} \mathrm{F}$ and $290^{\circ} \mathrm{F}\left(145^{\circ} \mathrm{C}\right.$ and $160^{\circ} \mathrm{C}$ ) for gas and electric cooking tops respectively.

Figure 10 shows that the ambient air temperature remains constant at about $72^{\circ} \mathrm{F}\left(22^{\circ} \mathrm{C}\right)$ throughout the test. The surface temperature, initially the same as the ambient air, rises about $18^{\circ} \mathrm{F}\left(10^{\circ} \mathrm{C}\right)$ above the ambient air while the surface unit is on full power, then remains constant when the power is reduced. The surface temperature rise depends on the distance of the thermocouple from the surface unit under test. For all cooking top tests, the thermocouple was located approximately $1 \mathrm{ft}(0.3 \mathrm{~m})$ from the surface units tested. 
Figure 10: Conventional Cooking Top Test: Temperature versus Time

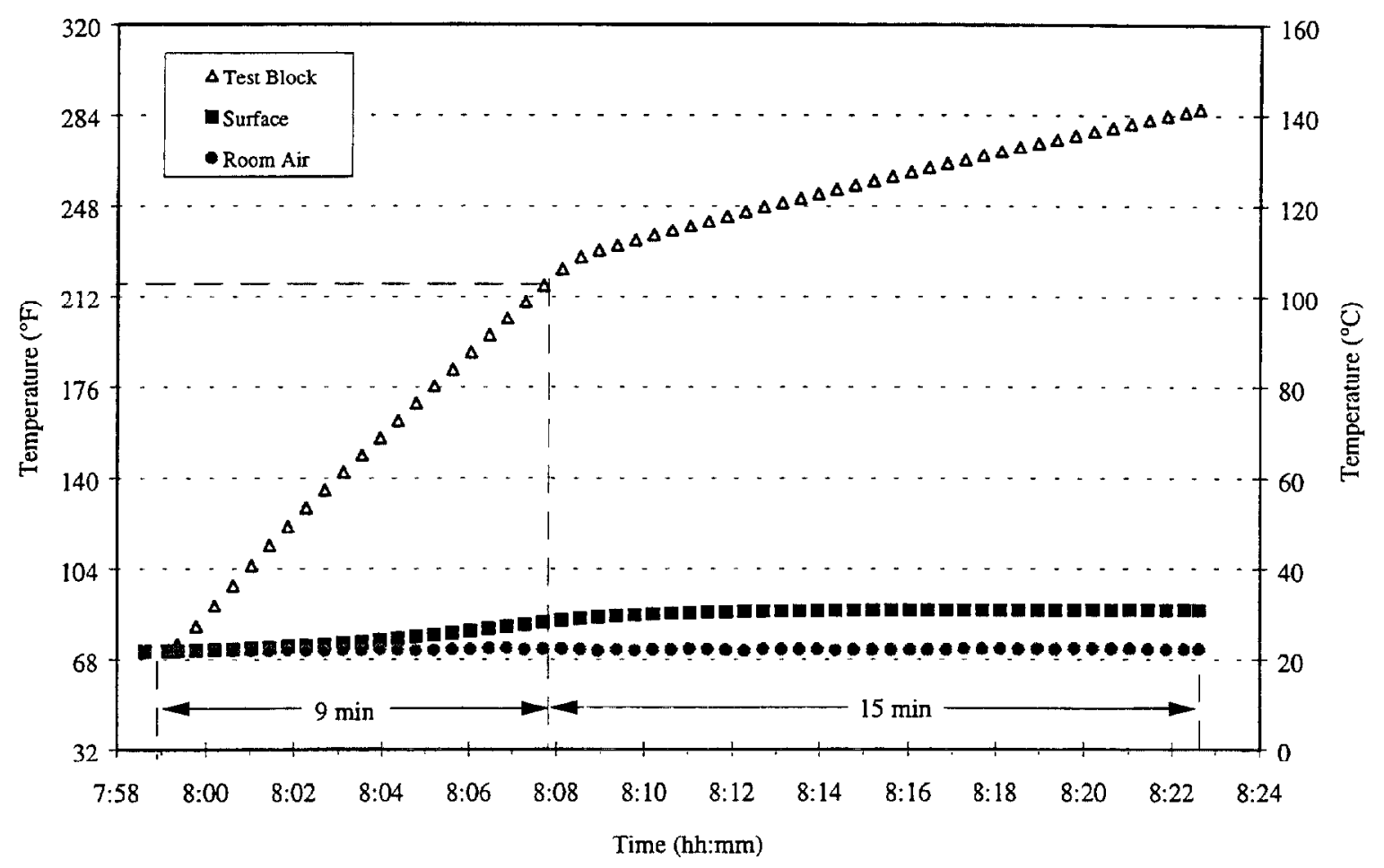

\section{Summary of Results}

Figures 11 and 12 show a summary of the results of single electric and gas cooking top tests. For the electric and gas cooking tops tested, the test results were based entirely on the individual surface unit test results; this is because there is no "non-cooking" energy usage associated with the cooking tops. The gas cooking top employed electronic ignition devices of negligible energy consumption, rather than continuously buming gas pilot lights. A summary of the individual small and large electric cooking top surface units tests is presented in Figure 13, while a summary of the individual small and large gas cooking top surface units is presented in Figure 14.

The electric and gas cooking top test results in Figures 11 and 12 first present the values of the parameters required to determine the first of the four surface unit efficiencies presented in the example. These parameters are shown in the boxed-in area at the top of the figures and consist of the room temperature, $T_{R}$, the initial test block temperature, $T_{I}$, the final temperature of the test block, $T_{C T}$, and the increase in the test block temperature, $T_{S U}=T_{C T}-T_{1}$. The second block at the top of Figure 11 contains the weight (mass), $\mathrm{W}_{2}$, of the test block $8.38 \mathrm{lb}(3.81 \mathrm{~kg}$ ) for the first two surface unit tests and the measured energy consumption at the end of the $15 \mathrm{~min}$ reduced-energy consumption period, $\mathrm{E}_{\mathrm{CT}}$. The weight (mass) of the test block, $\mathrm{W}_{3}$, is $18.5 \mathrm{lb}$ $(8.39 \mathrm{~kg})$ for the large electric surface unit tests. The remaining parameters included in the raw test data are presented in the third boxed in area. They are the annual useful cooking energy 
output, $\mathrm{O}_{\mathrm{CT}}$, the specific heat of the test block, $\mathrm{C}_{\mathrm{p}}$, and a conversion factor, $\mathrm{H}_{\mathrm{e}}$, from $\mathrm{kJ}$ to Wh. The first set of results under the blocked-in area consists of the surface unit cooking efficiency results, $\mathrm{Eff}_{\mathrm{SU}}$, for the four surface units of the cooking top, and shows the equation employed to determine the surface unit cooking efficiency. The cooking efficiency of the first small surface unit test (determined from the example test values presented in the blocked-in area) is $76.7 \%$ in this example. The cooking efficiencies of the other three cooking top surface units are $77.0 \%$, $83.0 \%$, and $82.5 \%$. The position and size of the surface unit tested is noted to the right of each efficiency value. The large electric surface units are about $5 \%$ more efficient than the small units under the test conditions. After presenting the efficiencies of the four surface unit tests, the cooking top cooking efficiency is presented in the next step, calculated as the average of the surface unit efficiencies. For this example, the cooking top cooking efficiency, $\mathrm{Eff}_{\mathrm{CT}}$, is $79.8 \%$. The cooking top annual energy consumption, $\mathrm{E}_{\mathrm{CA}}$, is presented next as the annual useful cooking energy output $\mathrm{O}_{\mathrm{CT}}$ divided by the cooking top cooking efficiency. In this example the cooking top annual energy consumption is $262.4 \mathrm{kWh} / \mathrm{yr}$. The annual energy consumption is followed by the final result, the energy factor of the cooking top, $\mathrm{R}_{\mathrm{CT}}$, calculated as the annual useful cooking energy output, $\mathrm{O}_{\mathrm{CT}}$, divided by the cooking top annual energy consumption, $\mathrm{E}_{\mathrm{CA}}$. 
Figure 11: Results of Conventional Electric Cooking Top Test

\begin{tabular}{|c|c|c|c|c|}
\hline \multicolumn{3}{|c|}{ Temperature } & Mass/Energy & Constants \\
\hline & $\left({ }^{\circ} \mathrm{F}\right)$ & $\left({ }^{\circ} \mathrm{C}\right)$ & & \\
\hline $\mathrm{T}_{\mathrm{R}}=$ & 73.4 & 23.0 & & $\mathrm{O}_{\mathrm{CT}}=732,500 \mathrm{Btu}(214.7 \mathrm{kWh})$ \\
\hline $\mathrm{T}_{1}=$ & 71.1 & 21.7 & $\mathrm{~W}_{3}=18.5 \mathrm{lb}(8.39 \mathrm{~kg})$ & $\mathrm{C}_{\mathrm{p}}=0.23 \mathrm{Btu} / \mathrm{b}-{ }^{\circ} \mathrm{F}\left(0.96 \mathrm{~kJ} / \mathrm{k}^{\circ} \mathrm{C}\right.$ \\
\hline $\mathrm{T}_{\mathrm{CT}}=$ & 289.9 & 143.3 & $\mathrm{E}_{\mathrm{CT}}=295 \mathrm{Btu}(866.1 \mathrm{Wh})$ & $\mathrm{H}_{\mathrm{e}}=3.6 \mathrm{~kJ} / \mathrm{Wh}$ \\
\hline$T_{C T}=$ & 250.9 & 121.6 & $\mathrm{E}_{\mathrm{IC}}=0.0 \mathrm{Btu}(0.0 \mathrm{Wh})$ & \\
\hline
\end{tabular}

Surface Unit Cooking Efficiency

$$
\begin{aligned}
& \mathrm{Eff}_{\mathrm{SU}}=\mathrm{W} * \mathrm{C}_{\mathrm{p}} * \mathrm{~T}_{\mathrm{SU}} /\left(\mathrm{E}_{\mathrm{CT}} * \mathrm{H}_{\mathrm{e}}\right) \\
& \mathrm{Eff}_{\mathrm{SU} 1}=32 \% \text { right front (large }-9 \text { in. coil) } \\
& \mathrm{Eff}_{\mathrm{SU} 2}=32 \% \text { left rear (large }-9 \text { in. coil) } \\
& \mathrm{Eff}_{\mathrm{SU} 3}=29 \% \text { left front (small }-7 \text { in. coil) } \\
& \mathrm{Eff}_{\mathrm{SU} 4}=30 \% \text { right rear } \quad \text { (small }-7 \text { in. coil) }
\end{aligned}
$$

Cooking Top Cooking Efficiency

$\operatorname{Eff}_{\mathrm{CT}}=(1 / n) * \sum\left(\mathrm{EFF}_{\mathrm{su}}\right)_{\mathrm{i}}$, where $\mathrm{i}=1$ to $\mathrm{n} ; \mathrm{n}=$ number of surface units

$$
\text { Eff }_{\mathrm{CT}}=30.7 \%
$$

Cooking Top Annual Cooking Energy Consumption

$$
\begin{aligned}
\mathrm{E}_{\mathrm{CC}}=\mathrm{O}_{\mathrm{CT}} / \mathrm{Eff}_{\mathrm{CT}} \\
\mathrm{E}_{\mathrm{CC}}=2.39 \mathrm{E}+06 \quad \mathrm{Btu}=699.7 \mathrm{kWh} / \mathrm{yr}
\end{aligned}
$$

Cooking Top Total Annual Energy Consumption

$$
\mathrm{E}_{\mathrm{CA}}=\mathrm{E}_{\mathrm{CC}}+\mathrm{E}_{\mathrm{CP}} \text {, where the pilot light energy, } \mathrm{E}_{\mathrm{CP}} \text {, is zero }
$$

$$
\mathrm{E}_{\mathrm{CA}}=2.39 \mathrm{E}+06 \quad \mathrm{Btu}=699.7 \mathrm{kWh} / \mathrm{yr}
$$

Energy Factor of Cooking Top

$$
\begin{aligned}
& \mathrm{R}_{\mathrm{CT}}= \mathrm{O}_{\mathrm{M}} / \mathrm{E}_{\mathrm{CA}} \\
& \mathrm{R}_{\mathrm{CT}}=0.307
\end{aligned}
$$


Figure 12 presents a similar set of example results for a conventional gas cooking top test. The basic difference between Figures 11 and 12 is that the gas cooking top test contains an additional result after the cooking top annual cooking energy consumption, $\mathrm{E}_{\mathrm{CC}}$, which is calculated the same as $\mathrm{E}_{\mathrm{CA}}$ for electric cooking tops. For gas cooking tops, the additional energy consumed by an electronic ignition device or pilot light is added to the cooking energy to obtain the cooking top total annual energy consumption, $\mathrm{E}_{\mathrm{CA}}$. However, the energy consumption of the ignition device, $\mathrm{E}_{\mathrm{IO}}$, of the gas cooking top tested was negligible, being about $0.003 \mathrm{Wh}$ for the test. Furthermore, there was no pilot light, so the cooking top total annual energy consumption, $E_{C A}$, is equal to the cooking top annual cooking energy consumption, $E_{C C}$. As seen in Figure 12, the four surface unit efficiencies are $31.5 \%$ and $32.7 \%$ for the two large units, and $29.3 \%$ and $30.2 \%$ for the two small units. The difference between the large and small surface unit efficiencies is smaller than it was for the electric surface units. This may be due to the fact that the large test block is used for all surface unit tests of a gas cooking top, whereas the small test block is used on small electric surface units and the large test block on large electric surface units.

The cooking top cooking efficiency, $\mathrm{Eff}_{\mathrm{CT}}$, was determined to be $30.7 \%$, while the cooking top annual cooking energy consumption, $\mathrm{E}_{\mathrm{CC}}$, was determined as $2.39 \times 10^{6} \mathrm{Btu} / \mathrm{yr}$ $(699.7 \mathrm{kWh} / \mathrm{yr})$. Since there is no pilot light and the ignition device energy consumption is negligible, the cooking top total energy consumption, $\mathrm{E}_{\mathrm{CA}}$, is also $2.39 \times 10^{6} \mathrm{Btu} / \mathrm{yr}$ $(699.7 \mathrm{kWh} / \mathrm{yr})$. The energy factor, $\mathrm{R}_{\mathrm{CT}}$, for the gas cooking top is equivalent to the energy efficiency, having a value of 0.307 . 
Figure 12: Results of Conventional Gas Cooking Top Test

\begin{tabular}{|lll|l|l|}
\hline \multicolumn{3}{|c|}{ Temperature } & \multicolumn{1}{c|}{ Mass/Energy } & \multicolumn{1}{c|}{ Constants } \\
\hline \hline & $\left({ }^{\circ} \mathrm{F}\right)$ & $\left({ }^{\circ} \mathrm{C}\right)$ & & \\
$\mathrm{T}_{\mathrm{R}}=$ & 72.3 & 22.4 & $\mathrm{~W}_{2}=8.38 \mathrm{lb}(3.81 \mathrm{~kg})$ & $\mathrm{O}_{\mathrm{CT}}=699,100 \mathrm{Btu}(209.4 \mathrm{kWh})$ \\
$\mathrm{T}_{1}=$ & 71.9 & 22.2 & $\mathrm{~W}_{3}=18.5 \mathrm{lb}(8.39 \mathrm{~kg})$ & $\mathrm{C}_{\mathrm{p}}=0.23 \mathrm{Btu} / \mathrm{b}-{ }^{\circ} \mathrm{F}\left(0.96 \mathrm{~kJ} / \mathrm{k}^{\circ} \mathrm{C}\right)$ \\
$\mathrm{T}_{\mathrm{CT}}=$ & 364.3 & 184.6 & $\mathrm{E}_{\mathrm{CT}}=214.8 \mathrm{Wh}$ & $\mathrm{H}_{\mathrm{e}}=3.6 \mathrm{~kJ} / \mathrm{Wh}$ \\
$\mathrm{T}_{\mathrm{CT}}=$ & 324.3 & 162.4 & & \\
\hline
\end{tabular}

Surface Unit Cooking Efficiency

$$
\begin{aligned}
& \mathrm{Eff}_{\mathrm{SU}}=\mathrm{W} * \mathrm{C}_{\mathrm{p}} * \mathrm{~T}_{\mathrm{SU}} /\left(\mathrm{E}_{\mathrm{CT}} * \mathrm{H}_{\mathrm{e}}\right) \\
& \mathrm{Eff}_{\mathrm{SU1}}=77 \% \text { left front (small }-7 \text { in. coil) } \\
& \text { Eff }_{\mathrm{SU}_{2}}=77 \% \text { right rear } \quad \text { (small }-7 \text { in. coil) } \\
& \mathrm{Eff}_{\mathrm{SU}_{3}}=83 \% \text { right front (large }-9 \text { in. coil) } \\
& \mathrm{Eff}_{\mathrm{SU} 4}=82 \% \text { left rear (large }-9 \text { in. coil) }
\end{aligned}
$$

Cooking Top Cooking Efficiency

$$
\begin{gathered}
\mathrm{Eff}_{\mathrm{CT}}=(1 / \mathrm{n}) * \sum\left(\mathrm{EFF}_{\mathrm{SU}}\right)_{\mathrm{i}} \text {, where } \mathrm{i}=1 \text { to } \mathrm{n} ; \mathrm{n}=\text { number of surface units } \\
\mathrm{Eff}_{\mathrm{CT}}=79.8 \%
\end{gathered}
$$

Cooking Top Annual Energy Consumption

$$
\begin{aligned}
\mathrm{E}_{\mathrm{CA}}= & \mathrm{O}_{\mathrm{CT}} / \mathrm{Eff}_{\mathrm{CT}} \\
& \mathrm{E}_{\mathrm{CA}}=262.4 \mathrm{kWh} / \mathrm{yr}
\end{aligned}
$$

Energy Factor of Cooking Top

$$
\begin{aligned}
\mathrm{R}_{\mathrm{CT}}= & \mathrm{O}_{\mathrm{M}} / \mathrm{E}_{\mathrm{CA}} \\
& \mathrm{R}_{\mathrm{CT}}=0.798
\end{aligned}
$$


Figure 13 presents a summary of the electric surface unit tests. It shows the test number, test block weight (mass), test block temperature rise, energy consumed to generate the temperature rise of the test block and the efficiency determined for the cooking top surface unit. The small and large surface units were each tested five times. Values of the overall cooking top efficiency and annual energy consumption were calculated from the surface unit efficiencies and the annual useful cooking energy. The annual useful cooking energy was $209.4 \mathrm{kWh} / \mathrm{yr}$ at the time of testing and has since been changed to $173.1 \mathrm{kWh} / \mathrm{yr}$ for the Final Rule.

As seen in Figure 13, the efficiency of the small electric surface units ranged from $76.7 \%$ to $77.5 \%$ with an average efficiency of $77.1 \%$, a standard deviation of $0.3 \%$ efficiency, and a coefficient of variance of $0.4 \%$. The efficiency of the large surface units ranged from $81.9 \%$ to $83.0 \%$ with an average of $82.4 \%$, a standard deviation of $0.4 \%$ efficiency and a coefficient of variance of $0.5 \%$. Using the average values for the large and small surface units, the average value for the cooking top efficiency, Eff $\mathrm{CT}_{\mathrm{CT}}$ is $79.8 \%$, with an estimated standard error of $0.4 \%$ and a C.V. of about $0.5 \%$. The average value for the annual energy consumption, $\mathrm{E}_{\mathrm{CA}}$ is 262.4 $\mathrm{kWh} / \mathrm{yr}$ with an estimated standard error of $1.2 \mathrm{kWh} / \mathrm{yr}$ and a C.V. of $0.5 \%$. Based on these standard errors, the experimentally determined $95 \%$ confidence intervals are estimated to be $79.8 \% \pm 0.8 \%$ and $262.4 \mathrm{kWh} / \mathrm{yr} \pm 2.4 \mathrm{kWh} / \mathrm{yr}$ for the cooking top efficiency and annual energy consumption respectively. As stated in section 4.2 .3 of the Proposed Rule, the energy factor is the same as the cooking efficiency for electric cooking tops, therefore the $95 \%$ confidence interval of the electric cooking top's energy factor is $0.798 \pm 0.008$. 
Figure 13: Summary of Electric Cooktop Surface Unit Test Operations

\begin{tabular}{|c|cccccc|}
\hline $\begin{array}{c}\text { Test } \\
\text { Number }\end{array}$ & $\begin{array}{c}\mathrm{W} \\
{[\mathrm{Lb}]}\end{array}$ & $\begin{array}{c}\mathrm{W} \\
{[\mathrm{kg}]}\end{array}$ & $\begin{array}{c}\mathrm{T}_{\mathrm{SU}} \\
{\left[{ }^{\circ} \mathrm{F}\right]}\end{array}$ & $\begin{array}{c}\mathrm{T}_{\mathrm{SU}} \\
{\left[{ }^{\circ} \mathrm{C}\right]}\end{array}$ & $\begin{array}{c}\mathrm{E}_{\mathrm{CT}} \\
{[\mathrm{Wh}]}\end{array}$ & $\begin{array}{c}\mathrm{Eff}_{\mathrm{SU}} \\
{[\%]}\end{array}$ \\
\hline \hline 1 & 8.38 & 3.81 & 292.3 & 162.4 & 215 & $76.7 \%$ \\
2 & 8.38 & 3.81 & 290.7 & 161.5 & 212 & $77.5 \%$ \\
3 & 8.38 & 3.81 & 292.1 & 162.3 & 214 & $77.0 \%$ \\
4 & 8.38 & 3.81 & 292.0 & 162.2 & 213 & $77.2 \%$ \\
5 & 8.38 & 3.81 & 291.2 & 161.8 & 213 & $76.9 \%$ \\
\hline \multicolumn{7}{|c|}{ Large Burner } \\
\hline 1 & 18.5 & 8.39 & 264.4 & 146.9 & 396 & $83.0 \%$ \\
2 & 18.5 & 8.39 & 258.1 & 143.4 & 389 & $82.5 \%$ \\
3 & 18.5 & 8.39 & 259.6 & 144.2 & 392 & $82.4 \%$ \\
4 & 18.5 & 8.39 & 260.1 & 144.5 & 393 & $82.4 \%$ \\
5 & 18.5 & 8.39 & 261.2 & 145.1 & 396 & $81.9 \%$ \\
\hline Average & small & 291.7 & 162.0 & 213 & $77.1 \%$ \\
& large & 260.7 & 144.8 & 393 & $82.4 \%$ \\
\hline Stdev & small & 0.68 & 0.38 & 1.2 & $0.3 \%$ \\
& large & 2.37 & 1.31 & 3.1 & $0.4 \%$ \\
\hline C.V & small & $0.2 \%$ & $0.2 \%$ & $0.5 \%$ & $0.4 \%$ \\
& large & $0.9 \%$ & $0.9 \%$ & $0.8 \%$ & $0.5 \%$ \\
\hline
\end{tabular}


The summary of results of the gas cooking top surface unit tests are shown in Figure 14, which shows the test number, test block weight (mass), test block temperature rise, energy consumed to generate the temperature rise, and efficiency of the cooking top surface unit. The small surface units were tested 8 times and the large units 3 times. Values of the overall cooking top efficiency and annual energy consumption were calculated from the surface unit efficiencies and the annual useful cooking energy. The annual useful cooking energy was $7,325 \mathrm{kBtu} / \mathrm{yr}$ $(214.7 \mathrm{kWh} / \mathrm{yr})$ at the time of testing and has since been changed to $527.6 \mathrm{kBtu} / \mathrm{yr}(154.6$ $\mathrm{kWh} / \mathrm{yr}$ ) for the Final Rule.

Figures 14a and 14b: Summary of Gas Cooking Top Surface Unit Operation Tests.

Figure 14a : Results in IP Units

\begin{tabular}{|c|cccc|}
\hline $\begin{array}{c}\text { Test } \\
\text { Number }\end{array}$ & $\begin{array}{c}\mathrm{W} \\
{[\mathrm{Lb}]}\end{array}$ & $\begin{array}{c}\mathrm{T}_{\mathrm{SU}} \\
{\left[{ }^{\circ} \mathrm{F}\right]}\end{array}$ & $\begin{array}{c}\mathrm{E}_{\mathrm{CT}} \\
{[\mathrm{Btu}]}\end{array}$ & $\begin{array}{c}\text { Eff }_{\mathrm{SU}} \\
{[\%]}\end{array}$ \\
\hline \hline \multicolumn{5}{|c|}{ Small Burner } \\
\hline 1 & 18.5 & 218.8 & 2955 & $31.5 \%$ \\
2 & 18.5 & 216.1 & 2899 & $31.7 \%$ \\
3 & 18.5 & 210.0 & 2855 & $31.3 \%$ \\
4 & 18.5 & 203.8 & 2847 & $30.5 \%$ \\
5 & 18.5 & 198.3 & 2825 & $29.9 \%$ \\
6 & 18.5 & 190.1 & 2806 & $28.8 \%$ \\
7 & 18.5 & 200.5 & 2771 & $30.8 \%$ \\
8 & 18.5 & 190.7 & 2736 & $29.7 \%$ \\
\hline \multicolumn{5}{|c|}{ Large Burner } \\
\hline 1 & 18.5 & 171.0 & 2487 & $29.3 \%$ \\
2 & 18.5 & 174.6 & 2457 & $30.2 \%$ \\
3 & 18.5 & 189.8 & 2618 & $30.9 \%$ \\
\hline Average & small & 203.5 & 2837 & $30.5 \%$ \\
& large & 178.5 & 2521 & $30.1 \%$ \\
\hline Stdev & small & 10.8 & 69.5 & $1.0 \%$ \\
& large & 10.0 & 85.6 & $0.8 \%$ \\
\hline C.V & small & $5.3 \%$ & $2.5 \%$ & $3.3 \%$ \\
& large & $5.6 \%$ & $3.4 \%$ & $2.7 \%$ \\
\hline
\end{tabular}

Figure 14b: Results in SI units

\begin{tabular}{|c|cccc|}
\hline $\begin{array}{c}\text { Test } \\
\text { Number }\end{array}$ & $\begin{array}{c}\mathrm{W} \\
{[\mathrm{kg}]}\end{array}$ & $\begin{array}{c}\mathrm{T}_{\mathrm{SU}} \\
{\left[{ }^{\circ} \mathrm{C}\right]}\end{array}$ & $\begin{array}{c}\mathrm{E}_{\mathrm{CT}} \\
{[\mathrm{Wh}]}\end{array}$ & $\begin{array}{c}\text { Eff }_{\text {SU }} \\
{[\%]}\end{array}$ \\
\hline \hline \multicolumn{5}{|c|}{ Small Burner } \\
\hline 1 & 8.39 & 121.6 & 866 & $31.5 \%$ \\
2 & 8.39 & 120.0 & 850 & $31.7 \%$ \\
3 & 8.39 & 116.7 & 837 & $31.3 \%$ \\
4 & 8.39 & 113.2 & 834 & $30.5 \%$ \\
5 & 8.39 & 110.2 & 828 & $29.9 \%$ \\
6 & 8.39 & 105.6 & 822 & $28.8 \%$ \\
7 & 8.39 & 111.4 & 812 & $30.8 \%$ \\
8 & 8.39 & 105.9 & 802 & $29.7 \%$ \\
\hline \multicolumn{5}{|c|}{ Large Burner } \\
\hline 1 & 8.39 & 95.0 & 729 & $29.3 \%$ \\
2 & 8.39 & 97.0 & 720 & $30.2 \%$ \\
3 & 8.39 & 105.5 & 767 & $30.9 \%$ \\
\hline Average & small & 113.1 & 831 & $30.5 \%$ \\
& large & 99.2 & 739 & $30.1 \%$ \\
\hline Stdev & small & 6.0 & 20.4 & $1.0 \%$ \\
& large & 5.5 & 25.1 & $0.8 \%$ \\
\hline C.V & small & $5.3 \%$ & $2.5 \%$ & $3.3 \%$ \\
& large & $5.6 \%$ & $3.4 \%$ & $2.7 \%$ \\
\hline
\end{tabular}

The individual surface unit efficiencies were calculated for 8 small and 3 large gas cooktop bumer (surface unit) tests. The efficiency of the small burner ranged from $28.8 \%$ to $31.7 \%$ with an average efficiency of $30.5 \%$, a standard deviation of $1.0 \%$ and a coefficient of variance of $3.3 \%$. The efficiency of the large bumer ranged from $29.3 \%$ to $30.9 \%$ with an 
average efficiency of $30.1 \%$, a standard deviation of $1.0 \%$ and a coefficient of variance of $3.3 \%$. Combining the single-unit efficiencies of the large and small surface unit tests, the surface unit tests yield cooking top efficiencies, Eff $\mathrm{CT}$, ranging from $29.5 \%$ to $31.2 \%$. The range of the efficiency corresponds to annual cooking energy consumption values, $\mathrm{E}_{\mathrm{CC}}$, ranging from $2.49 \times 10^{6} \mathrm{Btu} / \mathrm{yr}(728.8 \mathrm{kWh} / \mathrm{yr})$ to $2.35 \times 10^{6} \mathrm{Btu} / \mathrm{yr}(688.6 \mathrm{kWh} / \mathrm{yr})$. This is a difference of $0.14 \times 10^{6} \mathrm{Btu} / \mathrm{yr}(40.2 \mathrm{kWh} / \mathrm{yr})$, or about $6 \%$. Using the average efficiencies of the large and small surface unit tests, we obtain an average gas cooking top efficiency, Eff $\mathrm{CT}_{\mathrm{CT}}$, and standard deviation of $30.3 \%$ and $0.6 \%$ and an average annual cooking energy consumption, $\mathrm{E}_{\mathrm{CC}}$, and standard deviation of $2.42 \times 10^{6} \mathrm{Btu} / \mathrm{yr} \pm 50 \mathrm{Btu} / \mathrm{yr}(708.1 \mathrm{kWh} / \mathrm{yr} \pm 14.5 \mathrm{kWh} / \mathrm{yr})$. Since there is no pilot light and the electric ignition device's energy consumption is negligible, the total annual energy consumption, $E_{C A}$, of the gas cooking top tested is equal to the annual cooking energy consumption; $\mathrm{E}_{\mathrm{CA}}=\mathrm{E}_{\mathrm{CC}}=2.42 \times 10^{6} \mathrm{Btu} / \mathrm{yr}(708.1 \mathrm{kWh} / \mathrm{yr})$. For the same reason, the gas cooking top energy factor, $R_{C A}$, of 0.303 , is equal to the cooking top efficiency.

\section{Microwave Oven Tests}

This section presents the results of the microwave oven tests. The first section contains a time-series plot of the input power to the microwave oven during an oven test, which is used to describe the microwave oven's response to the energy consumption/energy efficiency test. The second section presents an example of the results from an individual test and a summary of all the results.

\section{Response of Microwave Oven to Energy Consumption Test}

This section describes the response of the microwave oven during an energy efficiency/energy consumption test as prescribed by the Proposed Rule and IEC 705. Figure 15 is a time-series plot of the input power during a test of the oven studied at NIST. When the oven is off and only the clock is running, the power consumption is about 3 to 4 watts. The test starts when the duration of the test time is programmed into the oven controls, the pre-measured test load is placed in the center of the microwave oven cavity and the power to the magnetron is turned on. The magnetron is then activated and begins a warm-up period, during which a surge in the input power occurs. This initial power surge typically appears as a spike near the beginning of the test as shown in Figure 15. The timing of the surge varies from test to test; in this example it occurs about $0.25 \mathrm{~s}$ after starting the oven and lasts roughly $0.5 \mathrm{~s}$. After the power surge, there is a sharp decrease and then full power is applied to the magnetron, at which time the power rises to over $1400 \mathrm{~W}$. The entire transient period, from the start of the test until the magnetron is fully energized, typically lasts from $2 \mathrm{~s}$ to $3 \mathrm{~s}$. Once the power rises to its maximum value, it remains relatively constant throughout the remainder of the test until the magnetron shuts down. Throughout the period of full power, the magnetron temperature rises, along with that of the transformer and other components of the control circuit. As this happens, the impedance of the circuit increases, and the input power decreases at a fairly constant rate. This drop of input power is shown in the plot of input power in Figure 16. For this test, there is a decrease of $31 \mathrm{~W}$ or $2.2 \%$ in the power. At the end of the test, when the magnetron turns off, a 
sharp drop in power occurs and a small amount of energy is consumed as the input power drops back to the 3 to $4 \mathrm{~W}$ consumed by the clock. The duration of the entire test typically ranged from $56 \mathrm{~s}$ to $57 \mathrm{~s}$ for the microwave oven tested. The energy consumed during the transient energy consumption period generally accounts for about $1 \%$ of the total energy consumed throughout the test. In the example of Figures 15 and 16 the transient energy accounted for $1.3 \%$ of total energy consumed. Prior to and after the test, while only the clock is in use, the power and power factor remain constant at approximately 3 to $4 \mathrm{~W}$ true RMS power and 0.63 respectively. During the power surge, the power factor changes rapidly until the maximum power is reached, at which time the power factor remains constant at about 0.93 . 
Figure 15 Input Power During Microwave Oven Test

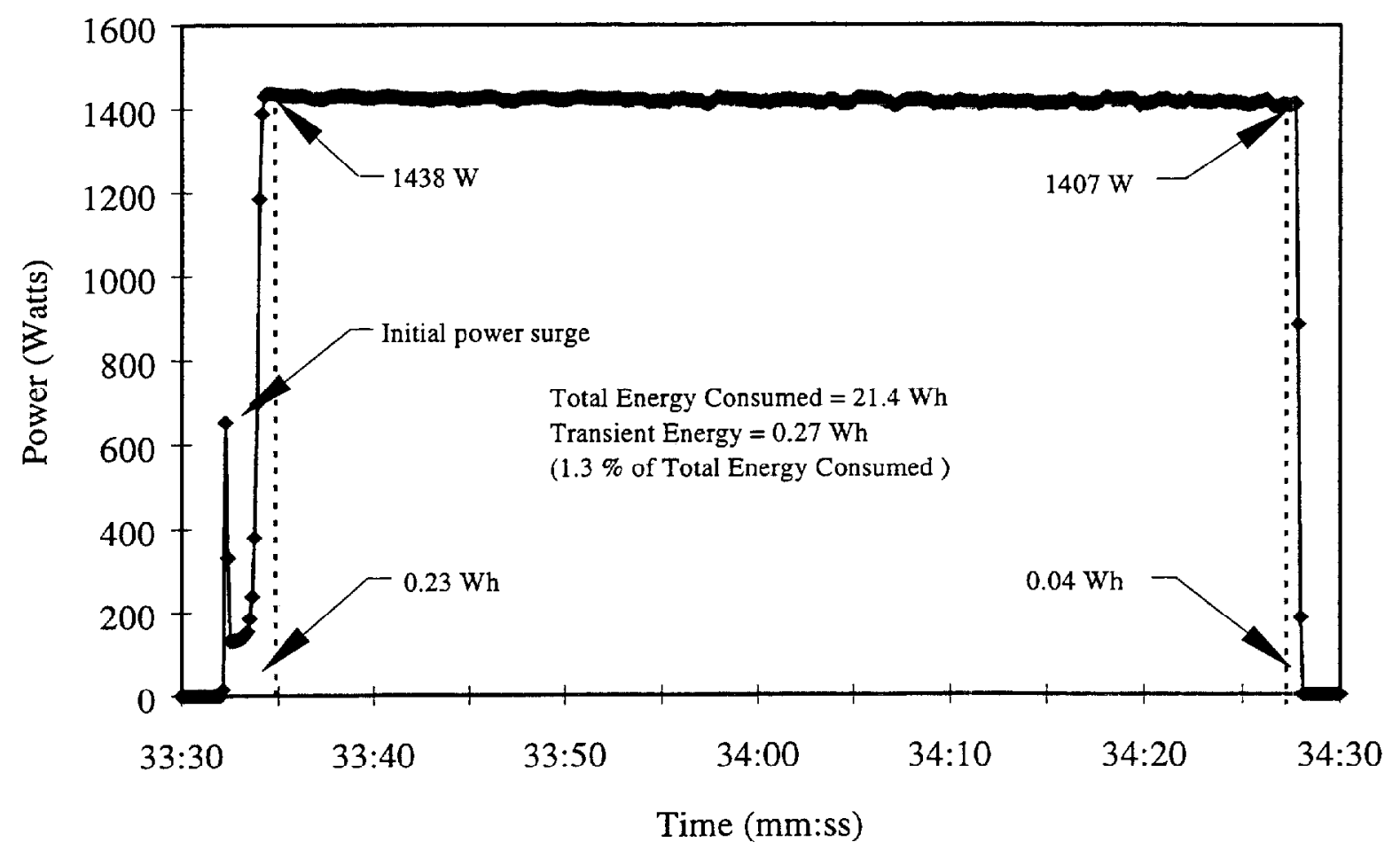

Figure 16: Input Power during Microwave Oven Test

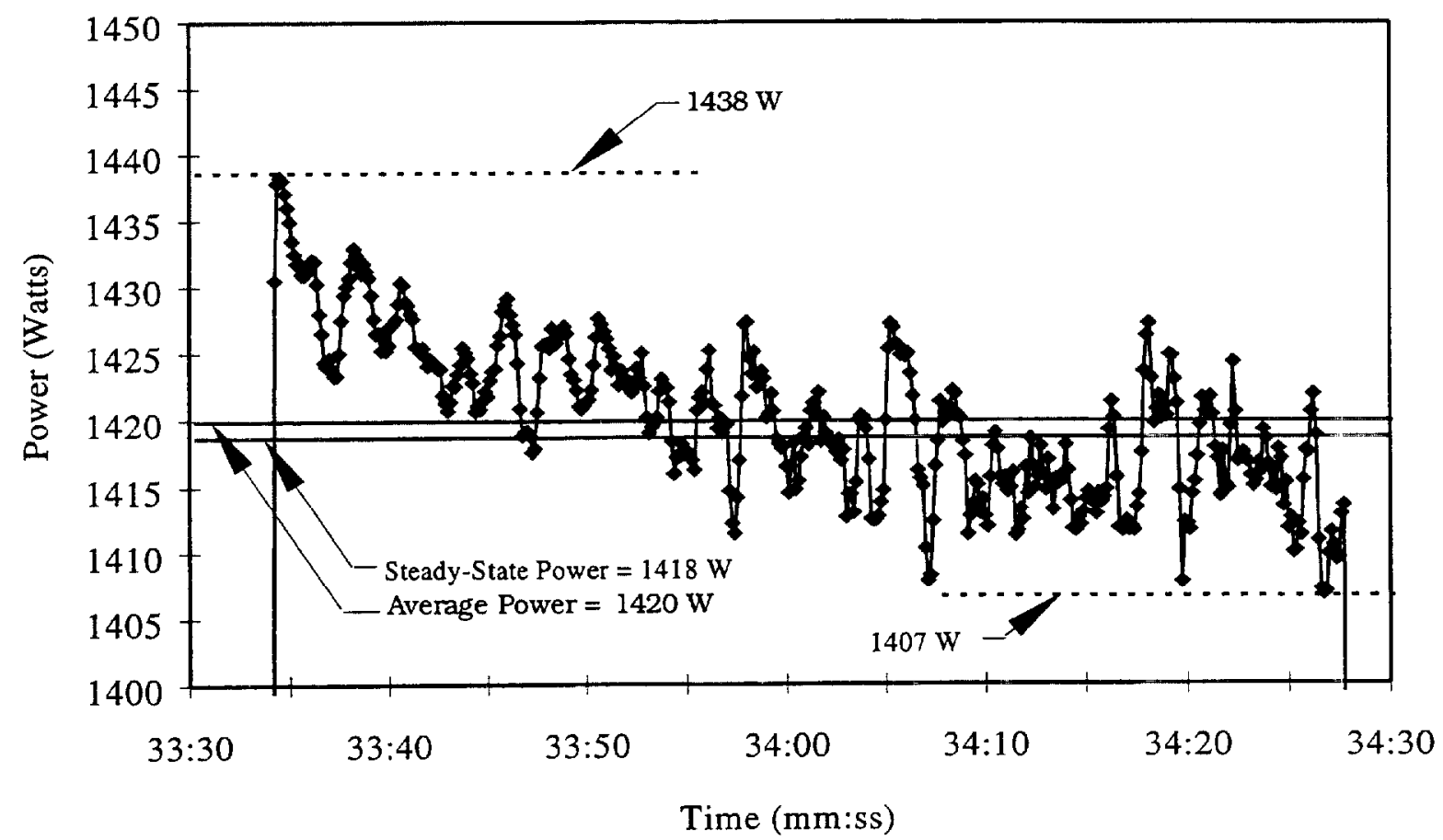




\section{Summary of Results}

The results of the microwave oven tests performed at NIST are shown in Figures 17 and 18. Figure 17 shows measurements and results of a single microwave oven test performed according to the Proposed Rule and IEC 705 procedures. The enclosed blocks at the top of Figure 17 contain constants and measured values that were used to calculate the energy consumption values below. The first block labeled "Temperature" contains the room $\left(\mathrm{T}_{0}\right)$, initial $\left(\mathrm{T}_{1}\right)$ and final $\left(\mathrm{T}_{2}\right)$ test load, and magnetron $\left(\mathrm{T}_{\text {mag }}\right)$ temperatures just prior to the start the microwave oven test. The initial load temperature refers to the temperature of the chilled water while still in the chiller, and the final load temperature refers to the temperature of the water in the test container after the test is complete. The second block labeled "Measured Energy/Power" contains the input energy, $\mathrm{E}_{\mathrm{M}}$, in Wh. The average input power, $\mathrm{P}_{\mathrm{M}}$, along with the maximum and minimum power, $\mathrm{P}_{\mathrm{MAX}}$ and $\mathrm{P}_{\mathrm{MIN}}$ respectively, recorded during the test, are also presented in the second block, along with the time, $t$ at which the power remained above $90 \%$ of its highest value. The third block labeled "Constants" contains the annual useful cooking energy for microwave ovens $\mathrm{O}_{\mathrm{M}}$, a conversion factor $\mathrm{H}_{\mathrm{e}}$ from $\mathrm{kJ}$ to Wh, the specific heats of the water $\mathrm{C}_{\mathrm{PW}}$ and the container holding the water $\mathrm{C}_{\mathrm{PC}}$, and the weights (masses) of the test load and container, $\mathrm{M}_{\mathrm{W}}$ and $\mathrm{M}_{\mathrm{C}}$. The steps included in the test data analysis are presented below the three blocks. The first step in the analysis is to determine the output energy as the test load weight (mass) times the heat capacity of the water times the temperature difference between the initial and final water test load plus the container weight (mass) times the heat capacity of the container times the difference between the room air temperature and the final test load temperature. This sum is then divided by $\mathrm{H}_{\mathrm{e}}$ to convert $\mathrm{kJ}$ to $\mathrm{Wh}$. The second step is to determine the annual energy consumption of the microwave oven, which is the input energy divided by the output energy per test times the annual useful cooking energy consumption. The third step determines the energy factor by dividing the annual useful cooking energy output by the annual energy consumption. The output power is determined in step four as the test load weight (mass) times the heat capacity of the water times the difference between the initial and final water temperatures plus the container weight (mass) times the heat capacity of the container times the difference between the room air temperature and the final test load temperature. This sum is then divided by the time, $t$ (in seconds during which the magnetron power remains above $90 \%$ of full power. The final step determines the efficiency of the microwave oven based on dividing the input power, $\mathrm{P}_{\mathrm{M}}$, into the output power, $\mathrm{P}_{\mathrm{T}}$. This efficiency is presented based on the average, maximum, and minimum measured input power. 
Figure 17: Results of Microwave Oven Test

\begin{tabular}{|cc|c|cc|cc|}
\hline \multicolumn{2}{|c|}{ Temperature } & \multicolumn{2}{c|}{$\begin{array}{c}\text { Measured } \\
\text { Energy/Power }\end{array}$} & \multicolumn{2}{c|}{ Constants } \\
\hline \hline Room $\left(\mathrm{T}_{0}\right)$ & $75.9{ }^{\circ} \mathrm{F}$ & $24.4^{\circ} \mathrm{C}$ & Energy $=\mathrm{E}_{\mathrm{M}}=$ & $21.44 \mathrm{Wh}$ & $\mathrm{O}_{\mathrm{M}}=$ & $77.3 \mathrm{kWh} / \mathrm{yr}$ \\
Initial Load $\left(\mathrm{T}_{1}\right)$ & $56.8{ }^{\circ} \mathrm{F}$ & $13.8{ }^{\circ} \mathrm{C}$ & Avg Power $=\mathrm{P}_{\mathrm{M}}=$ & $1420 \mathrm{~W}$ & $\mathrm{H}_{\mathrm{e}}=$ & $3.6 \mathrm{~kJ} / \mathrm{Wh}$ \\
Final Load $\left(\mathrm{T}_{2}\right)$ & $74.8^{\circ} \mathrm{F}$ & $23.8^{\circ} \mathrm{C}$ & $\mathrm{P}_{\mathrm{MAX}}=$ & $1438 \mathrm{~W}$ & $\mathrm{C}_{\mathrm{PW}}=$ & $4.187 \mathrm{~kJ} /\left(\mathrm{kg}-{ }^{\circ} \mathrm{C}\right)$ \\
Magnetron $\left(\mathrm{T}_{\mathrm{mag}}\right)$ & $76.8{ }^{\circ} \mathrm{F}$ & $24.9^{\circ} \mathrm{C}$ & $\mathrm{P}_{\mathrm{MIN}}=$ & $1408 \mathrm{~W}$ & $\mathrm{C}_{\mathrm{PC}}=$ & $0.210 \mathrm{Btu} / \mathrm{lb}{ }^{\circ} \mathrm{F}\left(0.88 \mathrm{~kJ} / \mathrm{kg}-{ }^{\circ} \mathrm{C}\right)$ \\
& & & & & $\mathrm{M}_{\mathrm{W}}=$ & $2.180 \mathrm{lb}(0.999 \mathrm{~kg})$ \\
& & & & & $\mathrm{M}_{\mathrm{C}}=$ & $0.623 \mathrm{lb}(0.283 \mathrm{~kg})$ \\
\hline
\end{tabular}

Output Energy of Microwave oven to Test Load and Container

$$
\begin{aligned}
& \mathrm{E}_{\mathrm{T}}=\left[4.187 * \mathrm{M}_{\mathrm{W}} *\left(\mathrm{~T}_{2}-\mathrm{T}_{1}\right)+0.88 * \mathrm{M}_{\mathrm{C}} *\left(\mathrm{~T}_{2}-\mathrm{T}_{0}\right)\right] / \mathrm{H}_{\mathrm{e}} \\
& \mathrm{E}_{\mathrm{T}}=11.6 \mathrm{Wh}
\end{aligned}
$$

Annual Energy Consumption of Microwave Oven

$$
\begin{aligned}
& \mathrm{E}_{\mathrm{MO}}=\mathrm{E}_{\mathrm{M}} / \mathrm{E}_{\mathrm{T}}{ }^{*} \mathrm{O}_{\mathrm{M}} \\
& \mathrm{E}_{\mathrm{MO}}=143.3 \mathrm{kWh} / \mathrm{yr}
\end{aligned}
$$

Energy Factor of Microwave Test

$$
\begin{aligned}
& \mathrm{R}_{\mathrm{M}}=\mathrm{O}_{\mathrm{M}} / \mathrm{E}_{\mathrm{MO}} \\
& \mathrm{R}_{\mathrm{M}}=0.539
\end{aligned}
$$

Output Power of Microwave oven to Test Load and Container

$$
\begin{aligned}
& \mathrm{P}_{\mathrm{T}}=\left[4.187 * \mathrm{M}_{\mathrm{W}} *\left(\mathrm{~T}_{2}-\mathrm{T}_{1}\right)+0.88 * \mathrm{M}_{\mathrm{C}} *\left(\mathrm{~T}_{2}-\mathrm{T}_{0}\right)\right] / \mathrm{t} \\
& \mathrm{P}_{\mathrm{T}}=777 \mathrm{~W}
\end{aligned}
$$

Efficiency of Microwave Oven

$$
\text { Eff }_{\mathrm{MO}}=\mathrm{P}_{\mathrm{T}} / \mathrm{P}_{\mathrm{M}}
$$

Based on Average Power

$$
\begin{array}{ll}
\text { Eff }_{\mathrm{MO}}= & 54.7 \% \\
\text { Based on } \mathrm{P}_{\mathrm{MAX}}, \text { Eff }_{\mathrm{MO}}= & 54.0 \% \\
\text { Based on } \mathrm{P}_{\mathrm{MN}}, \text { Eff }_{\mathrm{MO}}= & 55.2 \%
\end{array}
$$


Figure 18 contains a summary of the microwave oven results determined using Meter B and a mercury thermometer for measuring the required temperatures. The columns of this figure, from left to right, contain the test $\mathrm{ID}$ code, the average, maximum and minimum input power recorded by the meter, the output power $\mathrm{P}_{T}$, the average, maximum, and minimum efficiency calculated from the three input power measurements, the input and output energy, the annual energy consumption, and the energy factor multiplied by $100 \%$ and re-titled "Efficiency by Energy". The data in each column is summarized at the bottom in terms of the average, standard deviation, and coefficient of variance.

Based on the results presented in Figure 18, the average input power values of the microwave tests ranged from $1398 \mathrm{~W}$ to $1441 \mathrm{~W}$. The average of these values is $1416 \mathrm{~W}$ with a standard deviation of $13 \mathrm{~W}$ and a coefficient of variance (C.V.) of $0.9 \%$. The maximum input power ranged from $1411 \mathrm{~W}$ to $1477 \mathrm{~W}$, with an average of $1445 \mathrm{~W}$, a standard deviation of 20 $\mathrm{W}$ and a C.V. of $1.4 \%$. The minimum input power ranged from $1384 \mathrm{~W}$ to $1431 \mathrm{~W}$, with an average of $1402 \mathrm{~W}$, a standard deviation of $14 \mathrm{~W}$ and a C.V. of $1.0 \%$. The output power ranged from $766 \mathrm{~W}$ to $819 \mathrm{~W}$ with the average, standard deviation and C.V. of $789 \mathrm{~W}, 15 \mathrm{~W}$ and $1.9 \%$ respectively. 
Figure 18: Summary of Microwave Oven Test Results

\begin{tabular}{|c|c|c|c|c|c|c|c|c|c|c|c|}
\hline \multirow[t]{2}{*}{ Test ID } & \multicolumn{4}{|c|}{ Power (Watts) } & \multicolumn{3}{|c|}{ Efficiency from Power } & \multirow{2}{*}{$\begin{array}{c}\text { Input } \\
\text { Energy, } \\
\mathrm{E}_{\mathrm{M}}(\mathrm{Wh})\end{array}$} & \multirow{2}{*}{$\begin{array}{l}\text { Output } \\
\text { Energy, } \\
\mathbf{E}_{\mathrm{T}}(\mathbf{W h})\end{array}$} & \multirow{2}{*}{$\begin{array}{c}\text { Energy } \\
\text { Consumption } \\
(\mathrm{kWh} / \mathrm{yr})\end{array}$} & \multirow{2}{*}{$\begin{array}{c}\text { Efficiency } \\
\text { by } \\
\text { Energy } \\
(\%) \\
\end{array}$} \\
\hline & Avg & Max & Min & Output $\mathbf{P}_{T}$ & Avg & $\operatorname{Max}$ & $\operatorname{Min}$ & & & & \\
\hline MW0309 & 1416 & 1428 & 1405 & 766 & $54.1 \%$ & $53.7 \%$ & $54.5 \%$ & 21.4 & 11.4 & 144.8 & $53.4 \%$ \\
\hline MW0313 & 1429 & 1440 & 1415 & 799 & $55.9 \%$ & $55.5 \%$ & $56.5 \%$ & 21.6 & 11.9 & 140.2 & $55.1 \%$ \\
\hline MW0314a & 1422 & 1482 & 1402 & 786 & $55.3 \%$ & $53.0 \%$ & $56.0 \%$ & 21.5 & 11.7 & 141.9 & $54.5 \%$ \\
\hline MW0327a & 1405 & 1435 & 1391 & 779 & $55.4 \%$ & $54.3 \%$ & $56.0 \%$ & 21.0 & 11.6 & 140.1 & $55.2 \%$ \\
\hline MW0327b & 1398 & 1411 & 1384 & 819 & $58.6 \%$ & $58.0 \%$ & $59.2 \%$ & 21.1 & 12.2 & 133.8 & $57.8 \%$ \\
\hline MW0327c & 1408 & 1468 & 1391 & 780 & $55.4 \%$ & $53.1 \%$ & $56.1 \%$ & 21.3 & 11.6 & 141.6 & $54.6 \%$ \\
\hline MW0327d & 1411 & 1431 & 1397 & 807 & $57.2 \%$ & $56.4 \%$ & $57.8 \%$ & 21.3 & 12.0 & 137.2 & $56.3 \%$ \\
\hline MW0327e & 1405 & 1464 & 1389 & 789 & $56.2 \%$ & $53.9 \%$ & $56.8 \%$ & 21.2 & 11.8 & 139.7 & $55.3 \%$ \\
\hline MW0328 & 1406 & 1427 & 1393 & 796 & $56.6 \%$ & $55.8 \%$ & $57.1 \%$ & 21.2 & 11.8 & 138.4 & $55.8 \%$ \\
\hline MW0329d & 1398 & 1447 & 1384 & 781 & $55.9 \%$ & $54.0 \%$ & $56.4 \%$ & 21.1 & 11.6 & 140.4 & $55.1 \%$ \\
\hline MW0417b & 1439 & 1454 & 1430 & 809 & $56.2 \%$ & $55.7 \%$ & $56.6 \%$ & 21.8 & 12.1 & 139.6 & $55.4 \%$ \\
\hline MW0417c & 1436 & 1461 & 1426 & 805 & $56.1 \%$ & $55.1 \%$ & $56.5 \%$ & 21.6 & 12.0 & 139.3 & $55.5 \%$ \\
\hline MW0418b & 1407 & 1456 & 1393 & 812 & $57.7 \%$ & $55.8 \%$ & $58.3 \%$ & 22.0 & 12.1 & 140.5 & $55.0 \%$ \\
\hline MW0419c & 1427 & 1443 & 1410 & 785 & $55.0 \%$ & $54.4 \%$ & $55.6 \%$ & 21.6 & 11.7 & 142.9 & $54.1 \%$ \\
\hline MW0420a & 1428 & 1477 & 1414 & 787 & $55.1 \%$ & $53.3 \%$ & $55.7 \%$ & 21.4 & 11.7 & 140.8 & $54.9 \%$ \\
\hline MW0420b & 1420 & 1438 & 1407 & 777 & $54.7 \%$ & $54.0 \%$ & $55.2 \%$ & 21.4 & 11.6 & 143.3 & $53.9 \%$ \\
\hline MW0421a & 1410 & 1458 & 1394 & 778 & $55.2 \%$ & $53.3 \%$ & $55.8 \%$ & 21.3 & 11.6 & 142.2 & $54.3 \%$ \\
\hline MW0421b & 1404 & 1417 & 1390 & 766 & $54.6 \%$ & $54.1 \%$ & $55.1 \%$ & 21.1 & 11.4 & 143.0 & $54.1 \%$ \\
\hline MW0424a & 1409 & 1420 & 1398 & 772 & $54.8 \%$ & $54.4 \%$ & $55.2 \%$ & 21.3 & 11.5 & 142.9 & $54.1 \%$ \\
\hline MW0424b & 1413 & 1425 & 1403 & 783 & $55.4 \%$ & $54.9 \%$ & $55.8 \%$ & 21.3 & 11.7 & 141.4 & $54.7 \%$ \\
\hline MW0424c & 1441 & 1457 & 1431 & 801 & $55.6 \%$ & $55.0 \%$ & $56.0 \%$ & 21.8 & 11.9 & 141.0 & $54.8 \%$ \\
\hline Average & 1416 & 1445 & 1402 & 789 & $55.8 \%$ & $54.6 \%$ & $56.3 \%$ & 21.4 & 11.8 & 140.7 & $54.9 \%$ \\
\hline Stdev & 13.1 & 19.9 & 14.4 & 15.2 & $1.1 \%$ & $1.2 \%$ & $1.1 \%$ & 0.25 & 0.23 & 2.39 & $0.9 \%$ \\
\hline $\mathrm{CV}$ & $0.9 \%$ & $1.4 \%$ & $1.0 \%$ & $1.9 \%$ & $19 \%$ & $2.3 \%$ & $2.0 \%$ & $12 \%$ & $12 \%$ & $1.7 \%$ & $1.7 \%$ \\
\hline
\end{tabular}


The average efficiency of the microwave oven calculated using the average input power on an individual test ranged from $54.1 \%$ to $58.6 \%$. The average, standard deviation and C.V. of the efficiencies determined using the average test power are $55.8 \%, 1.1 \%$ (in efficiency units) and $1.9 \%$. The efficiencies based on the maximum power range from $53.1 \%$ to $58.0 \%$ with an average value of $54.6 \%$; whereas the efficiencies based on the minimum power measurement range from 54.2 to $59.5 \%$ with an average value of $56.3 \%$. The entire range of efficiencies calculated for the microwave oven, is bounded by the lowest value of $53.7 \%$ based on calculations using maximum input power values and by $59.2 \%$ based on calculations using the minimum input power values. The entire range exhibits a 5.5\% change from the lowest to highest efficiency, or roughly a $10 \%$ relative difference between the lowest and highest efficiency calculated based on power. This assessment is without consideration of the fact that the IEC states that power measurements begin at $90 \%$ of the final current value and therefore could include lower power measurements yielding higher efficiencies. From the manufacturer's stated input and output power ratings, the efficiency rating of the microwave oven is calculated as $58.0 \%$. Only the highest of the efficiencies presented in Figure 18 are comparable. However, based on propagation of error calculations shown in the discussion portion of this report, $58.0 \%$ efficiency is within the range of a $95 \%$ confidence interval estimated for the microwave oven efficiency.

The average input energy, $\mathrm{E}_{\mathrm{M}}$, calculated from all the tests was $21.4 \mathrm{Wh}$, with a standard deviation of $0.2 \mathrm{Wh}$ and a C.V. of $1.2 \%$. The output energy to the test load $\mathrm{E}_{\mathrm{T}}$ had an average value of $11.8 \mathrm{Wh}$, a standard deviation of $0.2 \mathrm{Wh}$ and a C.V. of $1.9 \%$. The efficiencies (energy factor multiplied by 100 and expressed as percent) ranged from $53.4 \%$ to $57.8 \%$, while the average efficiency, standard deviation and C.V. were $54.9 \%, 0.9 \%$ (in efficiency units) and $1.7 \%$ respectively. Comparison of the average efficiency of the microwave based on all tests shows that use of average test input power yields an average efficiency about $1 \%$ higher than that of the efficiency based on the input energy. This is expected based on the fact that the measured input energy includes the transient energy input to the microwave oven during the magnetron warmup and shut down periods. This energy is about $1 \%$ of the overall energy consumed during a test and is not accounted for in the IEC method of determining efficiency using input and output power. 


\section{DISCUSSION}

The discussion section contains three subsections on the appliances tested: ovens, cooking tops, and microwave ovens. These sections discuss the workability of the Proposed Rule and issues specifically related to the appliance and the associated test procedure.

\section{Ovens}

This section discusses the workability of the test procedures in the Proposed Rule. Other issues that are discussed include the significance of the exclusion of the clock energy when the clock cannot be disconnected, the use of a gas flow meter to determine energy consumption, the determination and use of a single conversion factor to convert gas volume consumed to standard gas volume consumed, and the fact that there is no equipment specified in the rule for conversion of measured gas volume to standard cubic feet.

No significant problems were encountered while following the Proposed Rule test procedures to determine the oven test energy consumption, the clock energy consumption, or the self-cleaning oven operation energy consumption. Neither were there any significant problems using the equations of the Proposed Rule to calculate the annual energy consumption, energy efficiency, or energy factor for the oven tested. However, NIST did not test convertible cooking appliances (those capable of operating on either natural gas or propane), gas units with pilot lights or ovens with the forced-convection option. Tests were also not performed on multipleoven appliances or combined appliances, i.e., ranges with an oven, cooking top and microwave oven or non-conventional ovens with microwave ovens sharing the same oven cavity.

The specifications of the equipment required for compliance to the Proposed Rule were used to evaluate the range of possible error in the measured and calculated results. The range of the error or combined uncertainty for each measured and calculated test value is expressed as the average of the test values plus or minus one standard deviation of the results calculated from the specified equipment accuracy. The average value plus or minus a standard deviation conveys the standard error in which there is a $68 \%$ confidence level that the true value lies between the lower and upper bounds of the calculated range. To have $95 \%$ confidence that the actual value will lie within the range listed, the standard error must be multiplied by two. The actual values of the error or combined uncertainty for each oven test, self-cleaning test and clock energy consumption measurement were consistent among the tests performed. The confidence interval for the single electric oven test energy values, $\mathrm{E}_{\mathrm{O}}$, based on the propagation of error, range from $862 \mathrm{Wh}$ to 898 Wh. This is equivalent to the average value of $880 \mathrm{Wh} \pm 13 \mathrm{Wh}$, (or on a relative basis, $\pm 1.5 \%$ ). The average values cited in this section correspond to the average values of the seven electric and five gas oven tests, as the test values were used in the propagation of error formulas to determine the confidence intervals. The range of $\mathrm{E}_{\mathrm{O}}$ for the gas oven was determined to be $5.63 \times 10^{3} \mathrm{Btu} \pm$ $94 \mathrm{Btu}(1.65 \mathrm{kWh} \pm 0.03 \mathrm{kWh})$. The confidence limits of the secondary energy, $\mathrm{E}_{\mathrm{lO}}$, consumed by the glow plug during the gas oven tests are $118 \mathrm{Wh} \pm 2 \mathrm{Wh}$. The confidence interval of the annual primary cooking energy consumption for the electric oven, $\mathrm{E}_{\mathrm{CO}}$, is $274 \mathrm{kWh} \pm 5.3 \mathrm{kWh}$, 
while the confidence limits of the annual primary cooking energy consumption for the gas oven is $1.79 \times 10^{6} \mathrm{Btu} \pm 0.035 \times 10^{6} \mathrm{Btu}(525.5 \mathrm{kWh} \pm 10.3 \mathrm{kWh})$. The confidence interval of the average value for the annual secondary energy consumption $\mathrm{E}_{\mathrm{SO}}$, of the gas oven's glow plug is $36.6 \mathrm{kWh} / \mathrm{yr} \pm 0.7 \mathrm{kWh} / \mathrm{yr}$. The confidence interval of the average value of the seven selfcleaning energy consumption values, $E_{S}$, of the electric oven is $6.90 \mathrm{kWh} \pm 0.10 \mathrm{kWh}$ and the confidence interval of the average value of the five self-cleaning energy consumption values, $E_{\mathrm{S}}$, of the gas oven is $46.1 \times 10^{3} \mathrm{Btu} \pm 0.69 \times 10^{3} \mathrm{Btu}$. Propagating the error through to the annual primary self-cleaning energy consumption, $E_{S C}$, the confidence interval of the average value of the electric oven self-cleaning test was $75.9 \mathrm{kWh} \pm 1.12 \mathrm{kWh}$ while the confidence interval of the average value of the gas oven self-cleaning test was $323 \times 10^{3} \mathrm{Btu} \pm 7.62 \times 10^{3} \mathrm{Btu}(94.6$ $\mathrm{kWh} \pm 2.23 \mathrm{kWh}$ ). The confidence interval of the average value of the annual secondary energy consumption, $\mathrm{E}_{\mathrm{SS}}$, was $7.15 \mathrm{kWh} / \mathrm{yr} \pm 0.10 \mathrm{kWh} / \mathrm{yr}$.

The confidence interval of the average value of the seven annual clock energy consumption values from the electric oven was $25.7 \mathrm{kWh} / \mathrm{yr} \pm 1.29 \mathrm{kWh}$ while the confidence interval of the average value of the gas oven's clock was $27.9 \mathrm{kWh} / \mathrm{yr} \pm 1.40 \mathrm{kWh}$.

The confidence interval for the average value of the total annual primary energy consumption, $\mathrm{E}_{\mathrm{AO}}$, of the seven electric oven tests is $376 \mathrm{kWh} / \mathrm{yr} \pm 5.81 \mathrm{kWh}$ while the confidence interval of the total annual primary energy consumption, $\mathrm{E}_{\mathrm{AOG}}$, of the five gas oven tests is $2.12 \times 10^{6} \mathrm{Btu} / \mathrm{yr} \pm 0.048 \times 10^{6} \mathrm{Btu} / \mathrm{yr}(620.2 \mathrm{kWh} \pm 11.07 \mathrm{kWh})$. The confidence interval of the annual secondary energy, $\mathrm{E}_{\mathrm{AOE}}$, was calculated as $72.0 \mathrm{kWh} / \mathrm{yr} \pm 1.57 \mathrm{kWh} / \mathrm{yr}$.

The confidence interval for the average value of the annual conventional electric oven cooking efficiency, $\mathrm{Eff}_{\mathrm{AO}}$, is $13.0 \% \pm 0.3 \%$ and the confidence interval for the average value of the annual conventional gas oven cooking efficiency, Eff ${ }_{\mathrm{AO}}$, determined for the gas oven tests is $6.5 \% \pm 0.2 \%$.

The confidence interval of the average value of the seven electric oven energy factors, $R_{0}$, is calculated as $0.09 \pm 0.001$, while the confidence interval of the average value of the five gas oven energy factors, $R_{0}$, is calculated as $0.053 \pm .001 \mathrm{kWh}$.

An issue related to the 1995 public hearing on the Proposed Rule is the effect of including or subtracting the clock energy from the oven energy consumption test values. This was discussed earlier in the results section, and it was determined that the inclusion of the clock energy was insignificant in relation to the efficiency. Based on the seven electric oven tests, the average electric oven clock power was $2.9 \mathrm{~W}$ and the average gas oven clock power was $3.2 \mathrm{~W}$. The average power consumption of the electric oven during the tests (including the off periods) ranged from about $1350 \mathrm{~W}$ to $1400 \mathrm{~W}$. Assuming a clock power of $3 \mathrm{~W}$ and using the average test wattage of $1375 \mathrm{~W}$, the clock power is about $0.2 \%$ of the oven test wattage and therefore about $0.2 \%$ of the cooking energy consumption. Since the gas oven consumed about twice as much energy as the electric oven during an oven test, the contribution of the clock energy consumption to the overall test energy consumption would be about $0.1 \%$ of the gas oven test 
energy. The energy consumption during each electric oven test was determined both with and without the clock energy included to determine the error associated with including the clock energy in the oven energy consumption test results. The difference between the oven test energy consumption with and without the clock energy included was less than $0.1 \%$. This demonstrates that the effect of including the clock power in the calculation of the oven efficiency, annual energy consumption and energy factor is insignificant. However, the annual clock energy ranged from $24.3 \mathrm{kWh} / \mathrm{yr}$ to $26.3 \mathrm{kWh} / \mathrm{yr}$, roughly $7 \%$ of the total annual energy consumption for the oven tests, and therefore, it can not be neglected.

A gas flow rate meter was placed in the natural gas supply line to the gas oven to investigate its use for measuring the gas energy consumption of a conventional gas oven. The rule specifies that a flow meter can be used to measure the energy consumed by pilot lights, but does not address the use of flow meters to determine the energy consumed by a gas oven during the cooking and self-cleaning energy consumption tests required in sections 3.2.1.1 and 3.2.1.2 of the Proposed Rule.

A gas flow meter can be used to determine the gas energy consumption during any gas oven test provided the volume of gas consumed can be measured with acceptable accuracy. Applicable portions of the Proposed Rule include the pilot light, oven cooking, and self-cleaning gas energy consumption tests. The gas consumed by a pilot light flows continuously at a constant rate. The flow rate and duration of flow can be measured with a sufficiently accurate flow meter over any specified duration using a timer. Therefore the use of a gas flow meter to determine pilot light energy consumption is acceptable provided the heating value of the gas is known.

During the gas cooking energy consumption test of the oven model tested, the gas flow cycled on and off in a periodic fashion. The gas flow rate remained constant through each "on" period during the test and at the same rate during all periods throughout the test. Though the gas flow for the test oven is cyclic, it could be monitored such that the beginning and end of each "on" period of the test can be recorded. By summing the durations of all "on" periods, the total duration of gas flow during the test can be calculated. Employing the above procedure along with knowledge of the heating value of the supply gas, a gas flow meter of acceptable accuracy can be used to determine the gas energy consumed by a gas oven during the cooking energy consumption test.

The gas flow was also monitored constantly during the self-cleaning energy consumption tests, and the gas flow rate was measured and recorded at 1 minute intervals at all times when gas flow occurred. Continuous monitoring of the gas flow revealed that it was periodic, cycling on and off throughout the duration of the test. Frequent flow rate measurements revealed that the gas flow rate remained constant throughout individual "on" periods, yet it did not stay the same throughout the duration of testing. The data revealed that the flow rates were at the same value during all "on" periods during the first 40 minutes each test, after which, the flow rate increased by $36 \%$ (when the broil burner came on) and remained at that measured value all "on" periods 
throughout the remainder of the test.

Using the procedure above, it was possible to employ a gas flow rate meter to determine the energy consumption during the self-cleaning operation of the test oven. However, proper monitoring and recording of the gas flow on and off cycles, and the frequency of monitoring and recording gas flow rates measured by a flow meter during a self-cleaning test is required.

The measured heating value of the natural gas was determined with a calorimeter in units of Btu/ft ${ }^{3}\left(\mathrm{~J} / \mathrm{m}^{3}\right)$. To obtain accurate and comparable primary energy consumption values for the gas oven and cooking top tests, the volume of gas consumed during the test had to be converted to the equivalent volume under standard temperature and pressure. This required the determination of the appropriate conversion factor for each test. While the measurement of the ambient temperature and pressure is not included in the Proposed Rule for determining the conversion factor, these measurements were made during the tests at NIST. The average correction factor used to convert the measured volumes of natural gas consumption from cubic feet at local temperature and pressure conditions to the standard volume in cubic feet ranged from $0.971 \mathrm{scf} / \mathrm{ft}^{3} \pm 0.008 \mathrm{scf} / \mathrm{ft}^{3}(0.971 \mathrm{sL} / \mathrm{L} \pm 0.008 \mathrm{sL} / \mathrm{L})$ for the fifteen tests. Since the standard error of the conversion factor was less than $1 \%$, the average value of $0.971 \mathrm{scf} / \mathrm{ft}^{3}$ $(0.971 \mathrm{sL} / \mathrm{L})$ was used in the calculations of the gas energy consumption of each test.

\section{Cooking Tops}

This section discusses the workability and accuracy of the Proposed Rule test procedures, the measurement of electronic ignition device energy consumption, and the significance of excluding the clock energy when the clock is an integral part of the temperature control circuit and cannot be disconnected.

No significant problems were encountered in following the Proposed Rule test procedures to determine the cooking top test energy consumption. Neither were there any significant problems using the equations of the Proposed Rule to calculate the annual energy consumption, energy efficiency, or energy factor for the cooking tops tested. NIST did not test convertible cooking tops (those capable of operating on natural gas or propane) or gas units with pilot lights.

Though no significant problems were encountered while performing the conventional gas or electric cooking top test measurements as specified within the Proposed Rule, the energy consumption of the surface unit ignition devices of the gas cooking top was sufficiently small that it could not be directly measured with a watt or watt hour device during the surface unit tests for the model tested at NIST. Essentially, section 3.2.2 of the Proposed Rule says to “... measure any electrical energy consumed by an ignition device of a gas heating element in Wh (kJ)." The method of measurement is not explicitly stated, and the magnitude of energy consumption of the ignition device may determine if the watt-hour or watt meter should be used. The gas cooking top under test at NIST included a clock with a power rating of approximately 3 $\mathrm{W}$, and ignition devices with power ratings of similar magnitude which were activated for only 
two to four seconds per test. While neither the watt-hour or watt meter could be used to determine the energy consumption of the ignition device, NIST was able to measure the electrical energy consumption of the ignition devices by turning the gas to the cooking top off and then turning the ignition device on for an extended period while measuring the clock and ignition device power combined. After a period of sufficient duration to determine the combined clock and ignition power, the ignition device was turned off and the clock power alone was measured. The average clock power was then subtracted from the combined clock and ignition device power to obtain the average power consumption of the ignition device. Once the ignition device power was known (about $3 \mathrm{~W}$ for the cooking top tested), the amount of time the device was employed to light each burner (roughly $3 \mathrm{~s}$ ) was multiplied by the power to determine the energy consumption of the ignition device, $\mathrm{E}_{\mathrm{TC}}$, per test. For the surface units of the gas cooking top tested, $\mathrm{E}_{\mathrm{IC}}$ was estimated to be about $0.003 \mathrm{Wh}$ per test. Though for this particular cooking top, the energy consumed by the ignition device is insignificant and could not be measured easily, the process may be more straightforward for other cooking tops if their ignition devices use significantly more power. The energy consumption of this cooking top's ignition devices can be neglected, which may indicate that measurement of electronic ignition energy consumption is unnecessary. However, without further investigation it is not known whether all ignition devices are of similar design. Therefore, this procedure should remain in the rule to include the energy consumption of ignition devices that may consume a significant amount of energy.

Though the Proposed Rule at the time of testing did not account for electric clock energy consumption as a part of cooking top tests, the clock, being an integral part of the tested cooking top's circuitry, could not be disconnected. The clock of the electric cooking top has a nominal power rating of $3 \mathrm{~W}$, which, over an electric surface unit test period of 20 min amounts to about 1 Wh of energy consumed. This is less than $0.5 \%$ of the cooking energy consumed during a small electric surface unit test and less than $0.3 \%$ of the cooking energy consumed in a large surface unit test. Since the surface units of the gas cooking top consumed about 2.5 times the energy of the electric cooking top surface units, the clock energy consumption during a gas surface unit test is even less significant. However, the annual clock energy consumption is not negligible (about $28 \mathrm{kWh} / \mathrm{yr}$ as demonstrated in the Oven Test Results, Summary of Results section of this report), and should be included in the annual energy consumption of cooking tops with their own independent clocks. Since, in this test case, the clock was a part of the combined oven and cooking top (range), the annual clock energy was added to the oven's total annual energy consumption as required in section 4.1.2.5 of the Proposed Rule, and excluded from calculations involving the cooking tops. If the gas and/or electric cooking tops featured their own clocks, (independent of the ovens), assuming an annual clock energy consumption of 28 $\mathrm{kWh} / \mathrm{yr}$, the effect of including the annual clock energy consumption would increase the cooking top's total annual energy consumption by $4 \%$ and $11 \%$.

The average small and large electric cooking top surface unit efficiencies were calculated as $77.1 \%$ and $82.4 \%$ with combined uncertainties of less than $2 \%$ relative to efficiency. The overall electric cooking top efficiency was $79.8 \%$ with a combined uncertainty of less than $2 \%$. The average small and large gas cooking top surface unit efficiencies were calculated as $30.3 \%$ 
and $30.1 \%$ with combined uncertainties less than $2 \%$ of the measured values. The overall gas cooking top efficiency was $30.3 \%$ with relative uncertainty of $1.3 \%$.

\section{Microwave Ovens}

There were no significant problems encountered while performing the microwave oven tests measurements as specified within the Proposed Rule and the IEC 705. However, there was substantial difficulty in the determination of a single value for the efficiency of the microwave oven due to a lack of clearly defined procedures in the IEC 705 method for measuring the input power to the oven. In addition to this issue of input power, several other issues were examined in conducting the microwave oven tests. These issues are as follows:

1 Differences between the Proposed Rule (July 1994 version) and the IEC 705, Amendment 2 test procedures, identification of any significant inaccuracies of either method, and the feasibility of adopting the IEC 705 standard by reference within the Proposed Rule.

2 The impact of using a watt-hour meter as prescribed by the Proposed Rule, as compared with a watt meter as prescribed by the IEC 705 test procedure.

3 The effect of using a variety of energy and power measurement devices on the test results.

4 The effect of using different temperature measurement devices on the test results.

5 The effect of the timing of the initial test load temperature measurement on the test results, that is, prior to transferring the load from the chiller to the test container as in the IEC test procedure as opposed to measuring the temperature after transfer of the load.

6 The time required to cool the microwave oven's circuitry, specifically the magnetron, to within $9^{\circ} \mathrm{F}\left(5^{\circ} \mathrm{C}\right)$ of the ambient temperature, and whether or not the 6 -h waiting period between consecutive tests is appropriate.

7 The effect of non-centered test loads inside the microwave oven on the test results.

8 Accounting for clock energy in annual energy consumption equations.

\section{$1 \quad$ Differences between DOE and IEC Test Procedures}

There are three major differences between the Proposed Rule and the IEC test procedures. First, the Proposed Rule specifies a watt-hour meter to measure the input energy consumption during the microwave oven test period while the IEC specifies a watt meter to make a single power measurement to obtain the input power consumption during the test. As such, the energy meter is used to make an integral measurement of the total input energy throughout the entire duration of the test while the single power measurement is assumed to be representative of the average power consumption level throughout the test. However, the procedure for making the input power measurement, especially the timing, is not well-defined. The only guidance is a note in Amendment 2 of the IEC procedure stating that "the magnetron filament heat-up time is to be neglected, the measurement starting when the input current reaches $90 \%$ of its final value." This may be interpreted to mean that any power measurement made while the input current is above $90 \%$ of its final value, and after the magnetron warm-up period is over, is suitable to determine the input power. Presumably the "final value" of the input current is the value of the current just 
before the magnetron is shut off, however, this is not clear. Although the input current is the basis of determining when power measurement begins, there is no instruction describing whether, when or how to measure the input current in the procedure.

Second, the IEC procedure requires a stopwatch or timer to measure the duration of the test, and specifies that the time measurements are to be accurate within $0.25 \mathrm{~s}$. Test measurements with a watt-hour meter do not require a time measurement.

Third, the Proposed Rule requires the determination of the annual energy consumption, the efficiency (by reference to IEC 705) and the energy factor. The fundamental difference between the calculated energy factor and the calculated efficiency is that the energy factor includes all of the input energy, whereas the single input power measurement used to determine the efficiency excludes the transient energy at the beginning and end of the test. Though the difference between the efficiency and energy factor is not extremely large for microwave ovens, it is measurable. As seen in Figure 18, the difference is about $1 \%$ (in efficiency units) or about $2 \%$ relative to the measured values.

\section{Effect of Watt-hour Meter versus Watt Meter}

One of the major differences between the DOE Proposed Rule and IEC test procedures is the requirement of a watt-hour meter to measure energy in the Proposed Rule method and a watt meter to measure power in the IEC method. Figure 18, summarizes the microwave oven test results, presenting them in terms of both power and energy. It is seen that the effect of using a watt meter in contrast to a watt-hour meter to determine efficiency (and therefore energy consumption) ranges from about $2 \%$ to $3 \%$ difference relative to the efficiency depending on the timing of the power measurement(s) and the procedure used to determine the input power. For the tests in Figure 18, the energy factor (efficiency based on energy) ranged from $53.4 \%$ to $57.8 \%$, with an average of $54.9 \%$. The power-based efficiency ranged from $53.0 \%$ to $59.2 \%$, with an average of $55.6 \%$. The average efficiency determined as the average of the minimum power values is $56.3 \%$, while the average using the maximum power values is $54.6 \%$ and the average efficiency using the average of the 21 test values is $55.8 \%$. If a value of the power equal to $90 \%$ of its final value, based on the " $90 \%$ of final current" guideline of the IEC method, is used the average of the power based efficiencies is roughly $62 \%$. This is about $7 \%$ greater in units of efficiency (or $13 \%$ relative to the efficiency) than the average energy factor of about $55 \%$ determined by the watt-hour meter. Therefore, the ambiguity in the timing of the power measurement leads to the possibility of significant variability in the efficiency based on power as well as differences with the efficiency based on energy.

Single-test efficiency and energy factor results from Meters C and D yield average efficiencies of $55.1 \%+/-1.8 \%$ and $53.8 \%+/-1.3 \%$. Based on an instruction within the Proposed Rule and IEC 705, procedures to average 2 or 3 test results to obtain microwave oven efficiency were followed. Averages of 3 test values obtained from Meters $C$ and $D$ were found to produce the same efficiencies as the single-test values with less than $0.3 \%$ differences. Therefore the use 
of different Watt and Watt-hour meters also shows that the IEC method neglects transients and produces results about $1 \%$ higher ( $2 \%$ relative to efficiency) than the Proposed Rule method using watt-hour meter.

\section{Effect of Various Energy and Power Consumption Meters}

Figures 19 through 22 present power and energy consumption measurement results from Meters A, B, C, and D. The specifics of these meters were described earlier in the "Laboratory Setup" section of this report. The important difference between Meters A and B is that Meter A recorded the average of measured parameters at the end of each one-second period, while Meter $\mathrm{B}$ recorded the instantaneous values every 0.1 to 0.2 seconds. This affects the difference in results between Meters A and B is seen by considering the "Max-Min" input power and "Transient" input energy columns for the two meters presented in Figures 19 and 20. In Figure 20 , the average Max-Min difference for Meter B is 41 with a standard deviation among test of $19 \mathrm{~W}$ and a coefficient of variation of about $46 \%$. The dampening effect of recording $1-\mathrm{s}$ averages with Meter $A$ is compared to Figure 19, where the average variation between single-test maximum and minimum values is $35 \mathrm{~W}$ with a significantly smaller standard deviation of $4.7 \mathrm{~W}$ and coefficient of variation of $13 \%$. Similarly, the average transient "watt-hours" and the "\% of total" transient are roughly $0.2 \mathrm{Wh}$ and $1 \%$ respectively for Meters A and B, yet the increased repeatability of the transient energy measurements due to the measurement technique of Meter $B$ is obvious with standard deviations 3 to 5 times lower than those of Meter A. These statistics indicate that the results reported by Meter B better represents the range of power measurements and the potential error that may be realized by utilizing a single power measurement taken anytime after the magnetron reaches full power. If the " $90 \%$ of its final value" criteria is utilized, the variability and possible error of the measurements increases. 
Figure 19: Calculated Efficiencies for Microwave Oven Tests (Meter B)

\begin{tabular}{|c|c|c|c|c|c|c|c|c|c|c|c|c|c|c|c|}
\hline \multirow{3}{*}{ Test } & \multicolumn{6}{|c|}{ Input Power } & \multicolumn{3}{|c|}{ Input Energy } & \multirow{3}{*}{$\begin{array}{c}\text { Output } \\
\text { Energy, Et } \\
\text { (Wh) }\end{array}$} & \multirow{3}{*}{ Energy } & \multicolumn{4}{|c|}{ Efficiency } \\
\hline & \multirow{2}{*}{$\begin{array}{l}\text { Sieady-State } \\
\text { (Watts) }\end{array}$} & \multirow{2}{*}{$\begin{array}{l}\text { Average } \\
\text { (Watts) }\end{array}$} & \multirow{2}{*}{$\begin{array}{l}\text { Maximum } \\
\text { (Watts) }\end{array}$} & \multirow{2}{*}{$\begin{array}{l}\text { Minimum } \\
\text { (Watts) }\end{array}$} & \multicolumn{2}{|c|}{ Max-Min } & \multirow{2}{*}{$\begin{array}{l}\text { Energy, Em } \\
\text { (Wh) }\end{array}$} & \multicolumn{2}{|c|}{ Transient } & & & & & & \\
\hline & & & & & (Watts) & $(\%)$ & & (Wh) & of total & & & SS & Avg & $\operatorname{Max}$ & Min \\
\hline MW0313 & 1409 & 1412 & 1434 & 1389 & 45 & $3.2 \%$ & 21.3 & 0.12 & $0.6 \%$ & 11.9 & $55.9 \%$ & $57.5 \%$ & $57.6 \%$ & $56.6 \%$ & $58.5 \%$ \\
\hline MW0314a & 1402 & 1406 & 1423 & 1389 & 34 & $2.4 \%$ & 21.2 & 0.12 & $0.6 \%$ & 11.7 & $55.2 \%$ & $56.6 \%$ & $56.7 \%$ & $55.9 \%$ & $57.3 \%$ \\
\hline MW0327a & 1421 & 1421 & 1440 & 1402 & 38 & $2.7 \%$ & 21.4 & 0.51 & $2.4 \%$ & 11.6 & $54.1 \%$ & $54.3 \%$ & $54.3 \%$ & $53.6 \%$ & $55.0 \%$ \\
\hline MW0328 & 1420 & 1423 & 1440 & 1409 & 31 & $2.2 \%$ & 21.5 & 0.12 & $0.6 \%$ & 11.8 & $55.2 \%$ & $57.1 \%$ & $57.2 \%$ & $56.5 \%$ & $57.7 \%$ \\
\hline MW0329d & 1410 & 1413 & 1433 & 1396 & 37 & $2.6 \%$ & 21.3 & 0.13 & $0.6 \%$ & 11.6 & $54.5 \%$ & $57.1 \%$ & $57.2 \%$ & $56.3 \%$ & $57.8 \%$ \\
\hline MW0330a & 1424 & 1426 & 1442 & 1406 & 36 & $2.5 \%$ & 21.5 & 0.14 & $0.6 \%$ & 11.7 & $54.5 \%$ & $55.9 \%$ & $55.9 \%$ & $55.3 \%$ & $56.7 \%$ \\
\hline MW0330b & 1422 & 1428 & 1446 & 1420 & 26 & $1.8 \%$ & 21.5 & 0.12 & $0.6 \%$ & 11.8 & $54.8 \%$ & $54.7 \%$ & $54.9 \%$ & $54.0 \%$ & $55.0 \%$ \\
\hline MW0330c & 1450 & 1453 & 1468 & 1437 & 31 & $2.1 \%$ & 21.9 & 0.12 & $0.6 \%$ & 12.0 & $54.9 \%$ & $54.8 \%$ & $54.9 \%$ & $54.3 \%$ & $55.4 \%$ \\
\hline MW0410b & 1424 & 1421 & 1435 & 1406 & 29 & $2.0 \%$ & 21.4 & 0.11 & $0.5 \%$ & 11.7 & $54.5 \%$ & $55.6 \%$ & $55.5 \%$ & $55.0 \%$ & $56.2 \%$ \\
\hline MW0410c & 1441 & 1444 & 1466 & 1427 & 39 & $2.7 \%$ & 21.8 & 0.12 & $0.6 \%$ & 11.9 & $54.8 \%$ & $55.8 \%$ & $55.9 \%$ & $54.9 \%$ & $56.4 \%$ \\
\hline MW0411a & 1422 & 1424 & 1440 & 1407 & 33 & $2.3 \%$ & 21.6 & 0.25 & $1.1 \%$ & 11.6 & $53.7 \%$ & $54.9 \%$ & $55.0 \%$ & $54.3 \%$ & $55.6 \%$ \\
\hline MW041lb & 1437 & 1439 & 1458 & 1415 & 43 & $3.0 \%$ & 21.7 & 0.12 & $0.6 \%$ & 11.8 & $54.3 \%$ & $55.3 \%$ & $55.3 \%$ & $54.5 \%$ & $56.2 \%$ \\
\hline MW0411c & 1424 & 1428 & 1443 & 1412 & 31 & $2.2 \%$ & 21.6 & 0.14 & $0.6 \%$ & 11.7 & $54.3 \%$ & $55.3 \%$ & $55.4 \%$ & $54.7 \%$ & $55.9 \%$ \\
\hline MW0419b & 1407 & 1411 & 1432 & 1395 & 37 & $2.6 \%$ & 21.4 & 0.25 & $1.2 \%$ & 11.5 & $53.6 \%$ & $54.5 \%$ & $54.7 \%$ & $53.7 \%$ & $55.2 \%$ \\
\hline MW0419c & 1431 & 1435 & 1453 & 1417 & 36 & $2.5 \%$ & 21.7 & 0.19 & $0.9 \%$ & 11.7 & $53.8 \%$ & $54.9 \%$ & $55.1 \%$ & $54.2 \%$ & $55.6 \%$ \\
\hline MW0420a & 1434 & 1436 & 1454 & 1420 & 34 & $2.4 \%$ & 21.5 & 0.39 & $1.8 \%$ & 11.7 & $54.5 \%$ & $54.5 \%$ & $54.6 \%$ & $53.8 \%$ & $55.1 \%$ \\
\hline MW0421a & 1416 & 1419 & 1433 & 1396 & 37 & $2.6 \%$ & 21.4 & 0.12 & $0.6 \%$ & 11.6 & $54.1 \%$ & $54.1 \%$ & $54.2 \%$ & $53.6 \%$ & $55.0 \%$ \\
\hline MW0421b & 1406 & 1411 & 1428 & 1392 & 36 & $2.6 \%$ & 21.3 & 0.15 & $0.7 \%$ & 11.4 & $53.5 \%$ & $54.7 \%$ & $54.8 \%$ & $54.0 \%$ & $55.4 \%$ \\
\hline MW0424a & 1417 & 1418 & 1433 & 1404 & 29 & $2.0 \%$ & 21.5 & 0.19 & $0.9 \%$ & 11.5 & $53.6 \%$ & $54.4 \%$ & $54.4 \%$ & $53.9 \%$ & $55.0 \%$ \\
\hline MW: $0424 \mathrm{c}$ & 1447 & 1451 & 1469 & 1431 & 38 & $2.6 \%$ & 21.9 & 0.13 & $0.6 \%$ & 11.9 & $54.4 \%$ & $55.0 \%$ & $55.1 \%$ & $54.3 \%$ & $55.8 \%$ \\
\hline A verage & 1423 & 1426 & 1444 & 1409 & 35 & $2.5 \%$ & 21.5 & 0.18 & $0.8 \%$ & 11.7 & $54.4 \%$ & $55.3 \%$ & $55.4 \%$ & $54.7 \%$ & $56.0 \%$ \\
\hline Stder & 13.3 & 13.4 & 13.6 & 13.9 & 4.7 & $0.3 \%$ & 0.2 & 0.10 & $0.5 \%$ & 0.2 & $0.6 \%$ & $1.0 \%$ & $1.0 \%$ & $1.0 \%$ & $1.1 \%$ \\
\hline C.V. & $0.9 \%$ & $0.9 \%$ & $0.9 \%$ & $1.0 \%$ & $13.4 \%$ & $13.5 \%$ & $0.9 x$ & $58.4 \%$ & $58.6 \%$ & $1.4 \%$ & $1.1 \%$ & $1.8 \%$ & $1.8 \%$ & $1.8 \%$ & $1.9 \%$ \\
\hline
\end{tabular}

Input Power = Uke power input to dre nicis uwave uven during testing

Input Power, Steady-State Average = the average power recorded during the hast 30 seconds of the test period, exchding the transient power at the end of the test period

Input Power, A ver age $=$ the aver age power recorued during the test period, exchuding the transient periods at beginning and end of the test perind

Input Power, Maximum = the maximum power recorded during the test period, exchuding the transient periods at beginning and end of the test period

Inpur Power, $M$ Minimm = the minimum power recorded during the test period, exchuding the transient perbds at beginning and end of the rest period

Input Power, Max-Min (watts) = the maximum power minus the minimum power

Input Power, $\operatorname{Max}-\mathrm{Min}(\%)=$ the percent difference between the maximum and minimum power $=($ Max-Min)/Average Power

Input Energy = the energy input to the microwave oven during testing

Input Energy, Energy, Em = the total input energy thoughout the test period, inchding the transient periods at the beginning and end of the test

Input Energy, Transient (Wh) = the input energy during transient periods at the begining and end of the test

Input Energy, \% of Toxal= the percent of the total input energy made up from the transient input energy

Load Energy, Et = the energy output of the microwave oven to the test bad

Efficiency $=$ the ratio of the output energy divided by the input energy, or the output power divided by the input power

Efficiency, Energy = the ratio of the output energy divided by the input energy based on the use of a watt-hour meter

Efficincy, Power $=$ the ratio of the output power divided by the input power based on the use of a walt meter

Effciency, Power, SS Avg = the efficiency based on the steady-state average power

Efficiency, Power, $\mathrm{Avg}=$ the efficicicy based on the average power

Efficiency, Power, Max $=$ the efficiency based on the maximum power

Efficiency, Power, $\mathrm{Avg}=$ the efficiency based on the minimum power 
Figure 20: Calculated Efficiencies for Microwave Oven Tests (Meter A)

\begin{tabular}{|c|c|c|c|c|c|c|c|c|c|c|c|c|c|c|c|}
\hline \multirow{3}{*}{ Test } & \multicolumn{6}{|c|}{ Input Power } & \multicolumn{3}{|c|}{ Input Energy } & \multirow{3}{*}{$\begin{array}{c}\text { Output } \\
\text { Energy, Et } \\
\text { (Wh) }\end{array}$} & \multirow{3}{*}{$\begin{array}{c}\text { Energy } \\
(\%)\end{array}$} & \multicolumn{4}{|c|}{ Efficiency } \\
\hline & \multirow{2}{*}{$\begin{array}{l}\text { Steady-State } \\
\text { (Watts) }\end{array}$} & \multirow{2}{*}{$\begin{array}{l}\text { Average } \\
\text { (Watts) }\end{array}$} & \multirow{2}{*}{$\begin{array}{c}\text { Maximum } \\
\text { (Watts) }\end{array}$} & \multirow{2}{*}{$\begin{array}{c}\text { Minimum } \\
\text { (Watts) }\end{array}$} & \multicolumn{2}{|c|}{ Max-MIn } & \multirow{2}{*}{$\begin{array}{c}\text { Energy, Em } \\
(W h)\end{array}$} & \multicolumn{2}{|c|}{ Transient } & & & & & & \\
\hline & & & & & (Watts) & $(\%)$ & & $(\mathrm{Wh})$ & $\%$ of total & & & ss & Avg & $\operatorname{Max}$ & Min \\
\hline MW0309 & 1412 & 1416 & 1428 & 1405 & 22 & $1.6 \%$ & 21.4 & 0.22 & $1.0 \%$ & 11.4 & $53.4 \%$ & $54.2 \%$ & $54.1 \%$ & $53.7 \%$ & $54.5 \%$ \\
\hline MW0313 & 1426 & 1429 & 1440 & 1415 & 25 & $1.7 \%$ & 21.6 & 0.23 & $1.1 \%$ & 11.9 & $55.1 \%$ & $56.0 \%$ & $55.9 \%$ & $55.5 \%$ & $56.5 \%$ \\
\hline MW0314a & 1418 & 1422 & 1482 & 1402 & 80 & $5.6 \%$ & 21.5 & 0.23 & $1.1 \%$ & 11.7 & $54.5 \%$ & $55.4 \%$ & $55.3 \%$ & $53.0 \%$ & $56.0 \%$ \\
\hline MW0327a & 1403 & 1405 & 1435 & 1391 & 44 & $1.6 \%$ & 21.0 & 0.18 & $0.9 \%$ & 11.6 & $55.2 \%$ & $56.1 \%$ & $56.0 \%$ & $54.8 \%$ & $56.6 \%$ \\
\hline MW0328 & 1403 & 1406 & 1427 & 1393 & 34 & $2.4 \%$ & 21.2 & 0.21 & $1.0 \%$ & 11.8 & $55.8 \%$ & $56.7 \%$ & $56.6 \%$ & $55.8 \%$ & $57.1 \%$ \\
\hline MW0329c & 1374 & 1377 & 1420 & 1368 & 52 & $3.8 \%$ & 20.8 & 0.20 & $1.0 \%$ & 11.4 & $54.7 \%$ & $55.5 \%$ & $55.4 \%$ & $53.7 \%$ & $55.8 \%$ \\
\hline MW0329d & 1395 & 1398 & 1447 & 1384 & 63 & $4.5 \%$ & 21.1 & 0.22 & $1.0 \%$ & 11.6 & $55.1 \%$ & $56.0 \%$ & $55.9 \%$ & $54.0 \%$ & $56.4 \%$ \\
\hline MW0417b & 1437 & 1439 & 1454 & 1430 & 23 & $1.6 \%$ & 21.8 & 0.23 & $1.0 \%$ & 12.1 & $55.4 \%$ & $56.3 \%$ & $56.2 \%$ & $55.7 \%$ & $56.6 \%$ \\
\hline MW0417c & 1434 & 1436 & 1461 & 1426 & 35 & $2.4 \%$ & 21.6 & 0.23 & $1.1 \%$ & 12.0 & $55.5 \%$ & $56.1 \%$ & $56.1 \%$ & $55.1 \%$ & $56.5 \%$ \\
\hline MW04 18b & 1405 & 1407 & 1456 & 1393 & 63 & $4.5 \%$ & 22.0 & 0.17 & $0.8 \%$ & 12.1 & $55.0 \%$ & $57.8 \%$ & $57.7 \%$ & $55.8 \%$ & $58.3 \%$ \\
\hline MW0419c & 1425 & 1427 & 1443 & 1410 & 32 & $2.3 \%$ & 21.6 & 0.17 & $0.8 \%$ & 11.7 & $54.1 \%$ & $55.1 \%$ & $55.0 \%$ & $54.4 \%$ & $55.6 \%$ \\
\hline MW0420a & 1425 & 1428 & 1477 & 1414 & 63 & $4.4 \%$ & 21.4 & 0.25 & $1.2 \%$ & 11.7 & $54.9 \%$ & $55.3 \%$ & $55.1 \%$ & $53.3 \%$ & $55.7 \%$ \\
\hline MW0420b & 1418 & 1420 & 1438 & 1407 & 32 & $2.2 \%$ & 21.4 & 0.27 & $1.3 \%$ & 11.6 & $53.9 \%$ & $54.8 \%$ & $54.7 \%$ & $54.0 \%$ & $55.2 \%$ \\
\hline MW0421a & 1408 & 1410 & 1458 & 1394 & 64 & $4.5 \%$ & 21.3 & 0.21 & $1.0 \%$ & 11.6 & $54.3 \%$ & $55.3 \%$ & $55.2 \%$ & $53.3 \%$ & $55.8 \%$ \\
\hline MW0421b & 1402 & 1404 & 1417 & 1390 & 28 & $2.0 \%$ & 21.1 & 0.19 & $0.9 \%$ & 11.4 & $54.1 \%$ & $54.6 \%$ & $54.6 \%$ & $54.1 \%$ & $55.1 \%$ \\
\hline MW0424a & 1407 & 1409 & 1420 & 1398 & 22 & $1.6 \%$ & 21.3 & 0.18 & $0.8 \%$ & 11.5 & $54.1 \%$ & $54.9 \%$ & $54.8 \%$ & $54.4 \%$ & $55.2 \%$ \\
\hline MW0424b & 1411 & 1413 & 1425 & 1403 & 23 & $1.6 \%$ & 21.3 & 0.23 & $1.1 \%$ & 11.7 & $54.7 \%$ & $55.5 \%$ & $55.4 \%$ & $54.9 \%$ & $55.8 \%$ \\
\hline MW0424c & 1440 & 1441 & 1457 & 1431 & 26 & $1.8 \%$ & 21.8 & 0.24 & $1.1 \%$ & 11.9 & $54.8 \%$ & $55.6 \%$ & $55.6 \%$ & $55.0 \%$ & $56.0 \%$ \\
\hline Average & 1414 & 1416 & 1444 & 1403 & 41 & $2.8 \%$ & 21.4 & 0.21 & $1.0 \%$ & 11.7 & $54.7 \%$ & $55.6 \%$ & $55.5 \%$ & $54.5 \%$ & $56.0 \%$ \\
\hline Sidev & 16.3 & 16 & 19 & .16 & 19 & $1.3 \%$ & 0.3 & 0.03 & $0.1 \%$ & 0.2 & $0.6 \%$ & $0.8 \%$ & $0.8 \%$ & $0.9 \%$ & $0.8 \%$ \\
\hline C.V. & $1.2 \%$ & $1.1 \%$ & $1.3 \%$ & $1.2 \%$ & $45.6 \%$ & $48.5 \%$ & $1.4 \%$ & $13.3 \%$ & $13.1 \%$ & $1.9 \%$ & $1.1 \%$ & $1.5 \%$ & $1.5 \%$ & $1.6 \%$ & $1.5 \%$ \\
\hline
\end{tabular}

Input Power - the power input to the microwave oven during testing

Input Power, Steady-State Average - the average power tecorded during the last 30 seconds of the test period, excluding the transient power at the end of the test period Input Power, Average - the average power recorded during the test period, excluding the transient periods at beginning and end of the test period

Input Power, Maximum $=$ the maximum power recorded during the test period, excluding the transient periods at beginning and end of the test period

Input Power, Minimum - the minimum power recorded during the test period, excluding the transient periods at beginning and end of the test period Input Power, Max-Min (watts) - the maximum power minus the minimum power

Input Power, Max-Min $(\%)-$ the percent difference between the maximum and minimum power $=($ Max-Min)/Average Power

Input Energy $=$ the energy input to the microwave oven during testing

Input Energy, Energy, Em - the total input energy thoughout the test period, including the transient periods at the beginning and end of the test

Input Energy, Transient (Wh) - the input energy during transient periods at the beginning and end of the test

Input Energy, $\%$ of Total - the percent of the total input energy made up from the transient input energy

Load Encrgy, Et = the energy output of the microwave oven to the test load

Efficiency - the ratio of the output energy divided by the input energy, or the output power divided by the input power

Efficiency, Energy = the ratio of the output energy divided by the input energy based on the use of a watt-hour meter

Efficiency, Power = the ratio of the output power divided by the input power based on the use of a watt meter

Efficiency, Power, SS Avg = the efficiency based on the steady-state average power

Efficiency, Power, Avg - the efficiency based on the average power

Efficiency, Power, Max - the efficiency based on the maximum power

Efficiency, Power, Avg - the efficiency based on the minimum power 
Figure 21 presents the results from Meter C, which displayed the power in watts and energy consumption in watt-hours during a test. After the initial rise to maximum power, the "High" power was visually monitored for several seconds, and an estimate of the average was recorded by hand, as shown in column 3. An estimate of the "Low" input power, occurring near the end of the test, was also recorded along with the energy consumption at the end of the test. These values are recorded in columns 4 and 5. The average of the high and low measurements was calculated and recorded in column 2 as the average power. The highest and lowest of all power measurements ranged from $1459 \mathrm{~W}$ to $1413 \mathrm{~W}$, a difference of $46 \mathrm{~W}$ or $3.2 \%$ of the average power. The average power and the energy measurements, along with the energy factor and efficiency are $1436 \mathrm{~W}, 21.7 \mathrm{Wh}, 54.5 \%$ and $55.3 \%$ respectively. These values are comparable to those determined by Meters A and B, being $1 \%$ to $2 \%$ different from the corresponding values of Meter $B$ and less than $1 \%$ different from the corresponding values of Meter A. These differences are within the $2 \%$ difference allowed by the $\pm 1 \%$ uncertainty specification of the meters, and are well within the possible $10 \%$ difference allowed by the $\pm 5 \%$ uncertainty for the watt meter and the $3 \%$ allowed by the $\pm 1.5 \%$ uncertainty for the watt-hour meter specified in the Proposed Rule. This verifies that there is essentially no affect on the results obtained from these three meters.

Figure 21: Calculated Efficiencies for Microwave Oven Tests (Meter C)

\begin{tabular}{|c|ccc|c|c|ccc|}
\hline \multirow{2}{*}{ Test } & \multicolumn{3}{|c|}{ Input Power } & Input & \multicolumn{3}{c|}{ Efficiency } \\
\cline { 2 - 9 } & $\begin{array}{c}\text { Average } \\
\text { (Watts) }\end{array}$ & $\begin{array}{c}\text { High } \\
\text { (Watts) }\end{array}$ & $\begin{array}{c}\text { Low } \\
\text { (Watts) }\end{array}$ & $\begin{array}{c}\text { Energy } \\
(\mathrm{Wh})\end{array}$ & $\begin{array}{c}\mathrm{R}_{\mathrm{O}} \\
(\%)\end{array}$ & $\begin{array}{c}\text { Average } \\
(\%)\end{array}$ & $\begin{array}{c}\text { High } \\
(\%)\end{array}$ & $\begin{array}{c}\text { Low } \\
(\%)\end{array}$ \\
\hline MW0410a & 1438 & 1445 & 1431 & 21.8 & $53.1 \%$ & $54.1 \%$ & $53.4 \%$ & $54.0 \%$ \\
MW0410b & 1435 & 1439 & 1420 & 21.6 & $54.1 \%$ & $54.7 \%$ & $54.1 \%$ & $54.9 \%$ \\
MW0411a & 1433 & 1438 & 1448 & 21.7 & $53.6 \%$ & $54.4 \%$ & $53.8 \%$ & $53.5 \%$ \\
MW0411b & 1451 & 1457 & 1445 & 21.9 & $53.9 \%$ & $54.1 \%$ & $53.9 \%$ & $54.4 \%$ \\
MW0411c & 1438 & 1442 & 1433 & 21.7 & $53.9 \%$ & $54.7 \%$ & $54.1 \%$ & $54.5 \%$ \\
MW0412a & 1435 & 1439 & 1430 & 21.7 & $53.7 \%$ & $54.5 \%$ & $53.9 \%$ & $54.3 \%$ \\
MW0413a & 1436 & 1440 & 1432 & 21.9 & $53.4 \%$ & $54.7 \%$ & $54.2 \%$ & $54.5 \%$ \\
MW0413b & 1449 & 1453 & 1444 & 21.9 & $53.9 \%$ & $54.6 \%$ & $54.0 \%$ & $54.4 \%$ \\
MW0417a & 1433 & 1437 & 1428 & 21.7 & $54.1 \%$ & $55.1 \%$ & $54.5 \%$ & $54.9 \%$ \\
MW0417b & 1446 & 1451 & 1440 & 21.7 & $55.5 \%$ & $56.0 \%$ & $55.3 \%$ & $55.8 \%$ \\
MW0417c & 1441 & 1446 & 1436 & 21.8 & $55.1 \%$ & $55.9 \%$ & $55.7 \%$ & $56.1 \%$ \\
MW0418a & 1435 & 1440 & 1430 & 21.3 & $55.4 \%$ & $55.2 \%$ & $54.6 \%$ & $54.9 \%$ \\
MW0418b & 1452 & 1459 & 1445 & 21.9 & $55.1 \%$ & $55.9 \%$ & $55.2 \%$ & $55.7 \%$ \\
MW0419a & 1449 & 1454 & 1444 & 21.9 & $54.4 \%$ & $55.1 \%$ & $54.9 \%$ & $55.3 \%$ \\
MW0419b & 1406 & 1412 & 1400 & 21.2 & $54.1 \%$ & $54.4 \%$ & $54.2 \%$ & $54.7 \%$ \\
MW0420a & 1431 & 1435 & 1427 & 21.6 & $54.2 \%$ & $55.0 \%$ & $55.3 \%$ & $55.6 \%$ \\
MW0420b & 1424 & 1428 & 1420 & 21.5 & $53.8 \%$ & $54.5 \%$ & $54.2 \%$ & $54.5 \%$ \\
MW0421a & 1417 & 1422 & 1413 & 21.3 & $54.3 \%$ & $54.9 \%$ & $54.4 \%$ & $54.8 \%$ \\
MW0421b & 1407 & 1411 & 1403 & 21.2 & $53.8 \%$ & $54.5 \%$ & $54.3 \%$ & $54.6 \%$ \\
MW0421c & 1423 & 1426 & 1420 & 21.5 & $59.6 \%$ & $60.5 \%$ & $60.0 \%$ & $60.2 \%$ \\
\hline Average & 1436 & 1441 & 1432 & 21.7 & $54.5 \%$ & $55.3 \%$ & $54.8 \%$ & $55.2 \%$ \\
Stdev & 10 & 10 & 10 & 0.2 & $1.5 \%$ & $1.5 \%$ & $1.5 \%$ & $1.5 \%$ \\
\hline C.V. & $0.7 \%$ & $0.7 \%$ & $0.7 \%$ & $0.9 \%$ & $2.7 \%$ & $2.6 \%$ & $2.7 \%$ & $2.7 \%$ \\
\hline
\end{tabular}


The transient energy could not be determined from Meter C or D, nor could power be recorded by Meter $\mathrm{D}$. However, an estimate of the average power during the "full power" portion of the test, was estimated by subtracting the transient energy, determined by Meter $\mathrm{A}$ or $\mathrm{B}$, from the total energy measured by Meter $\mathrm{D}$ and dividing the duration of the full power period into the remaining energy. Columns 1 through 5 of Figure 22 contain the identification code, estimated input power, measured input energy, efficiency and energy factor (formatted as efficiency) for each test from the induction type watt-hour Meter, D. The average of the 7 singletest power values is $1452 \mathrm{~W}$, ranging from $1424 \mathrm{~W}$ to $1471 \mathrm{~W}$, a difference of $47 \mathrm{~W}$, or $3.2 \%$ of the average power. The power related efficiency ranged from $51.3 \%$ to $56.5 \%$, a difference of $5.2 \%$ in units of efficiency or about $10 \%$ relative to the average efficiency of $53.9 \%$. The estimated power and efficiency values from Meter $D$ should not be taken as conclusive evidence that its results are the same as those of Meters A, B, and C, since the power and efficiency were determined using transient energy measurements from Meters A and B.

Figure 22: Calculated Efficiencies for Microwave Oven Tests (Meter D)

\begin{tabular}{|c|c|c|c|c|}
\hline \multirow{2}{*}{ Test } & Input & Input & \multicolumn{2}{|c|}{ Efficiency } \\
\cline { 4 - 5 } & power & energy & Power & Energy \\
(Watts) & (Wh) & $(\%)$ & $(\%)$ \\
\hline MW0329b & 1424 & 21.4 & $56.5 \%$ & $56.0 \%$ \\
MW0329c & 1437 & 21.6 & $53.1 \%$ & $52.6 \%$ \\
MW0404a & 1464 & 21.9 & $51.3 \%$ & $51.1 \%$ \\
MW0404b & 1471 & 22.0 & $54.1 \%$ & $53.8 \%$ \\
MW0404c & 1451 & 22.1 & $54.8 \%$ & $53.6 \%$ \\
MW0405a & 1457 & 21.8 & $53.3 \%$ & $53.1 \%$ \\
MW0406a & 1461 & 22.1 & $54.3 \%$ & $53.5 \%$ \\
MW0412a & & 21.3 & & $54.7 \%$ \\
MW0413a & & 21.8 & & $53.7 \%$ \\
MW0413b & & 22.0 & & $53.6 \%$ \\
MW0417a & & 21.8 & & $53.9 \%$ \\
\hline Average & 1452 & 21.8 & $53.9 \%$ & $53.6 \%$ \\
Stdev. & 16.3 & 0.3 & $1.6 \%$ & $1.2 \%$ \\
C.V. & $1.1 \%$ & $1.2 \%$ & $3.0 \%$ & $2.3 \%$ \\
\hline
\end{tabular}


The energy consumption measurements of the 11 tests using Meter $\mathrm{D}$ ranged from 21.3 Wh to $22.1 \mathrm{Wh}$ with an average of $21.8 \mathrm{Wh}$ and a standard deviation of $0.3 \mathrm{Wh}$. The range of the energy factor was from $51.1 \%$ to $56.0 \%$, a difference of $4.9 \%$ in efficiency units or about $9 \%$ relative to the average energy factor of $53.6 \%$. The standard deviation of the energy factors was $1.2 \%$. The overall average test energy of Meter D is higher than that of Meters $\mathrm{A}, \mathrm{B}$, and $\mathrm{C}$, while the energy factor, $53.6 \%$ in units of efficiency, is roughly $1 \%$ lower $(2 \%$ relative to efficiency) than the energy factors from Meters A, B, and C. The $1 \%$ lower average is within the possible difference of $2.5 \%$ established by the specifications of $1 \%$ for Meters $\mathrm{A}, \mathrm{B}$ and $\mathrm{C}$, and $1.5 \%$ for Meter D.

These results are evidence that, though the watt meters consistently yield efficiencies about $2 \%$ higher than the energy factors from watt-hour meters, there is no other discernable difference between the results obtained with the different meters. However, as may be expected, when the average test power consisted of a large number readings throughout the test, as with Meters $A$ and $B$, the variability of efficiency results was smaller (about 6\%), relative to Meters C and D, (around 10\%). However, the IEC 705 (1988) clause 14, which has been adopted by DOE in the Proposed Rule, requires that the watt meter be an induction type meter. Since the results of induction meters are no better than those of other meter types, NIST believes that the important issue is the instrument specifications, rather than meter type.

\section{$4 \quad$ Effect of Different Temperature Measurement Devices}

There does not appear to be any significant error or difference in the efficiency or energy factor results calculated from the use of different temperature measurement devices. Any error associated with the temperature measurement devices is manifested in the equations for output power $P_{T}$ and output energy $E_{T}$ as seen in Figure 17 of the microwave oven results section of this report. The efficiency and energy factor were compared using a single power and energy monitoring device with three different temperature measurement devices. Figure 23 is a table of the calculated efficiencies determined using Meter B and three different temperature measurement devices to measure the ambient and test load temperatures. The three devices were a mercury thermometer, a type " $E$ " beaded thermocouple wire, and a thermistor. The efficiency results based on energy and power measurements exhibit essentially no difference among the three devices. These results show that the type of temperature measurement device used to satisfy the test procedures is irrelevant as long as the accuracy specifications are met. 
Figure 23: Efficiency Calculated Using Different Temperature Measurement Devices

\begin{tabular}{|c|ccc|ccc|}
\hline \multirow{2}{*}{ Test } & \multicolumn{3}{|c|}{ Effciency by Energy Measurements } & \multicolumn{3}{c|}{ Efficiency by Power Measurements } \\
\cline { 2 - 7 } & $\begin{array}{c}\text { Thermometer } \\
(\%)\end{array}$ & $\begin{array}{c}\text { Thermocouple } \\
(\%)\end{array}$ & $\begin{array}{c}\text { Thermister } \\
(\%)\end{array}$ & $\begin{array}{c}\text { Thermometer } \\
(\%)\end{array}$ & $\begin{array}{c}\text { Thermocouple } \\
(\%)\end{array}$ & $\begin{array}{c}\text { Thernister } \\
(\%)\end{array}$ \\
\hline MW0419c & $54.1 \%$ & $54.3 \%$ & $53.9 \%$ & $55.0 \%$ & $55.3 \%$ & $54.8 \%$ \\
MW0420a & $54.9 \%$ & $54.6 \%$ & $54.6 \%$ & $55.1 \%$ & $54.8 \%$ & $54.8 \%$ \\
MW0420b & $53.9 \%$ & $54.3 \%$ & $53.9 \%$ & $54.7 \%$ & $55.1 \%$ & $54.7 \%$ \\
MW0421a & $54.3 \%$ & $53.7 \%$ & $54.9 \%$ & $55.2 \%$ & $54.5 \%$ & $55.7 \%$ \\
MW0421b & $54.1 \%$ & $545 \%$ & $54.1 \%$ & $54.6 \%$ & $55.0 \%$ & $54.6 \%$ \\
MW0424a & $54.1 \%$ & $54.1 \%$ & $53.9 \%$ & $54.8 \%$ & $54.8 \%$ & $54.6 \%$ \\
MW0424b & $54.7 \%$ & $54.6 \%$ & $54.4 \%$ & $55.4 \%$ & $55.3 \%$ & $55.1 \%$ \\
MW0424c & $54.8 \%$ & $54.7 \%$ & $54.2 \%$ & $55.6 \%$ & $55.4 \%$ & $54.9 \%$ \\
\hline \hline Average & $54.4 \%$ & $54.4 \%$ & $54.2 \%$ & $55.0 \%$ & $55.0 \%$ & $54.9 \%$ \\
Stdev & $0.4 \%$ & $0.3 \%$ & $0.4 \%$ & $0.3 \%$ & $0.3 \%$ & $0.4 \%$ \\
\hline C.V. & $0.7 \%$ & $0.6 \%$ & $0.7 \%$ & $0.6 \%$ & $0.6 \%$ & $0.7 \%$ \\
\hline
\end{tabular}

\section{Effect of Timing of Initial Test Load Temperature Measurement}

NIST was requested by DOE to determine whether it makes a difference if the initial load temperature is measured after, rather than before it is transferred to the test container. Following the NIST protocol, the test load temperature was not only measured while in the chiller before transferring it to the test container, but also immediately prior to placing it in the microwave oven. The average of all measurements of the temperature immediately prior to transferring the load to the microwave oven was $1.3^{\circ} \mathrm{F}\left(0.7^{\circ} \mathrm{C}\right)$ warmer than while in the chiller. If this adjusted temperature difference is used in the equations for $\mathrm{E}_{\mathrm{T}}$ and $\mathrm{P}_{\mathrm{T}}$, the efficiency will be reduced by about $7.0 \%$ (or about $14 \%$ in relative terms). Therefore, violating the procedure for obtaining the initial load temperature does make a significant difference.

\section{Magnetron Cool-down Period and Effect of Initial Magnetron Temperature}

The IEC test method requires that the temperature of the magnetron and the supply main circuit of a microwave oven be within $9^{\circ} \mathrm{F}\left(5^{\circ} \mathrm{C}\right)$ of the ambient room air temperature before starting a test. To insure this condition, a $6 \mathrm{~h} \mathrm{cool-down} \mathrm{period} \mathrm{between} \mathrm{tests} \mathrm{is} \mathrm{required} \mathrm{if} \mathrm{the}$ magnetron or supply main temperature is not measured. Some tests were performed to determine the characteristic cooling curve of the magnetron in the oven and the effect of the initial magnetron temperature on the input power. 
Figure 24 is a plot of the magnetron's temperature following a test. The cooling curve shows that it takes about $1 \mathrm{~h}$ for the magnetron temperature to decrease to within $9^{\circ} \mathrm{F}\left(5^{\circ} \mathrm{C}\right)$ of its initial temperature. In two hours the magnetron is within $2^{\circ} \mathrm{F}\left(1^{\circ} \mathrm{C}\right)$ of the initial magnetron temperature, which is within $9^{\circ} \mathrm{F}\left(5^{\circ} \mathrm{C}\right)$ of the initial ambient room temperature. Therefore, the $6 \mathrm{~h}$ cool-down interval between testing, required by the IEC 705 when the magnetron temperature is not known, appears to be ample time for this oven. However, without further testing, the cooling rates of other magnetrons in other ovens is uncertain.

Figure 24: Magnetron Cooling Curve, Temperature verses Time

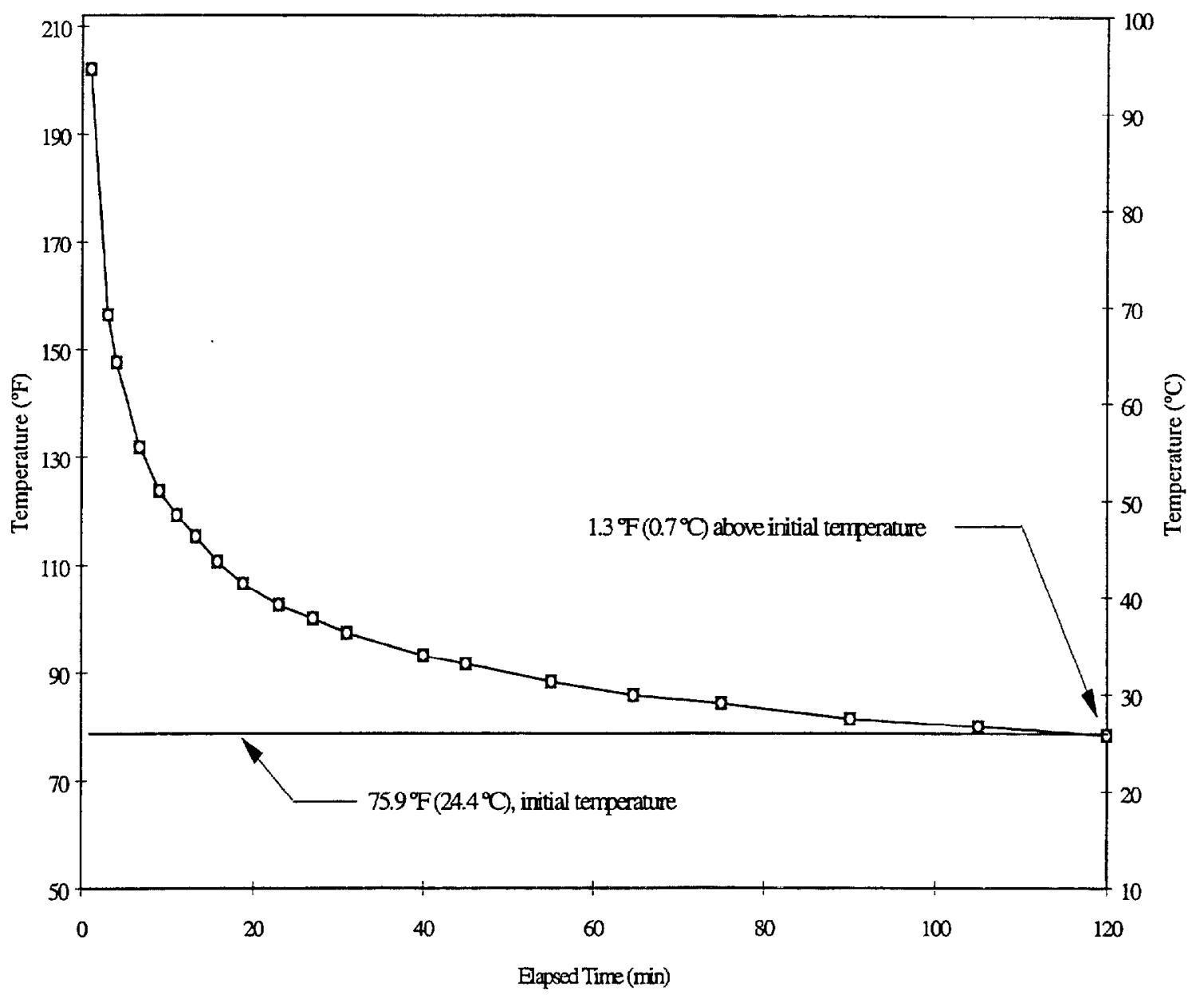


Microwave oven and microwaveable food manufacturers as well as consumers have been aware of the uneven cooking effect and the presence of so called "hot spots" in microwave ovens. Manufacturers have incorporated devices such as mode stirrers and turn-tables to cause a more even distribution of the microwaves over the surface of the food. Without alteration, the microwave density distribution is not only non-uniform within an oven, but it depends on the shape, size and material composition of the load. The intended result of stirring the microwaves or turning the food is to distribute the microwaves evenly over the surface of the food. This effect was confirmed in the oven tested by placing the test load 2 in. $(5 \mathrm{~cm})$ off center during some of the tests and comparing the results to tests performed with a centered load. The difference between the average efficiency of 10 load-centered tests and 7 non-centered load tests measured by Meter $\mathrm{C}$ was $0.2 \%$, while the difference between energy factors from the same sets of tests was $0.7 \%$. The results of similar test sets based on Meters A and B do not change to any appreciable degree which verifies that when a turntable is used, the effects of a non-centered load on test results is negligible. Microwave ovens with mode stirrers and ovens without turn-tables or mode stirrers were not tested.

\section{Accounting for Clock Energy in Annual Energy Consumption}

The Proposed Rule calculates the annual cooking energy consumption, $\mathrm{E}_{\mathrm{MO}}$, but does not include the annual clock energy consumption except for the insignificant amount included during the test period. For the microwave oven tested, the clock power is about $4 \mathrm{~W}$. This translates to an annual energy consumption, $\mathrm{E}_{\mathrm{CL}}=4 \mathrm{~W} \times 8760 \mathrm{hr} / \mathrm{yr}=35.04 \mathrm{kWh} / \mathrm{yr}$. When added to the annual energy consumption, $E_{\mathrm{MO}}=\left(\mathrm{E}_{\mathrm{m}} \times \mathrm{O}_{\mathrm{O}}\right) / \mathrm{E}_{\mathrm{T}}$, nominally $141 \mathrm{kWh} / \mathrm{yr}$, the total annual energy consumption becomes $196 \mathrm{kWh} / \mathrm{yr}$. This is an increase of $38 \%$, and consideration should be given to changing the Rule to include the annual energy of the clock. An obvious consequence of changing the cooking energy of microwave ovens in this way is that the energy factor, being equal to $\mathrm{O}_{\mathrm{O}} / \mathrm{E}_{\mathrm{MO}}$, will be reduced significantly. 


\section{SUMMARY}

The Energy Policy and Conservation Act of 1977 required the Department of Energy (DOE) to establish an energy conservation program for consumer products other than automobiles. To meet this requirement for kitchen cooking appliances, DOE published a Final Rule (43 FR 20120) in 1978 which prescribed test methods for measuring the energy efficiency and energy consumption of conventional ranges, conventional ovens, conventional cooking tops, and microwave ovens. When an energy consumption standard was proposed for these appliances in 1993, the appropriateness of the 1978 test methods came into question, which prompted DOE to initiate a revision of the 1978 Rule. On March 23, 1995 the revision was published in the federal register as a Proposed Rule for kitchen cooking appliance energy consumption test methods.

In order to assess the 1995 Proposed Rule, NIST tested five kitchen appliances using the proposed test procedures. The appliances tested include a conventional electric oven, a conventional gas oven, a conventional electric cooking top, a conventional gas cooking top, and a microwave oven. A series of tests was performed on each of the five appliances to evaluate the workability of the revised test methods and the accuracy of the results obtained through use of these methods. The results for each of the appliances tested consisted of the appliance annual energy consumption, efficiency and energy factor, determined as required by the Proposed Rule. The accuracy and repeatability of the test results were evaluated based on the average test values and standard deviations.

The tests performed at NIST did not include all appliances covered by the Proposed Rule. For example, multiple ovens and ranges were not tested by NIST. The measurements and calculations for multiple ovens and ranges are simply combinations of the oven and cooking top measurements and calculations. Also, many possible combinations of design functions and features are available in ranges, ovens, cooking tops, and microwave ovens, and the appliances tested do not include all of these options. Also, the appropriateness of the Proposed Rule for appliances such as "cool top" or induction unit cooking tops, or microwave ovens combined with conventional ranges, were not addressed in this effort.

\section{Results}

From laboratory testing of the five cooking appliances, it was determined that the Proposed Rule test methods could be performed with little or no difficulty, and that the test methods are workable, repeatable and produced sufficiently accurate results.

A measure of the ability of the different test methods to provide accurate and repeatable results can be estimated using the average values, standard deviations and coefficients of variance (C.V.) for a series of tests of a single appliance. A summary of those parameters for the energy consumption, energy efficiency and energy factor results for the appliances tested follows. 
Ovens - The average total annual primary energy consumption, $\mathrm{E}_{\mathrm{AO}}$, of the electric oven tests was $376 \mathrm{kWh} / \mathrm{yr}$ with a standard deviation of $3.92 \mathrm{kWh} / \mathrm{yr}$. The average total annual primary energy consumption, $\mathrm{E}_{\mathrm{AOG}}$, of the gas oven tests was $2.12 \times 10^{6} \mathrm{Btu} / \mathrm{yr}(620 \mathrm{kWh} / \mathrm{yr})$ with a standard deviation of $22.4 \times 10^{3} \mathrm{Btu} / \mathrm{yr}(6.6 \mathrm{kWh} / \mathrm{yr})$, while the average total annual secondary energy, $\mathrm{E}_{\mathrm{AOE}}$, of the gas oven tests was $71.6 \mathrm{kWh} / \mathrm{yr}$ with a standard deviation of 1.1 $\mathrm{kWh} / \mathrm{yr}$. The conventional electric oven average cooking efficiency, Eff ${ }_{\mathrm{AO}}$, was $13.0 \%$ with a standard deviation of $0.2 \%$, and the average efficiency of the gas oven was $6.5 \%$ with a standard deviation of $0.1 \%$. Also, the conventional electric oven energy factor, $R_{0}$, was 0.94 with a standard deviation of 0.001 , while the energy factor of the gas oven tests was 0.053 with a standard deviation of less than 0.001 . Nearly all of the coefficients of variance for these parameters listed above were about $1 \%$, and all were below $2 \%$, inferring that repeatability from test to test was good.

Cooking Tops - The average electric cooking top efficiency, Eff $\mathrm{CT}_{\mathrm{CT}}$, was $79.8 \%$ with an estimated standard deviation of $0.4 \%$ and a corresponding average annual energy consumption, $\mathrm{E}_{\mathrm{CA}}$, of $263 \mathrm{kWh} / \mathrm{yr}$ with an estimated standard deviation of $1.2 \mathrm{kWh} / \mathrm{yr}$. The energy factor is the same as the cooking efficiency for electric cooking tops. The average gas cooking top efficiency, Eff $_{\mathrm{CT}}$, was $30.3 \%$ with an estimated standard deviation of $0.6 \%$, while the corresponding average annual cooking energy consumption, $\mathrm{E}_{\mathrm{CC}}$, was $2.42 \times 10^{6} \mathrm{Btu} / \mathrm{yr}(708 \mathrm{kWh} / \mathrm{yr})$ with an estimated standard deviation of $49.6 \times 10^{3} \mathrm{Btu} / \mathrm{yr}(14.5 \mathrm{kWh} / \mathrm{yr})$. Because there was no pilot light and the electronic ignition energy consumption was negligible, the total annual energy consumption, $\mathrm{E}_{\mathrm{CA}}$, of the gas cooking top tested is equal to the annual cooking energy consumption, $\mathrm{E}_{\mathrm{CC}}$. The gas cooking top energy factor, $R_{C A}$, of 0.303 , is equal to the cooking top efficiency. All C.V.'s of the cooking top results were $2 \%$ or lower.

Microwave Oven - The average efficiency of the microwave oven calculated from the average input and output power, measured during the tests, ranged from $54.1 \%$ to $58.6 \%$. The average and standard deviation of the efficiencies determined using the average test power is $55.8 \% \pm 1.1 \%$ (in efficiency units). The single-test efficiency based on energy, as opposed to power, ranged from $53.4 \%$ to $57.8 \%$. The average efficiency was $54.9 \%$ and the standard deviation $0.9 \%$ (in efficiency units). Comparison of the average efficiency of all tests shows that use of average power yields efficiencies about $1 \%$ (in efficiency units) higher than those based on energy. The power-based efficiency is higher because it does not include the energy consumption during the transient periods at the beginning and end of the test. The average annual energy consumption of the microwave oven was equal to $141 \mathrm{kWh} / \mathrm{yr}$ with a standard deviation of $2.39 \mathrm{kWh} / \mathrm{yr}$ based on energy. If power is used to calculate the annual energy consumption, the energy consumption would be approximately $2 \%$ lower. The energy factor and its standard deviation are the same as the efficiency divided by $100 \%$. The C.V.'s of the above results were all less than $2 \%$. 


\section{Important Issues}

This section summarizes the important issues related to the oven, cooking top, and microwave oven test procedures. The section on ovens includes the issues of exclusion of clock energy, determination of self-cleaning energy consumption, and conversion of measured gas volumes to standard gas volumes. The section on cooking tops contains the issues of measurement of electronic ignition energy consumption and exclusion of clock energy. And the section on microwave ovens consists of three issues related to the adoption of IEC test procedures, power determination, watt-hour meter versus watt meter, and magnetron cool down period. Two other issues are also discussed, non-centered test load and accounting for clock energy.

\section{Ovens}

Exclusion of clock energy - The issue of excluding the clock energy from the oven energy consumption test values when the clock is an integral part of the temperature control circuit and can not be disconnected was addressed during the 1995 public hearing on the Proposed Rule. According to the 1995 Proposed Rule, the oven clock was to be disconnected during an oven test. The clock energy would then be included in the annual clock energy consumption, which is included in the calculation of the total annual oven energy consumption. The ovens tested at NIST contained clocks that could not be disconnected, so measurements and calculations were performed to determine the impact of the clock energy consumption. Based on the tests performed, an estimate of the clock power $\mathrm{P}_{\mathrm{CL}}$ was calculated while all other energy consuming devices were off. From, $\mathrm{P}_{\mathrm{CL}}$, and the number of hours in a year, the annual energy consumption of the clock, $\mathrm{E}_{\mathrm{CL}}$, was determined for the electric and gas ovens. The average electric oven clock power was $2.9 \mathrm{~W}$ and the average gas oven clock power was $3.2 \mathrm{~W}$ corresponding to an annual energy consumption for the electric oven of $25.6 \mathrm{kWh} / \mathrm{yr}$ and $27.8 \mathrm{kWh} / \mathrm{yr}$ for the gas oven. The difference in the final values for total annual energy consumption and the energy factor for a single test was usually less than $0.1 \%$ for the electric and gas ovens. This demonstrates that, for the ovens tested, the effect of including the clock energy in the calculation of the oven efficiency, annual energy consumption and energy factor for a single test is negligible. However, the annual clock energy is roughly $7 \%$ of the total annual energy consumption for the oven tests, and can not be neglected when determining the total annual energy consumption and the energy factor.

Determination of oven operation energy consumption - The rule specifies that a positive displacement gas meter used for measuring the gas consumed by oven or cooking top gas burners shall have a resolution of $0.01 \mathrm{ft}^{3}(0.28 \mathrm{~L})$, and that if a gas flow meter is used to measure the gas consumed by a pilot light it shall have a maximum error no greater than $1.5 \%$. The inference is that positive displacement meters will be used to measure gas volumes consumed by oven and cooking top burners while positive displacement meters or gas flow meters may be used to measure pilot light gas consumption. However, the rule does not explicitly require a particular measurement device or address the issue of using flow meters to determine the energy consumption of the oven burners. A gas flow rate meter was placed in the natural gas supply line to the gas oven to investigate the possibility of its use to measure the gas energy consumption 
during cooking and self-cleaning operations. It was found that the flow rate remained relatively constant during the cooking operation, but varied during the self cleaning operation. This is because during the cooking operation only the bake burner is used, hence there is a single flow rate. However, during the self-cleaning operation both the bake and broil burners are used at different times, hence the flow rate changes. Measurements of the gas flow rate showed that it was $36 \%$ higher when the bake burner was used as oppposed to the broil burner. The extent to which other oven models switch burners during self-cleaning or other oven operations is unknown and the rule does not address the issue of changing flow rates. In view of these results, DOE should include a procedure to insure proper use of a flow meter, i.e., sampling at a frequency high enough to accurately measure changes in flow rates and durations.

Conversion of measured gas volumes to standard gas volumes - During the tests at NIST, the measured heating value of the natural gas was determined with a calorimeter sampling the gas supply line upstream of the appliances. Comparable gas energy consumption values requires that the volume of gas consumed during a test be adjusted to standard temperature and pressure. As written, the Proposed Rule states that gas volumes are to be converted to standard volumes without providing details on the instruments to be used or how these conversion are to be made. Conversion requires measurement of the local barometric pressure, and the temperature and pressure in the gas supply line, yet the rule does not address these instrument needs. The standard error of the average conversion factor for the tests at NIST was less than $1 \%$; the average value being $0.971 \mathrm{scf} / \mathrm{ft}^{3}(0.971 \mathrm{sL} / \mathrm{L})$ with a standard error of $+/-0.008 \mathrm{scf} / \mathrm{ft}^{3}$ $(0.008 \mathrm{sL} / \mathrm{L})$. However, the conversion factor is dependent on the variables mentioned above and may not always be close to unity.

\section{Cooking Tops}

Measurement of electronic ignition energy consumption - The energy consumption of the ignition devices of the gas cooking top surface units was sufficiently small that it could not be directly obtained with a watt or watt hour meter. However, the procedure for measuring energy consumption of such devices is put forth only in general terms in section 3.2.2 of the Proposed Rule "... measure any electrical energy consumed by an ignition device of a gas heating element in watt-hours $(\mathrm{kJ})$." The magnitude of energy consumption of the ignition device may determine whether or not the watt-hour meter can be used to determine this value reliably. The gas cooking top under test at NIST included ignition devices with power ratings of approximately $3 \mathrm{~W}$. Being activated for only two to four seconds per test, neither the watt-hour or watt meter could be used to accurately determine the energy consumption of the ignition device during its normal functioning period because the activation time and the amount of energy used was too small. NIST measured the electrical energy consumption of the ignition devices through a series of measurements (explained in "Discussion" Section on cooking tops) and found it to be neglegible, about $0.003 \mathrm{Wh}$ per test. For the cooking top tested, a watt meter was used to determine the ignition device energy consumption. The energy consumption of this cooking top's ignition devices can be neglected, which may indicate that measurement of electronic ignition energy consumption is unnecessary, however, without further investigation it is not known that all ignition devices are of similar design. Given the degree of difficulty required to obtain energy 
consumption of negligible proportion, it would be beneficial to explicitly prescribe a procedure for excluding or obtaining such ignition device energy consumption. The procedure should include the measurement device along with accuracy and resolution criteria to cover the energy consumption of ignition devices that consume significant amounts of energy, unless it is determined that such devices do not exist, and exclude ignition devices from the measurement requirement if their energy consumption is expected to be negligible; for example, $0.5 \%$ of the surface unit test energy.

Exclusion of clock energy - The clock of the electric cooking top has a nominal power rating of $3 \mathrm{~W}$, which, over an electric surface unit test period of $20 \mathrm{~min}$ amounts to about $1 \mathrm{Wh}$ of energy consumed. This was determined to be less than $0.5 \%$ of the cooking energy consumed during a small electric surface unit test and less than $0.3 \%$ of the cooking energy consumed during a large electric surface unit test. Since the gas cooking top surface units consumed about 2.5 times the energy of the electric cooking top, the clock energy consumption during a gas surface unit test is even less significant with respect to the surface unit cooking energy consumption. However, the annual clock energy consumption is not negligible, being about 28 $\mathrm{kWh} / \mathrm{yr}$ as demonstrated by the oven test results, and should be included in the annual energy consumption when cooking tops employ their own independent clocks. In these tests, the annual clock energy was included in the oven's total annual energy consumption and excluded from calculations involving the cooking tops. If the gas and electric cooking tops feature their own clocks, assuming an annual clock energy consumption of $28 \mathrm{kWh} / \mathrm{yr}$, the effect of including the annual clock energy consumption would increase the gas and electric cooking tops' total annual energy consumption by $4 \%$ and $11 \%$ respectively.

\section{Microwave Ovens}

Adoption of IEC Test Procedures - A major issue in this overall effort was the adoption of the IEC 705 test method by reference into the Proposed Rule as the test method for determining the efficiency of microwave ovens. The IEC method raises a number of specific issues as discussed below.

Power determination - The IEC test procedure uses a watt meter to make a single power measurement to obtain the input power consumption during the test, which is assumed to be representative of the average power consumed throughout the test. The concern with the single input power measurement is that the timing of the measurement is not well-defined. The testing at NIST showed, for the microwave oven tested, the power typically varied by $+/-2 \%$, and as much as $5 \%$ in some tests. Also, the fact that the only guidance for measuring the input power is a note in Amendment 2 of the IEC procedure stating that "the magnetron filament heat-up time is to be neglected, the measurement starting when the input current reaches $90 \%$ of its final value," creates some ambiguity regarding how the procedure is to be carried out.

Watt-hour meter versus Watt meter - One of the major differences between the DOE and IEC test procedures is the requirement of a watt-hour meter to measure energy in the DOE method and a watt meter to measure power in the IEC method. The results in Figure 18 show 
that the effect of using a watt meter in contrast to a watt-hour meter to determine efficiency (and therefore energy consumption) ranges from about $2 \%$ to $3 \%$ difference relative to the efficiency depending on the timing of the power measurement(s) and the procedure used to determine the input power. For these 21 tests, the difference in the efficicncy based on energy was $4.4 \%$ and the difference in the power-based efficiency was $6.2 \%$ with the range of efficiencies determined by watt meter being $40 \%$ greater than that of the watt-hour meter. If power measurements based on the " $90 \%$ of final current" guideline of the IEC method are used, the average of the power based efficiencies is roughly $62 \%$; about $7 \%$ greater in units of efficiency (13\% relative to the efficiencies) than the average energy factor of about $55 \%$ determined by the watt-hour meter. Comparing results from a number of watt and watt-hour meters consistently showed the use of watt meters, which neglects the transient energy, produce energy consumption results approximately $2 \%$ lower and efficiencies about $1 \%$ higher ( $2 \%$ relative to the efficiency) than the watt-hour meters.

Magnetron Cool-down Period - The IEC 705 test method requires that the temperature of a microwave oven's magnetron and supply circuit be within $9^{\circ} \mathrm{F}\left(5^{\circ} \mathrm{C}\right)$ of the ambient room air temperature before starting a test. A $6 \mathrm{~h}$ cool-down period between tests is required by the test method to insure this condition exists if the magnetron or supply circuit temperature is not measured. Tests were performed to determine the characteristic cooling curves of the magnetron and supply circuit over time. Time-series plots of the magnetron temperature showed that it takes about $1 \mathrm{~h}$ for the magnetron to cool to within $9^{\circ} \mathrm{F}\left(5^{\circ} \mathrm{C}\right)$ of its initial temperature, and after two hours the magnetron is within $2^{\circ} \mathrm{F}\left(1^{\circ} \mathrm{C}\right)$ of the initial magnetron temperature. Therefore, the $6 \mathrm{~h}$ cool-down interval between testing, required by the IEC 705 when the magnetron temperature is not known, appears to be more than sufficient for the oven tested.

Non-centered Test Load - For several years, manufacturers have employed mode stirrers, turn-tables, and variable wave guides to evenly distribute the microwaves produced for cooking in microwave ovens over the surface of foods to eliminate so-called "hot spots" in cooked foods. Without these devices the microwave density distribution within an oven is not only nonuniform, but the non-uniformity is dependent on the shape, size and material composition of the load and the vessel containing the load. In order to investigate the impact of non-centered loads, limited tests were performed with the test load placed 2 in. $(5 \mathrm{~cm})$ off center. The difference between the average efficiency and energy factor of load-centered tests and non-centered load tests based on measurements from Meter $C$ were found to be only $0.2 \%$ and $0.7 \%$ respectively. The results of similar tests based on Meters A and B do not change to any appreciable degree, verifying that when a turntable is used, the effects of a non-centered load on test results is negligible. Microwave ovens with mode stirrers and ovens without turn-tables or mode stirrers were not tested.

Accounting for Clock Energy - Currently the energy consumption of the clock for ranges, ovens and cooking tops is accounted for in the calculation of the appliances' annual clock energy consumption, whereas, the energy consumed by a microwave oven clock is not accounted for in the IEC 705 or the Proposed Rule. For appliances other than the microwave oven, the Proposed Rule consistently defines an "annual cooking energy consumption" and a "total annual energy 
consumption". The difference between these being that the annual cooking energy consumption includes energy required for cooking on an annual basis and the total annual energy consumption includes energy related to cooking and other functions of the appliance, such as, the self-cleaning function of an oven, the pilot light energy of a gas appliance, and clock energy consumption. Also, for every appliance, including the microwave oven, the Proposed Rule states that the energy factor is calculated as the ratio of the useful cooking energy output to the total energy input on a yearly basis. As a matter of consistency, and given DOE's explicitly stated definition of an energy factor, the annual clock energy could be included at least in the energy factor of the microwave oven and consideration given to including it in the total annual energy consumption. For the microwave oven tested at NIST, the total annual clock energy, is equal to about 35 $\mathrm{kWh} / \mathrm{yr}$. When added to the nominal annual energy consumption, $\mathrm{E}_{\mathrm{Mo}}$ of about $141 \mathrm{kWh} / \mathrm{yr}$, the total annual energy consumption becomes $176 \mathrm{kWh} / \mathrm{yr}$, which is an increase of $27 \%$. The inclusion of the annual clock energy in the total annual energy would significantly reduce the energy factor. 


\section{FINAL RULE Issued In 1997}

The 1995 Proposed Rule was revised and published as the Final Rule in Appendix I to Subpart B of 10 CFR part 430 titled "Uniform Test Method for Measuring the Energy Consumption of Conventional Ranges, Conventional Cooking Tops, Conventional Ovens, and Microwave Ovens" on October 3, 1997. Changes to the Proposed Rule and included in the Final Rule are discussed in Section II, titled "Discussion" of the preamble of the Final Rule. This "Discussion" section includes topics concerning cooking appliances in general: i.e.; Combined Component Efficiency, Surface Temperature Probe Tolerance, and Comments Regarding Energy Conservation Standards for Cooking Products. It also includes comments on cooktops, ranges and ovens, i.e.: Annual Useful Cooking Energy, Elimination of Continuous Flow Calorimeter, Electric Clock, Number of Self-cleaning Oven Cycles per Year, Change of Symbol Representing Number of Hours per Year - $\mathrm{H}_{\mathrm{k}}$, and an Editorial Error in Section 3.1.1 titled Conventional Oven. It also contains discussions related to microwave ovens including: Annual Useful Cooking Energy, Microwave Clock Energy, Amend the DOE Test Procedure to Reference Portions of IEC 705 and Amendment 2, Editorial Error in Section 4.1.1 on Usage of Watt Meter and Watt-hour Meter, Application of the "Agreement on Technical Barriers to Trade" requiring incorporation of IEC Standard 705, Using IEC Updates to Automatically Amend DOE's Final Test Procedure, and Incorporation by Reference of Portions of IEC 705 and Amendment 2. Changes of substance, related to the Proposed and Final Rules for kitchen appliance test methods are summarized below.

Combined Component Efficiency - The combined components section, as written into the 1978 Final Rule, contained the equations for calculating the efficiency, energy consumption and energy factor of multiple appliances combined into one appliance, that is, ranges consisting of ovens and cooking tops, microwave ovens combined with conventional ovens, and microwave ovens combined with conventional ranges. The majority of this section was eliminated from the original 1978 rule and excluded from the 1995 Proposed Rule when the validity of the usage factors involved in the calculations could not be determined. Only a portion of this section, the text defining the annual energy consumption and energy factor of combined components remains in the 1997 Final Rule. However, the Final Rule contains no equations for determining these values or the efficiencies.

Annual Useful Cooking Energy - DOE proposed to modify the annual useful cooking energy values from those specified in the 1978 procedures for each product class to reflect the changes in cooking trends in the United States. Changes in the 1995 Proposed Rule were as follows: from $47.1 \mathrm{kWh} / \mathrm{yr}(169.5 \mathrm{MJ} / \mathrm{yr})$ to $35.5 \mathrm{kWh} / \mathrm{yr}(127.8 \mathrm{MJ} / \mathrm{yr})$ for electric ovens, from $160.7 \mathrm{kBtu} / \mathrm{yr}(169.5 \mathrm{~kJ} / \mathrm{yr})$ to $124.2 \mathrm{kBtu} / \mathrm{yr}(131.0 \mathrm{MJ} / \mathrm{yr})$ for gas ovens; from $277.7 \mathrm{kWh} / \mathrm{yr}$ ( $999.7 \mathrm{MJ} / \mathrm{yr}$ ) to $209.4 \mathrm{kWh} / \mathrm{yr}(753.8 \mathrm{MJ} / \mathrm{yr})$ for electric cooktops and from $947.5 \mathrm{kBtu} / \mathrm{yr}$ (999.7 MJ/yr) to $732.5 \mathrm{kBtu} / \mathrm{yr}$ ( $772.8 \mathrm{MJ} / \mathrm{yr}$ ) for gas cooktops. When several manufacturers contended that the annual useful energy consumption for ovens, cooking tops and ranges was overstated, the Lawrence Berkeley National Laboratory (LBNL) analyzed an extensive collection of studies (listed in Final Rule). Based on the results, DOE calculated the weighted average of 
annual useful cooking energy for each cooking product and lowered the annual useful cooking energy for each class accordingly. The lower annual useful cooking energy of each cooking product is stated in the Final Rule as: $29.3 \mathrm{kWh} / \mathrm{yr}(105.5 \mathrm{MJ})$ for electric ovens, $88.8 \mathrm{kBtu} / \mathrm{yr}$ $(93.7 \mathrm{MJ})$ for gas ovens, $173.1 \mathrm{kWh} / \mathrm{yr}(623.2 \mathrm{MJ})$ for electric cooktops, and $527.6 \mathrm{kBtu} / \mathrm{yr}$ $(556.7 \mathrm{MJ})$ for gas cooktops.

The annual useful cooking energy for microwave ovens was increased in the Proposed Rule to $77.3 \mathrm{kWh} / \mathrm{yr}(278.3 \mathrm{MJ} / \mathrm{yr})$ from $34.2 \mathrm{kWh} / \mathrm{yr}(123.1 \mathrm{MJ} / \mathrm{yr})$. When several commenters contended that the Proposed Rule overstated the annual energy consumption of microwave ovens, LBNL analyzed several microwave oven studies and reported the results to DOE. Based on the data from those studies, DOE calculated a weighted average of the annual useful cooking energy for microwave ovens of $79.8 \mathrm{kWh} / \mathrm{yr}(287.3 \mathrm{MJ})$. This revised value for the annual useful cooking energy for microwave ovens is in the Final Rule.

Electric Clock - In the 1978 Final Rule and 1995 Proposed Rule, it was prescribed that any continuously operating electric clock be disconnected during oven testing, except in the case of microwave ovens. Upon finding that it is impossible to disconnect some electric clocks that are an integral part of the oven and cooktop unit temperature control circuit, several sections of the Final Rule were revised to include statements allowing the energy consumed by such clocks during appliance testing to be subtracted from the final test energy consumption value.

Surface Temperature Probe Tolerance - The error specified for the surface temperature probe was changed from $1^{\circ} \mathrm{F}\left(0.6^{\circ} \mathrm{C}\right)$ in the original rule to $0.45^{\circ} \mathrm{F}\left(0.25^{\circ} \mathrm{C}\right)$ in the Proposed Rule. $0.45^{\circ} \mathrm{F}\left(0.25^{\circ} \mathrm{C}\right)$ was considered to be too strict by commenters at the public hearing on the Proposed Rule. DOE agreed and the tolerance was changed back to $1^{\circ} \mathrm{F}\left(0.6^{\circ} \mathrm{C}\right)$ in the Final Rule.

Number of Self-cleaning Oven Cycles per Year - The number of self-cleaning oven cycles per year was specified as 11 and 7 for electric and gas ovens respectively in the Proposed Rule. Internal marketing data of some manufactures showed that the number of self-cleaning cycles should be 4 per year for both electric and gas ovens. This specification was changed in the Final Rule to 4 cleaning cycles per year for both electric and gas ovens. 


\section{APPENDIX A: Summary of Results of Conventional Electric Oven Tests}

Appendix A contains summaries of the results of the seven individual conventional electric oven tests. Each of the sheets lists the measured temperatures $T_{A}, T_{B}, T_{C}$, and $T_{D}$, and energy consumption values $E_{A}, E_{B}, E_{C}$, and $E_{D}$, along with the constants and initial values pertinent to the tests. In addition, the sheets contain the required temperature rise $\mathrm{T}$ of the test block, the resultant setpoint temperature $T_{O}$ after adding the initial block temperature $T_{I}$ to $T$, the average clock power measured throughout the test $\mathrm{P}_{C \mathrm{C}}$, and the average temperatures $\mathrm{T}_{\mathrm{AB}}$ and $\mathrm{T}_{\mathrm{CD}}$ and average energy consumption values $E_{A B}$ and $E_{C D}$ used along with $T_{O}$ to determine the test energy $E_{0}$. Each sheet then presents the steps of the analysis procedure. The first line in each group is the name of the result from the Proposed Rule, the second line is the equation used to calculate the value or a description of how the value was obtained, and the third line provides the value of the parameter. Greater detail concerning each of the results addressed can be found in the section titled "Summary of Results" in the "Oven Test Results" section of this report. 


\section{Summary of Electric Oven Test \#1}

\begin{tabular}{|ccc|c|c|}
\hline \multicolumn{2}{|c|}{ Temperature } & Energy Consumption (Wh) & Constants, and Initial Values \\
\hline \hline $\mathrm{T}_{\mathrm{A}}$ & $256.3^{\circ} \mathrm{F}$ & $124.6^{\circ} \mathrm{C}$ & $\mathrm{E}_{\mathrm{A}}=850.0$ & $\mathrm{P}_{\mathrm{CL}}=3.1 \mathrm{~W}$ \\
$\mathrm{~T}_{\mathrm{B}}$ & $275.1^{\circ} \mathrm{F}$ & $135.1^{\circ} \mathrm{C}$ & $\mathrm{E}_{\mathrm{B}}=850.2$ & $\mathrm{O}_{\mathrm{O}}=35.5 \mathrm{kWh} / \mathrm{yr}$ \\
$\mathrm{T}_{\mathrm{C}}$ & $279.1^{\circ} \mathrm{F}$ & $137.3^{\circ} \mathrm{C}$ & $\mathrm{E}_{\mathrm{C}}=920.5$ & $\mathrm{~W}_{1}=8.38 \mathrm{lb}(3.81 \mathrm{~kg})$ \\
$\mathrm{T}_{\mathrm{D}}$ & $295.9^{\circ} \mathrm{F}$ & $146.6^{\circ} \mathrm{C}$ & $\mathrm{E}_{\mathrm{D}}=920.7$ & $\mathrm{C}_{\mathrm{p}}=0.23 \mathrm{Btu} / 1 \mathrm{~b}^{\circ} \mathrm{F}\left(0.96 \mathrm{~kJ} / \mathrm{kg}^{\circ} \mathrm{C}\right)$ \\
& & & & $\mathrm{T}=202.0{ }^{\circ} \mathrm{F}\left(112 .{ }^{\circ} \mathrm{C}\right)$ \\
$\mathrm{T}_{\mathrm{AB}}$ & $257.8^{\circ} \mathrm{F}$ & $129.9{ }^{\circ} \mathrm{C}$ & $\mathrm{E}_{\mathrm{AB}}=850.1$ & $\mathrm{H}_{\mathrm{e}}=3.6 \mathrm{~kJ} / \mathrm{Wh}$ \\
$\mathrm{T}_{\mathrm{CD}}$ & $287.6{ }^{\circ} \mathrm{F}$ & $142.0^{\circ} \mathrm{C}$ & $\mathrm{E}_{\mathrm{CD}}=920.6$ & $\mathrm{H}_{\mathrm{k}}=8760 \mathrm{hr} / \mathrm{yr}$ \\
$\mathrm{T}_{\mathrm{O}}$ & $276.6{ }^{\circ} \mathrm{F}$ & $135.9{ }^{\circ} \mathrm{C}$ & & $\mathrm{C}=0.001 \mathrm{~kW} / \mathrm{W}$ \\
\hline
\end{tabular}

Test energy consumption for conventional electric oven

$$
\begin{aligned}
& \mathrm{E}_{\mathrm{O}}=\left\{\mathrm{E}_{\mathrm{AB}}+\left[\left(\left(\mathrm{T}_{\mathrm{O}}-\mathrm{T}_{\mathrm{AB}}\right) /\left(\mathrm{T}_{\mathrm{CD}}-\mathrm{T}_{\mathrm{AB}}\right)\right) \times\left(\mathrm{E}_{\mathrm{CD}}-\mathrm{E}_{\mathrm{AB}}\right)\right]\right\} \\
& \mathrm{E}_{\mathrm{O}}=885.3 \mathrm{Wh}
\end{aligned}
$$

Annual primary energy consumption

$$
\begin{aligned}
& \mathrm{E}_{\mathrm{CO}}=\left(\mathrm{E}_{\mathrm{o}} \times \mathrm{H}_{\mathrm{e}} \times \mathrm{O}_{\mathrm{o}}\right) /\left(\mathrm{W}_{1} \times \mathrm{C}_{\mathrm{p}} \times \mathrm{T}\right) \\
& \mathrm{E}_{\mathrm{CO}}=275.9 \mathrm{kWh} / \mathrm{yr}
\end{aligned}
$$

Energy consumption of self-cleaning operation

$$
\begin{aligned}
& E_{\mathrm{s}}=\text { Direct measurement of electric consumption } \\
& E_{\mathrm{s}}=6.80 \mathrm{kWh}
\end{aligned}
$$

Annual self-cleaning energy consumption for electric oven

$$
\begin{aligned}
& E_{s c}=E_{s} \times S_{e}, S_{c}=11 \\
& E_{s C}=74.8 \mathrm{kWh} / \mathrm{yr}
\end{aligned}
$$

Annual clock energy consumption

$$
\begin{aligned}
& \mathrm{E}_{\mathrm{CL}}=\mathrm{P}_{\mathrm{CL}} \times \mathrm{H}_{\mathrm{k}} \times \mathrm{C} \\
& \mathrm{E}_{\mathrm{CL}}=27.2 \mathrm{kWh} / \mathrm{yr}
\end{aligned}
$$

Total annual energy consumption of single electric oven

$$
\begin{aligned}
& \mathrm{E}_{\mathrm{AO}}=\mathrm{E}_{\mathrm{CO}}+\mathrm{E}_{\mathrm{SC}}+\mathrm{E}_{\mathrm{CL}} \\
& \mathrm{E}_{\mathrm{AO}}=377.9 \mathrm{kWh} / \mathrm{yr}
\end{aligned}
$$

Annual conventional oven cooking efficiency

$$
\begin{aligned}
& \operatorname{Eff}_{\mathrm{AO}}=\left(\mathrm{W}_{1} \times \mathrm{C}_{\mathrm{p}} \times \mathrm{T}\right) /\left(\mathrm{E}_{\mathrm{O}} \times \mathrm{H}_{\mathrm{c}}\right) \\
& \mathrm{Eff}_{\mathrm{AO}}=12.9 \%
\end{aligned}
$$

Energy factor

$$
\begin{aligned}
& R_{0}=O_{d} / E_{A O} \\
& R_{O}=0.094
\end{aligned}
$$




\section{Summary of Electric Oven Test \#2}

\begin{tabular}{|ccc|c|c|}
\hline \multicolumn{2}{|c|}{ Temperature } & Energy Consumption (Wh) & Constants, and Initial Values \\
\hline \hline $\mathrm{T}_{\mathrm{A}}$ & $252.3^{\circ} \mathrm{F}$ & $122.4^{\circ} \mathrm{C}$ & $\mathrm{E}_{\mathrm{A}}=852.9$ & $\mathrm{P}_{\mathrm{CL}}=3.0 \mathrm{~W}$ \\
$\mathrm{~T}_{\mathrm{B}}$ & $271.4^{\circ} \mathrm{F}$ & $133.0^{\circ} \mathrm{C}$ & $\mathrm{E}_{\mathrm{B}}=853.1$ & $\mathrm{O}_{\mathrm{O}}=35.5 \mathrm{kWh} / \mathrm{yr}$ \\
$\mathrm{T}_{\mathrm{C}}$ & $275.7^{\circ} \mathrm{F}$ & $135.4^{\circ} \mathrm{C}$ & $\mathrm{E}_{\mathrm{C}}=922.4$ & $\mathrm{~W}_{1}=8.38 \mathrm{lb}(3.81 \mathrm{~kg})$ \\
$\mathrm{T}_{\mathrm{D}}$ & $291.9^{\circ} \mathrm{F}$ & $144.4^{\circ} \mathrm{C}$ & $\mathrm{E}_{\mathrm{D}}=922.6$ & $\mathrm{C}_{\mathrm{p}}=0.23 \mathrm{Btu} / \mathrm{b}^{\circ} \mathrm{F}\left(0.96 \mathrm{~kJ} / \mathrm{kg}^{\circ} \mathrm{C}\right)$ \\
& & & & $\mathrm{T}=202.0{ }^{\circ} \mathrm{F}\left(12.2^{\circ} \mathrm{C}\right)$ \\
$\mathrm{T}_{\mathrm{AB}}$ & $261.9^{\circ} \mathrm{F}$ & $127.7^{\circ} \mathrm{C}$ & $\mathrm{E}_{\mathrm{AB}}=853.0$ & $\mathrm{H}_{\mathrm{e}}=3.6 \mathrm{~kJ} / \mathrm{Wh}$ \\
$\mathrm{T}_{\mathrm{CD}}$ & $283.8^{\circ} \mathrm{F}$ & $139.9{ }^{\circ} \mathrm{C}$ & $\mathrm{E}_{\mathrm{CD}}=922.5$ & $\mathrm{H}_{\mathrm{k}}=8760 \mathrm{hr} / \mathrm{yr}$ \\
$\mathrm{T}_{\mathrm{O}}$ & $273.7^{\circ} \mathrm{F}$ & $133.3^{\circ} \mathrm{C}$ & & $\mathrm{C}=0.001 \mathrm{~kW} / \mathrm{W}$ \\
\hline
\end{tabular}

Test energy consumption for conventional electric oven

$$
\begin{aligned}
& \mathrm{E}_{\mathrm{O}}=\left\{\mathrm{E}_{\mathrm{AB}}+\left[\left(\left(\mathrm{T}_{\mathrm{O}}-\mathrm{T}_{\mathrm{AB}}\right) /\left(\mathrm{T}_{\mathrm{CD}}-\mathrm{T}_{\mathrm{AB}}\right)\right) \times\left(\mathrm{E}_{\mathrm{CD}}-\mathrm{E}_{\mathrm{AB}}\right)\right]\right\} \\
& \mathrm{E}_{\mathrm{O}}=884.9 \mathrm{Wh}
\end{aligned}
$$

Annual primary energy consumption

$$
\begin{aligned}
& E_{C O}=\left(E_{O} \times H_{e} \times O_{O}\right) /\left(W_{1} \times C_{p} \times T\right) \\
& E_{C O}=275.7 \mathrm{kWh} / y r
\end{aligned}
$$

Energy consumption of self-cleaning operation

$$
\begin{aligned}
& E_{\mathrm{s}}=\text { Direct measurement of electric consumption } \\
& E_{\mathrm{S}}=6.79 \mathrm{kWh}
\end{aligned}
$$

Annual self-cleaning energy consumption for electric oven

$$
\begin{aligned}
& E_{S C}=E_{S} \times S_{e}, S_{e}=11 \\
& E_{S C}=74.7 \mathrm{kWh} / \mathrm{yr}
\end{aligned}
$$

Annual clock energy consumption

$$
\begin{aligned}
& \mathrm{E}_{\mathrm{CL}}=\mathrm{P}_{\mathrm{CL}} \times \mathrm{H}_{\mathrm{k}} \times \mathrm{C} \\
& \mathrm{E}_{\mathrm{CL}}=25.7 \mathrm{kWh} / \mathrm{yr}
\end{aligned}
$$

Total annual energy consumption of single electric oven

$$
\begin{aligned}
& \mathrm{E}_{\mathrm{AO}}=\mathrm{E}_{\mathrm{CO}}+\mathrm{E}_{\mathrm{SC}}+\mathrm{E}_{\mathrm{CL}} \\
& \mathrm{E}_{\mathrm{AO}}=376.1 \mathrm{kWh} / \mathrm{yr}
\end{aligned}
$$

Annual conventional oven cooking efficiency

$$
\begin{aligned}
& \operatorname{Eff}_{A O}=\left(W_{1} \times C_{p} \times T\right) /\left(E_{O} \times H_{e}\right) \\
& \text { Eff }_{A O}=12.9 \%
\end{aligned}
$$

Energy factor

$$
\begin{aligned}
& R_{\mathrm{O}}=\mathrm{O}_{\mathrm{O}} / \mathrm{E}_{\mathrm{AO}} \\
& \mathrm{R}_{\mathrm{O}}=0.094
\end{aligned}
$$


Summary of Electric Oven Test \#3

\begin{tabular}{|ccc|c|c|}
\hline \multicolumn{2}{|c|}{ Temperature } & Energy Consumption (Wh) & Constants, and Initial Values \\
\hline \hline $\mathrm{T}_{\mathrm{A}}$ & $255.4^{\circ} \mathrm{F}$ & $124.1^{\circ} \mathrm{C}$ & $\mathrm{E}_{\mathrm{A}}=862.5$ & $\mathrm{P}_{\mathrm{CL}}=3.0 \mathrm{~W}$ \\
$\mathrm{~T}_{\mathrm{B}}$ & $274.8^{\circ} \mathrm{F}$ & $134.9^{\circ} \mathrm{C}$ & $\mathrm{E}_{\mathrm{B}}=862.7$ & $\mathrm{O}_{\mathrm{O}}=35.5 \mathrm{kWh} / \mathrm{yr}$ \\
$\mathrm{T}_{\mathrm{C}}$ & $278.6^{\circ} \mathrm{F}$ & $137.0^{\circ} \mathrm{C}$ & $\mathrm{E}_{\mathrm{C}}=932.8$ & $\mathrm{~W}_{\mathrm{l}}=8.38 \mathrm{lb}(3.81 \mathrm{~kg})$ \\
$\mathrm{T}_{\mathrm{D}}$ & $294.8^{\circ} \mathrm{F}$ & $146.0^{\circ} \mathrm{C}$ & $\mathrm{E}_{\mathrm{D}}=933.1$ & $\mathrm{C}_{\mathrm{P}}=0.23 \mathrm{Btu} / 1 \mathrm{~b}^{\circ} \mathrm{F}\left(0.96 \mathrm{~kJ} / \mathrm{kg}^{\circ} \mathrm{C}\right)$ \\
& & & & $\mathrm{T}=202.0^{\circ} \mathrm{F}\left(112.2^{\circ} \mathrm{C}\right)$ \\
$\mathrm{T}_{\mathrm{AB}}$ & $265.1^{\circ} \mathrm{F}$ & $129.5^{\circ} \mathrm{C}$ & $\mathrm{E}_{\mathrm{AB}}=862.6$ & $\mathrm{H}_{\mathrm{e}}=3.6 \mathrm{~kJ} / \mathrm{Wh}$ \\
$\mathrm{T}_{\mathrm{CD}}$ & $286.7^{\circ} \mathrm{F}$ & $141.5^{\circ} \mathrm{C}$ & $\mathrm{E}_{\mathrm{CD}}=933.0$ & $\mathrm{H}_{\mathrm{k}}=8760 \mathrm{hr} / \mathrm{yr}$ \\
$\mathrm{T}_{\mathrm{O}}$ & $274.5^{\circ} \mathrm{F}$ & $134.7^{\circ} \mathrm{C}$ & & $\mathrm{C}=0.001 \mathrm{~kW} / \mathrm{W}$ \\
\hline
\end{tabular}

Test energy consumption for conventional electric oven

$$
\begin{aligned}
& E_{o}=\left\{E_{A B}+\left[\left(\left(T_{O}-T_{A B}\right) /\left(T_{C D}-T_{A B}\right)\right) \times\left(E_{C D}-E_{A B}\right)\right]\right\} \\
& E_{O}=893.1 \mathrm{Wh}
\end{aligned}
$$

Annual primary energy consumption

$$
\begin{aligned}
& \mathrm{E}_{\mathrm{co}}=\left(\mathrm{E}_{\mathrm{o}} \times \mathrm{H}_{\mathrm{e}} \times \mathrm{O}_{\mathrm{o}}\right) /\left(\mathrm{W}_{1} \times \mathrm{C}_{\mathrm{p}} \times \mathrm{T}\right) \\
& \mathrm{E}_{\mathrm{co}}=278.3 \mathrm{kWh} / \mathrm{yr}
\end{aligned}
$$

Energy consumption of self-cleaning operation

$$
\begin{aligned}
& E_{s}=\text { Direct measurement of electric consumption } \\
& E_{s}=6.97 \mathrm{kWh}
\end{aligned}
$$

Annual self-cleaning energy consumption for electric oven

$$
\begin{aligned}
& E_{S C}=E_{S} \times S_{e}, S_{e}=11 \\
& E_{S C}=76.7 \mathrm{kWh} / \mathrm{yr}
\end{aligned}
$$

Annual clock energy consumption

$$
\begin{aligned}
& \mathrm{E}_{\mathrm{CL}}=\mathrm{P}_{\mathrm{CL}} \times \mathrm{H}_{\mathrm{k}} \times \mathrm{C} \\
& \mathrm{E}_{\mathrm{CL}}=26.3 \mathrm{kWh} / \mathrm{yr}
\end{aligned}
$$

Total annual energy consumption of single electric oven

$$
\begin{aligned}
& E_{\mathrm{AO}}=\mathrm{E}_{\mathrm{CO}}+\mathrm{E}_{\mathrm{SC}}+\mathrm{E}_{\mathrm{CL}} \\
& \mathrm{E}_{\mathrm{AO}}=381.3 \mathrm{kWh} / \mathrm{yr}
\end{aligned}
$$

Annual conventional oven cooking efficiency

$$
\begin{aligned}
& \mathrm{Eff}_{\mathrm{AO}}=\left(\mathrm{W}_{1} \times \mathrm{C}_{\mathrm{p}} \times \mathrm{T}\right) /\left(\mathrm{E}_{\mathrm{O}} \times \mathrm{H}_{\mathrm{e}}\right) \\
& \operatorname{Eff}_{\mathrm{AO}}=12.8 \%
\end{aligned}
$$

Energy factor

$$
\begin{aligned}
& R_{\mathrm{O}}=\mathrm{O}_{\sigma} / \mathrm{E}_{\mathrm{AO}} \\
& \mathrm{R}_{\mathrm{O}}=0.093
\end{aligned}
$$




\section{Summary of Electric Oven Test \#4}

\begin{tabular}{|ccc|c|c|}
\hline \multicolumn{2}{|c|}{ Temperature } & Energy Consumption (Wh) & Constants, and Initial Values \\
\hline \hline $\mathrm{T}_{\mathrm{A}}$ & $250.5^{\circ} \mathrm{F}$ & $121.4^{\circ} \mathrm{C}$ & $\mathrm{E}_{\mathrm{A}}=849.9$ & $\mathrm{P}_{\mathrm{CL}}=2.8 \mathrm{~W}$ \\
$\mathrm{~T}_{\mathrm{B}}$ & $268.9^{\circ} \mathrm{F}$ & $131.6^{\circ} \mathrm{C}$ & $\mathrm{E}_{\mathrm{B}}=850.1$ & $\mathrm{O}_{\mathrm{O}}=35.5 \mathrm{kWh} / \mathrm{yr}$ \\
$\mathrm{T}_{\mathrm{C}}$ & $272.8^{\circ} \mathrm{F}$ & $133.8^{\circ} \mathrm{C}$ & $\mathrm{E}_{\mathrm{C}}=921.0$ & $\mathrm{~W}_{1}=8.38 \mathrm{lb}(3.81 \mathrm{~kg})$ \\
$\mathrm{T}_{\mathrm{D}}$ & $289.9^{\circ} \mathrm{F}$ & $143.3^{\circ} \mathrm{C}$ & $\mathrm{E}_{\mathrm{D}}=921.2$ & $\mathrm{C}_{\mathrm{p}}=0.23 \mathrm{Btu} / \mathrm{b}^{\circ} \mathrm{F}\left(0.96 \mathrm{~kJ} / \mathrm{kg}^{\circ} \mathrm{C}\right)$ \\
& & & & $\mathrm{T}=202.0{ }^{\circ} \mathrm{F}\left(112.2{ }^{\circ} \mathrm{C}\right)$ \\
$\mathrm{T}_{\mathrm{AB}}$ & $259.7^{\circ} \mathrm{F}$ & $126.5^{\circ} \mathrm{C}$ & $\mathrm{E}_{\mathrm{AB}}=850.0$ & $\mathrm{H}_{\mathrm{c}}=3.6 \mathrm{~kJ} / \mathrm{Wh}$ \\
$\mathrm{T}_{\mathrm{CD}}$ & $281.5^{\circ} \mathrm{F}$ & $138.6{ }^{\circ} \mathrm{C}$ & $\mathrm{E}_{\mathrm{CD}}=921.1$ & $\mathrm{H}_{\mathrm{k}}=8760 \mathrm{hr} / \mathrm{yr}$ \\
$\mathrm{T}_{\mathrm{O}}$ & $274.5^{\circ} \mathrm{F}$ & $134.7^{\circ} \mathrm{C}$ & & $\mathrm{C}=0.001 \mathrm{~kW} / \mathrm{W}$ \\
\hline
\end{tabular}

Test energy consumption for conventional electric oven

$$
\begin{aligned}
& E_{O}=\left\{E_{A B}+\left[\left(\left(T_{O}-T_{A B}\right) /\left(T_{C D}-T_{A B}\right)\right) \times\left(E_{C D}-E_{A B}\right)\right]\right\} \\
& E_{O}=898.4 \mathrm{Wh}
\end{aligned}
$$

Annual primary energy consumption

$$
\begin{aligned}
& E_{c o}=\left(E_{o} \times H_{c} \times O_{o}\right) /\left(W_{1} \times C_{p} \times T\right) \\
& E_{c o}=280.0 \mathrm{kWh} / \mathrm{yr}
\end{aligned}
$$

Energy consumption of self-cleaning operation

$$
\begin{aligned}
& E_{s}=\text { Direct measurement of electric consumption } \\
& E_{S}=6.80 \mathrm{kWh}
\end{aligned}
$$

Annual self-cleaning energy consumption for electric oven

$$
\begin{aligned}
& E_{S C}=E_{S} \times S_{e}, S_{e}=11 \\
& E_{S C}=74.8 \mathrm{kWh} / \mathrm{yr}
\end{aligned}
$$

Annual clock energy consumption

$$
\begin{aligned}
& E_{C L}=P_{C L} \times H_{k} \times C \\
& E_{C L}=24.3 \mathrm{kWh} / \mathrm{yr}
\end{aligned}
$$

Total annual energy consumption of single electric oven

$$
\begin{aligned}
& \mathrm{E}_{\mathrm{AO}}=\mathrm{E}_{\mathrm{CO}}+\mathrm{E}_{\mathrm{SC}}+\mathrm{E}_{\mathrm{CL}} \\
& \mathrm{E}_{\mathrm{AO}}=379.0 \mathrm{kWh} / \mathrm{yr}
\end{aligned}
$$

Annual conventional oven cooking efficiency

$$
\begin{aligned}
& \mathrm{Eff}_{A O}=\left(W_{1} \times C_{p} \times T\right) /\left(E_{O} \times H_{e}\right) \\
& \operatorname{Eff}_{A O}=12.7 \%
\end{aligned}
$$

Energy factor

$$
\begin{aligned}
& R_{O}=O_{O} / E_{A O} \\
& R_{0}=0.094
\end{aligned}
$$




\section{Summary of Electric Oven Test \#5}

\begin{tabular}{|ccc|c|c|}
\hline \multicolumn{2}{|c|}{ Temperature } & Energy Consumption (Wh) & Constants, and Initial Values \\
\hline \hline $\mathrm{T}_{\mathrm{A}}$ & $271.9^{\circ} \mathrm{F}$ & $133.0^{\circ} \mathrm{C}$ & $\mathrm{E}_{\mathrm{A}}=885.2$ & $\mathrm{P}_{\mathrm{CL}}=2.8 \mathrm{~W}$ \\
$\mathrm{~T}_{\mathrm{B}}$ & $289.0^{\circ} \mathrm{F}$ & $142.8^{\circ} \mathrm{C}$ & $\mathrm{E}_{\mathrm{B}}=887.0$ & $\mathrm{O}_{\mathrm{O}}=35.5 \mathrm{kWh} / \mathrm{yr}$ \\
$\mathrm{T}_{\mathrm{C}}$ & $307 .{ }^{\circ} \mathrm{F}$ & $152.9^{\circ} \mathrm{C}$ & $\mathrm{E}_{\mathrm{C}}=981.2$ & $\mathrm{~W}_{\mathrm{l}}=8.38 \mathrm{lb}(3.81 \mathrm{~kg})$ \\
$\mathrm{T}_{\mathrm{D}}$ & $311.4^{\circ} \mathrm{F}$ & $155.2^{\circ} \mathrm{C}$ & $\mathrm{E}_{\mathrm{D}}=983.0$ & $\mathrm{C}_{\mathrm{p}}=0.23 \mathrm{Btu} / \mathrm{lb}{ }^{\circ} \mathrm{F}\left(0.96 \mathrm{~kJ} / \mathrm{kg}^{\circ} \mathrm{C}\right)$ \\
& & & & $\mathrm{T}=112 .{ }^{\circ} \mathrm{C}$ \\
$\mathrm{T}_{\mathrm{AB}}$ & $280.4^{\circ} \mathrm{F}$ & $138.0^{\circ} \mathrm{C}$ & $\mathrm{E}_{\mathrm{AB}}=886.1$ & $\mathrm{H}_{\mathrm{c}}=3.6 \mathrm{~kJ} / \mathrm{Wh}$ \\
$\mathrm{T}_{\mathrm{CD}}$ & $309.4{ }^{\circ} \mathrm{F}$ & $154.1{ }^{\circ} \mathrm{C}$ & $\mathrm{E}_{\mathrm{CD}}=982.1$ & $\mathrm{H}_{\mathrm{k}}=8760 \mathrm{hr} / \mathrm{yr}$ \\
$\mathrm{T}_{\mathrm{O}}$ & $273.4^{\circ} \mathrm{F}$ & $134.1{ }^{\circ} \mathrm{C}$ & & $\mathrm{C}=0.001 \mathrm{~kW} / \mathrm{W}$ \\
\hline
\end{tabular}

Test energy consumption for conventional electric oven

$$
\begin{aligned}
& \mathrm{E}_{\mathrm{O}}=\left\{\mathrm{E}_{\mathrm{AB}}+\left[\left(\left(\mathrm{T}_{\mathrm{O}}-\mathrm{T}_{\mathrm{AB}}\right) /\left(\mathrm{T}_{\mathrm{CD}}-\mathrm{T}_{\mathrm{AB}}\right)\right) \times\left(\mathrm{E}_{\mathrm{CD}}-\mathrm{E}_{\mathrm{AB}}\right)\right]\right\} \\
& \mathrm{E}_{\mathrm{O}}=862.4 \mathrm{Wh}
\end{aligned}
$$

Annual primary energy consumption

$$
\begin{aligned}
& E_{c o}=\left(E_{O} \times H_{c} \times O_{o}\right) /\left(W_{1} \times C_{p} \times T\right) \\
& E_{C O}=268.7 \mathrm{kWh} / y r
\end{aligned}
$$

Energy consumption of self-cleaning operation

$$
\begin{aligned}
& E_{S}=\text { Direct measurement of electric consumption } \\
& E_{S}=6.97 \mathrm{kWh}
\end{aligned}
$$

Annual self-cleaning energy consumption for electric oven

$$
\begin{aligned}
& E_{S C}=E_{s} \times S_{e}, S_{e}=11 \\
& E_{S C}=76.7 \mathrm{kWh} / \mathrm{yr}
\end{aligned}
$$

Annual clock energy consumption

$$
\begin{aligned}
& E_{\mathrm{CL}}=\mathrm{P}_{\mathrm{CL}} \times \mathrm{H}_{\mathrm{k}} \times \mathrm{C} \\
& \mathrm{E}_{\mathrm{CL}}=24.4 \mathrm{kWh} / \mathrm{yr}
\end{aligned}
$$

Total annual energy consumption of single electric oven

$$
\begin{aligned}
& \mathrm{E}_{\mathrm{AO}}=\mathrm{E}_{\mathrm{CO}}+\mathrm{E}_{\mathrm{SC}}+\mathrm{E}_{\mathrm{CL}} \\
& \mathrm{E}_{\mathrm{AO}}=369.8 \mathrm{kWh} / \mathrm{yr}
\end{aligned}
$$

Annual conventional oven cooking efficiency

$$
\begin{aligned}
& \mathrm{Eff}_{\mathrm{AO}}=\left(\mathrm{W}_{1} \times \mathrm{C}_{\mathrm{p}} \times \mathrm{T}\right) /\left(\mathrm{E}_{\mathrm{O}} \times \mathrm{H}_{\mathrm{e}}\right) \\
& \mathrm{Eff}_{\mathrm{AO}}=13.2 \%
\end{aligned}
$$

Energy factor

$$
\begin{aligned}
& R_{\mathrm{O}}=\mathrm{O}_{\mathrm{O}} / \mathrm{E}_{\mathrm{AO}} \\
& \mathrm{R}_{\mathrm{O}}=0.096
\end{aligned}
$$


Summary of Electric Oven Test \#6

\begin{tabular}{|ccc|c|c|}
\hline \multicolumn{2}{|c|}{ Temperature } & Energy Consumption (Wh) & Constants, and Initial Values \\
\hline \hline $\mathrm{T}_{\mathrm{A}}$ & $270.1^{\circ} \mathrm{F}$ & $132 .{ }^{\circ} \mathrm{C}$ & $\mathrm{E}_{\mathrm{A}}=882.2$ & $\mathrm{P}_{\mathrm{CL}}=3.0 \mathrm{~W}$ \\
$\mathrm{~T}_{\mathrm{B}}$ & $287.4^{\circ} \mathrm{F}$ & $141.9^{\circ} \mathrm{C}$ & $\mathrm{E}_{\mathrm{B}}=884.0$ & $\mathrm{O}_{\mathrm{O}}=35.5 \mathrm{kWh} / \mathrm{yr}$ \\
$\mathrm{T}_{\mathrm{C}}$ & $304.9^{\circ} \mathrm{F}$ & $151.6^{\circ} \mathrm{C}$ & $\mathrm{E}_{\mathrm{C}}=973.9$ & $\mathrm{~W}_{1}=8.38 \mathrm{lb}(3.81 \mathrm{~kg})$ \\
$\mathrm{T}_{\mathrm{D}}$ & $309.2^{\circ} \mathrm{F}$ & $154.0^{\circ} \mathrm{C}$ & $\mathrm{E}_{\mathrm{D}}=976.1$ & $\mathrm{C}_{\mathrm{p}}=0.23 \mathrm{Btu} / \mathrm{lb}{ }^{\circ} \mathrm{F}\left(0.96 \mathrm{~kJ} / \mathrm{kg}^{\circ} \mathrm{C}\right)$ \\
& & & & $\mathrm{T}=202.0^{\circ} \mathrm{F}\left(112.2{ }^{\circ} \mathrm{C}\right)$ \\
$\mathrm{T}_{\mathrm{AB}}$ & $278.8^{\circ} \mathrm{F}$ & $137.1{ }^{\circ} \mathrm{C}$ & $\mathrm{E}_{\mathrm{AB}}=883.1$ & $\mathrm{H}_{\mathrm{e}}=3.6 \mathrm{~kJ} / \mathrm{Wh}$ \\
$\mathrm{T}_{\mathrm{CD}}$ & $307.0^{\circ} \mathrm{F}$ & $152.8^{\circ} \mathrm{C}$ & $\mathrm{E}_{\mathrm{CD}}=975.0$ & $\mathrm{H}_{\mathrm{k}}=8760 \mathrm{hr} / \mathrm{yr}$ \\
$\mathrm{T}_{\mathrm{O}}$ & $274.3^{\circ} \mathrm{F}$ & $134.6^{\circ} \mathrm{C}$ & & $\mathrm{C}=0.001 \mathrm{~kW} / \mathrm{W}$ \\
\hline
\end{tabular}

Test energy consumption for conventional electric oven

$$
\begin{aligned}
& E_{O}=\left\{E_{A B}+\left[\left(\left(T_{O}-T_{A B}\right) /\left(T_{C D}-T_{A B}\right)\right) \times\left(E_{C D}-E_{A B}\right)\right]\right\} \\
& E_{O}=868.5 \mathrm{Wh}
\end{aligned}
$$

Annual primary energy consumption

$$
\begin{aligned}
& \mathrm{E}_{\mathrm{CO}}=\left(\mathrm{E}_{\mathrm{O}} \times \mathrm{H}_{\mathrm{c}} \times \mathrm{O}_{\mathrm{o}}\right) /\left(\mathrm{W}_{1} \times \mathrm{C}_{\mathrm{p}} \times \mathrm{T}\right) \\
& \mathrm{E}_{\mathrm{CO}}=270.6 \mathrm{kWh} / \mathrm{yr}
\end{aligned}
$$

Energy consumption of self-cleaning operation

$$
\begin{aligned}
& E_{\mathrm{s}}=\text { Direct measurement of electric consumption } \\
& E_{\mathrm{s}}=6.98 \mathrm{kWh}
\end{aligned}
$$

Annual self-cleaning energy consumption for electric oven

$$
\begin{aligned}
& \mathrm{E}_{\mathrm{SC}}=\mathrm{E}_{\mathrm{s}} \times \mathrm{S}_{\mathrm{e}}, \mathrm{S}_{\mathrm{e}}=11 \\
& \mathrm{E}_{\mathrm{SC}}=76.8 \mathrm{kWh} / \mathrm{yr}
\end{aligned}
$$

Annual clock energy consumption

$$
\begin{aligned}
& E_{\mathrm{CL}}=\mathrm{P}_{\mathrm{CL}} \times \mathrm{H}_{\mathrm{k}} \times \mathrm{C} \\
& \mathrm{E}_{\mathrm{CL}}=26.3 \mathrm{kWh} / \mathrm{yr}
\end{aligned}
$$

Total annual energy consumption of single electric oven

$\mathrm{E}_{\mathrm{AO}}=\mathrm{E}_{\mathrm{CO}}+\mathrm{E}_{\mathrm{SC}}+\mathrm{E}_{\mathrm{CL}}$

$\mathrm{E}_{\mathrm{AO}}=373.7 \mathrm{kWh} / \mathrm{yr}$

Annual conventional oven cooking efficiency

$$
\begin{aligned}
& \operatorname{Eff}_{A O}=\left(W_{1} \times C_{p} \times T\right) /\left(E_{0} \times H_{e}\right) \\
& \operatorname{Eff}_{A O}=13.1 \%
\end{aligned}
$$

Energy factor

$$
\begin{aligned}
& R_{\mathrm{O}}=\mathrm{O}_{\mathrm{O}} / \mathrm{E}_{\mathrm{AO}} \\
& \mathrm{R}_{\mathrm{O}}=0.095
\end{aligned}
$$


Summary of Electric Oven Test \#7

\begin{tabular}{|ccc|c|c|}
\hline \multicolumn{2}{|c|}{ Temperature } & Energy Consumption (Wh) & Constants, and Initial Values \\
\hline \hline $\mathrm{T}_{\mathrm{A}}$ & $271.4^{\circ} \mathrm{F}$ & $133.0^{\circ} \mathrm{C}$ & $\mathrm{E}_{\mathrm{A}}=890.6$ & $\mathrm{P}_{\mathrm{CL}}=3.0 \mathrm{~W}$ \\
$\mathrm{~T}_{\mathrm{B}}$ & $288.3^{\circ} \mathrm{F}$ & $142.4^{\circ} \mathrm{C}$ & $\mathrm{E}_{\mathrm{B}}=891.8$ & $\mathrm{O}_{\mathrm{O}}=35.5 \mathrm{kWh} / \mathrm{yr}$ \\
$\mathrm{T}_{\mathrm{C}}$ & $306.3^{\circ} \mathrm{F}$ & $152.4^{\circ} \mathrm{C}$ & $\mathrm{E}_{\mathrm{C}}=985.8$ & $\mathrm{~W}_{1}=8.38 \mathrm{lb}(3.81 \mathrm{~kg})$ \\
$\mathrm{T}_{\mathrm{D}}$ & $309.9^{\circ} \mathrm{F}$ & $154.8^{\circ} \mathrm{C}$ & $\mathrm{E}_{\mathrm{D}}=985.9$ & $\mathrm{C}_{\mathrm{p}}=0.23 \mathrm{Btu} / 1 \mathrm{~b}^{\circ} \mathrm{F}\left(0.96 \mathrm{~kJ} / \mathrm{kg}^{\circ} \mathrm{C}\right)$ \\
& & & & $\mathrm{T}=202.0^{\circ} \mathrm{F}\left(112 .{ }^{\circ} \mathrm{C}\right)$ \\
$\mathrm{T}_{\mathrm{AB}}$ & $279.9^{\circ} \mathrm{F}$ & $137.7^{\circ} \mathrm{C}$ & $\mathrm{E}_{\mathrm{AB}}=891.2$ & $\mathrm{H}_{\mathrm{e}}=3.6 \mathrm{~kJ} / \mathrm{Wh}$ \\
$\mathrm{T}_{\mathrm{CD}}$ & $308.5^{\circ} \mathrm{F}$ & $153.6^{\circ} \mathrm{C}$ & $\mathrm{E}_{\mathrm{CD}}=985.8$ & $\mathrm{H}_{\mathrm{k}}=8760 \mathrm{hr} / \mathrm{yr}$ \\
$\mathrm{T}_{\mathrm{O}}$ & $272.5^{\circ} \mathrm{F}$ & $133.6^{\circ} \mathrm{C}$ & & $\mathrm{C}=0.001 \mathrm{~kW} / \mathrm{W}$ \\
\hline
\end{tabular}

Test energy consumption for conventional electric oven

$$
\begin{aligned}
& E_{O}=\left\{E_{A B}+\left[\left(\left(T_{O}-T_{A B}\right) /\left(T_{C D}-T_{A B}\right)\right) \times\left(E_{C D}-E_{A B}\right)\right]\right\} \\
& E_{O}=866.6 \mathrm{Wh}
\end{aligned}
$$

Annual primary energy consumption

$$
\begin{aligned}
& \mathrm{E}_{\mathrm{CO}}=\left(\mathrm{E}_{\mathrm{o}} \times \mathrm{H}_{\mathrm{e}} \times \mathrm{O}_{\mathrm{o}}\right) /\left(\mathrm{W}_{1} \times \mathrm{C}_{\mathrm{p}} \times \mathrm{T}\right) \\
& \mathrm{E}_{\mathrm{CO}}=270.1 \mathrm{kWh} / \mathrm{yr}
\end{aligned}
$$

Energy consumption of self-cleaning operation

$$
\begin{aligned}
& E_{\mathrm{s}}=\text { Direct measurement of electric consumption } \\
& E_{\mathrm{S}}=7.01 \mathrm{kWh}
\end{aligned}
$$

Annual self-cleaning energy consumption for electric oven

$$
\begin{aligned}
& E_{S C}=E_{S} \times S_{e}, S_{e}=11 \\
& E_{S C}=77.1 \mathrm{kWh} / \mathrm{yr}
\end{aligned}
$$

Annual clock energy consumption

$$
\begin{aligned}
& E_{\mathrm{CL}}=\mathrm{P}_{\mathrm{CL}} \times \mathrm{H}_{\mathrm{k}} \times \mathrm{C} \\
& E_{\mathrm{CL}}=25.9 \mathrm{kWh} / \mathrm{yr}
\end{aligned}
$$

Total annual energy consumption of single electric oven

$$
\begin{aligned}
& E_{A O}=E_{C O}+E_{S C}+E_{C L} \\
& E_{A O}=373.1 \mathrm{kWh} / \mathrm{yr}
\end{aligned}
$$

Annual conventional oven cooking efficiency

$$
\begin{aligned}
& \text { Eff }_{A O}=\left(W_{1} \times C_{p} \times T\right) /\left(E_{O} \times H_{e}\right) \\
& \operatorname{Eff}_{A O}=13.2 \%
\end{aligned}
$$

Energy factor

$$
\begin{aligned}
& \mathrm{R}_{\mathrm{O}}=\mathrm{O}_{\mathrm{O}} / \mathrm{E}_{\mathrm{AO}} \\
& \mathrm{R}_{\mathrm{O}}=0.095
\end{aligned}
$$




\section{APPENDIX B: Summary of Results of Conventional Gas Oven Tests}

Appendix $B$ contains summaries of the results of the five individual conventional gas oven tests. Each of the sheets lists the measured temperatures $T_{A}, T_{B}, T_{C}$, and $T_{D}$, and energy consumption values $E_{A}, E_{B}, E_{C}$, and $E_{D}$, along with the constants and initial values pertinent to the tests. In addition, the sheets contain the required temperature rise $T$ of the test block, the resultant setpoint temperature $T_{0}$ after adding the initial block temperature $T_{1}$ to $T$, the average clock power measured throughout the test $P_{C L}$, and the average temperatures $T_{A B}$ and $T_{C D}$ and average energy consumption values $\mathrm{E}_{\mathrm{AB}}$ and $\mathrm{E}_{\mathrm{CD}}$ used along with $\mathrm{T}_{\mathrm{O}}$ to determine the test energy $\mathrm{E}_{\mathrm{O}}$. In addition, the gas volume consumed and the heating value of the natural gas used during testing is included. Each sheet then presents the steps of the data analysis procedures. The first line in each group is the name of the result from the Proposed Rule, the second line is the equation used to calculate the value or a description of how the value was obtained, and the third line provides the value of the parameter. Greater detail concerning each of the results addressed can be found in the section titled "Summary of Results" in the "Oven Test Results" section of this report. 
Summary of Gas Conventional Oven Test \#1

\begin{tabular}{|c|c|c|c|c|c|c|c|c|c|c|c|}
\hline \multicolumn{3}{|c|}{ Temperature } & \multicolumn{3}{|c|}{$\begin{array}{c}\text { Energy } \\
\text { Consumption }\end{array}$} & \multicolumn{3}{|c|}{ Gas Volume } & \multicolumn{3}{|c|}{ Constants, and Initial Values } \\
\hline & $\left({ }^{\circ} \mathrm{F}\right)$ & $\left({ }^{\circ} \mathrm{C}\right)$ & & (Btu) & (Wh) & & $\left(\mathrm{ft}^{3}\right)$ & (L) & & & \\
\hline $\mathrm{T}_{\mathrm{A}}$ & 269.4 & 131.9 & $\mathrm{E}_{\mathrm{A}}$ & 5653 & 1657 & $\mathrm{~V}_{\mathrm{A}}$ & 5.50 & 155.9 & $\mathrm{P}_{\mathrm{CL}}$ & $0.9 \mathrm{Btu}$ & $3.1 \mathrm{~W}$ \\
\hline $\mathrm{T}_{\mathrm{B}}$ & 278.7 & 137.1 & $\mathrm{E}_{\mathrm{B}}$ & 5653 & 1657 & $\mathrm{~V}_{\mathrm{B}}$ & 5.50 & 155.9 & $\mathrm{O}_{\mathrm{o}}$ & $124,200 \mathrm{Btu} / \mathrm{yr}$ & $36.4 \mathrm{KWh} / \mathrm{yr}$ \\
\hline $\mathrm{T}_{\mathrm{C}}$ & 281.9 & 138.8 & $E_{C}$ & 6044 & 1771 & $\mathrm{~V}_{\mathrm{C}}$ & 5.88 & 166.7 & $\mathrm{~W}_{1}$ & $8.38 \mathrm{lb}$ & $3.81 \mathrm{~kg}$ \\
\hline $\mathrm{T}_{\mathrm{D}}$ & 290.7 & 143.7 & $\mathrm{E}_{\mathrm{D}}$ & 6044 & 1771 & $\mathrm{~V}_{\mathrm{D}}$ & 5.88 & 166.7 & $C_{p}$ & $0.23 \mathrm{Btu} / \mathrm{lb}^{\circ} \mathrm{F}$ & $0.96 \mathrm{~kJ} / \mathrm{kg}^{\circ} \mathrm{C}$ \\
\hline & & & & & & & & & $\mathrm{T}$ & $202.0^{\circ} \mathrm{F}$ & $112.2^{\circ} \mathrm{C}$ \\
\hline $\mathrm{T}_{\mathrm{AB}}$ & 274.0 & 134.5 & $\mathrm{E}_{\mathrm{AB}}$ & 5653 & 1657 & $\mathrm{~V}_{\mathrm{AB}}$ & 5.50 & 155.9 & $\mathrm{H}_{\mathrm{e}}$ & 3.41 Btu/Wh & $3.6 \mathrm{KJ} / \mathrm{Wh}$ \\
\hline $\mathrm{T}_{\mathrm{CD}}$ & 286.3 & 141.3 & $\mathrm{E}_{\mathrm{CD}}$ & 6044 & 1771 & $\mathrm{~V}_{\mathrm{CD}}$ & 5.88 & 166.7 & $\mathrm{H}_{\mathrm{n}}$ & $1027 \mathrm{Btu} / \mathrm{ft}^{3}$ & $10.6 \mathrm{Wh} / \mathrm{L}$ \\
\hline$T_{0}$ & 276.6 & 276.6 & & & & & & & $\mathrm{H}_{\mathrm{k}}$ & $8760 \mathrm{hr} / \mathrm{yr}$ & $\mathrm{C}=0.001 \mathrm{~kW} / \mathrm{W}$ \\
\hline
\end{tabular}

Conventional gas oven test energy consumption

$$
\begin{array}{lc}
E_{O}=E_{A B}+\left[\left(\left(T_{O}-T_{A B}\right) /\left(T_{C D}=T_{A B}\right)\right) \times\left(E_{C D}-E_{A B}\right)\right] \\
E_{0}=5,735 \mathrm{Btu} & 1.681 \mathrm{kWh} / \mathrm{yr}
\end{array}
$$

Energy consumption of electrical components required for operation of gas oven

$\mathrm{E}_{\mathrm{IO}}=$ Direct measurement of gas ignition device

$\mathrm{E}_{\mathrm{IO}}=118.7 \mathrm{Wh}$

Annual primary energy consumption

$$
\begin{aligned}
& \left.\mathrm{E}_{\mathrm{CO}}=\left(\mathrm{E}_{\mathrm{O}} \times \mathrm{O}_{\mathrm{O}}\right) / \mathrm{W}_{1} \times \mathrm{C}_{\mathrm{p}} \times \mathrm{T}\right) \\
& \mathrm{E}_{\mathrm{CO}}=1.83 \times 10^{6} \mathrm{Btu} / \mathrm{yr}
\end{aligned}
$$

Annual secondary energy for gas ovens

(from glow plug)

$$
\begin{aligned}
& \mathrm{E}_{\mathrm{SO}}=\left(\mathrm{E}_{\mathrm{lO}} \times \mathrm{H}_{\mathrm{e}} \times \mathrm{O}_{\mathrm{o}}\right) /\left(\mathrm{W}_{1} \times \mathrm{C}_{\mathrm{P}} \times \mathrm{T}\right) \\
& \mathrm{E}_{\mathrm{so}}=36.9 \mathrm{kWh} / \mathrm{yr}
\end{aligned}
$$

Energy consumption of self-cleaning operation of gas oven

$$
\begin{aligned}
& E_{\mathrm{s}}=\text { Direct measurement of gas consumption } \\
& \mathrm{E}_{\mathrm{s}}=46.2 \times 10^{3} \mathrm{Btu}
\end{aligned}
$$

Annual energy consumption of self-cleaning operation for conventional gas oven

$$
\begin{aligned}
& E_{S C}=E_{S} \times E_{S S}, E_{S S}=7 \\
& E_{S C}=323 \times 10^{3} \mathrm{Btu} / \mathrm{yr}
\end{aligned}
$$

Annual secondary energy consumption for self-cleaning gas oven

$$
\begin{aligned}
& E_{S S}=E_{\mathrm{IS}} \times S_{\mathrm{g}} \times \mathrm{C} \\
& E_{\mathrm{sS}}=6.99 \mathrm{kWh} / \mathrm{yr}
\end{aligned}
$$

Annual clock energy consumption

$$
\begin{aligned}
& E_{C L}=P_{C L} \times H_{k} \times C \\
& E_{C L}=27.2 \mathrm{kWh} / \mathrm{yr}
\end{aligned}
$$

Total annual energy consumption of single conventional gas oven

$$
\begin{aligned}
& \mathrm{E}_{\mathrm{ACG}}=\mathrm{E}_{\mathrm{CO}}+\mathrm{E}_{\mathrm{SC}} \\
& \mathrm{E}_{\mathrm{AOG}}=2.15 \times 10^{6} \mathrm{Btu} / \mathrm{yr} \quad 630.6 \mathrm{kWh} / \mathrm{yr}
\end{aligned}
$$

Total annual electrical energy consumption of gas oven

$$
\begin{aligned}
& \mathrm{E}_{\mathrm{AOE}}=\mathrm{E}_{S \mathrm{O}}+\mathrm{E}_{\mathrm{SS}}+\mathrm{E}_{\mathrm{CL}} \\
& \mathrm{E}_{\mathrm{AOE}}=71.1 \mathrm{kWh} / \mathrm{yr}
\end{aligned}
$$

Annual conventional oven cooking efficiency

$$
\begin{aligned}
& \operatorname{Eff}_{A O}=\left(W_{1} \times C_{p} \times T\right) /\left(E_{O} \times\left(E_{1 O} \times H_{c}\right)\right) \\
& \operatorname{Eff}_{A O}=6.3 \%
\end{aligned}
$$

Energy factor

$$
\begin{aligned}
& R_{O}=O_{U} / E_{A U} \\
& R_{O}=0.052
\end{aligned}
$$




\section{Summary of Gas Oven Test \#2}

\begin{tabular}{|c|c|c|c|c|c|c|c|c|c|c|c|}
\hline \multicolumn{3}{|c|}{ Temperature } & \multicolumn{3}{|c|}{$\begin{array}{c}\text { Energy } \\
\text { Consumption }\end{array}$} & \multicolumn{3}{|c|}{ Gas Volume } & \multicolumn{3}{|c|}{ Constants, and Initial Values } \\
\hline & $\left({ }^{\circ} \mathrm{F}\right)$ & $\left({ }^{\circ} \mathrm{C}\right)$ & & (Btu) & $(\mathrm{Wh})$ & & $\left(\mathrm{ft}^{3}\right)$ & (L) & & & \\
\hline $\mathrm{T}_{\mathrm{A}}$ & 274.4 & 134.7 & $\mathrm{E}_{\mathrm{A}}$ & 5768 & 1690 & $\mathrm{~V}_{\mathrm{A}}$ & 5.62 & 159.1 & $\mathrm{P}_{\mathrm{CL}}$ & $1.0 \mathrm{Btu}$ & $3.4 \mathrm{~W}$ \\
\hline $\mathrm{T}_{\mathrm{B}}$ & 284.1 & 140.1 & $E_{B}$ & 5768 & 1690 & $V_{B}$ & 5.62 & 159.1 & $\mathrm{O}_{0}$ & $124,200 \mathrm{Btu} / \mathrm{yr}$ & $36.4 \mathrm{Kwh} / \mathrm{yr}$ \\
\hline $\mathrm{T}_{\mathrm{C}}$ & 287.7 & 142.0 & $\mathrm{E}_{\mathrm{C}}$ & 6142 & 1800 & $\mathrm{~V}_{\mathrm{C}}$ & 5.98 & 169.4 & $\mathrm{w}_{1}$ & $8.38 \mathrm{lb}$ & $3.81 \mathrm{~kg}$ \\
\hline$T_{D}$ & 295.9 & 146.6 & $\mathrm{E}_{\mathrm{D}}$ & 6142 & 1800 & $\mathrm{~V}_{\mathrm{D}}$ & 5.98 & 169.4 & $\mathrm{C}_{\mathrm{p}}$ & $0.23 \mathrm{Btu} / \mathrm{bb}^{\circ} \mathrm{F}$ & $0.96 \mathrm{~kJ} / \mathrm{kg}^{\circ} \mathrm{C}$ \\
\hline & & & & & & & & & $\mathrm{T}$ & $202.0^{\circ} \mathrm{F}$ & $112.2^{\circ} \mathrm{C}$ \\
\hline $\mathrm{T}_{\mathrm{AB}}$ & 279.3 & 137.4 & $\mathrm{E}_{\mathrm{AB}}$ & 5768 & 1690 & $\mathrm{~V}_{\mathrm{AB}}$ & 5.62 & 159.1 & $\mathrm{H}_{\mathrm{c}}$ & $3.41 \mathrm{Btu} / \mathrm{Wh}$ & $3.6 \mathrm{KJ} / \mathrm{Wh}$ \\
\hline $\mathrm{T}_{\mathrm{CD}}$ & 291.8 & 144.3 & $\mathrm{E}_{\mathrm{CD}}$ & 6142 & 1800 & $\mathrm{~V}_{\mathrm{CD}}$ & 5.98 & 169.4 & $\mathrm{H}_{\mathrm{n}}$ & $1027 \mathrm{Btu} / \mathrm{ft}^{3}$ & $10.6 \mathrm{Wh} / \mathrm{L}$ \\
\hline$T_{0}$ & 275.4 & 135.2 & & & & & & & $\mathrm{H}_{\mathrm{k}}$ & $8760 \mathrm{hr} / \mathrm{yr}$ & $\mathrm{C}=0.001 \mathrm{~kW} / \mathrm{W}$ \\
\hline
\end{tabular}

Conventional gas oven test energy consumption

$$
\begin{aligned}
& \mathrm{E}_{\mathrm{O}}=\mathrm{E}_{\mathrm{AB}}+\left[\left(\left(\mathrm{T}_{\mathrm{O}}-\mathrm{T}_{\mathrm{AB}}\right) /\left(\mathrm{T}_{\mathrm{CD}}=\mathrm{T}_{\mathrm{AB}}\right)\right) \times\left(\mathrm{E}_{\mathrm{CD}}-\mathrm{E}_{\mathrm{AB}}\right)\right] \\
& \mathrm{E}_{\mathrm{O}}=5,651 \mathrm{Btu} \\
& 1.656 \mathrm{kWh} / \mathrm{yr}
\end{aligned}
$$

Energy consumption of electrical components required for operation of gas oven

$\mathrm{E}_{\mathrm{1O}}=$ Direct measurement of gas ignition device

$\mathrm{E}_{\mathrm{IO}}=118.3 \mathrm{Wh}$

Annual primary energy consumption

$$
\begin{aligned}
& \left.\mathrm{E}_{\mathrm{co}}=\left(\mathrm{E}_{\mathrm{O}} \times \mathrm{O}_{\mathrm{O}}\right) / \mathrm{W}_{\mathrm{l}} \times \mathrm{C}_{\mathrm{p}} \times \mathrm{T}\right) \quad 528.0 \mathrm{kWh} / \mathrm{yr} \\
& \mathrm{E}_{\mathrm{co}}=1.80 \times 10^{6} \mathrm{Btu} / \mathrm{yr}
\end{aligned}
$$

Annual secondary energy for gas ovens (from glow plug)

$$
\begin{aligned}
& E_{\text {SO }}=\left(E_{\text {IO }} \times \mathrm{H}_{\mathrm{c}} \times \mathrm{O}_{\mathrm{O}}\right) /\left(\mathrm{W}_{1} \times \mathrm{C}_{\mathrm{P}} \times \mathrm{T}\right) \\
& \mathrm{E}_{\mathrm{SO}}=36.8 \mathrm{kWh} / \mathrm{yr}
\end{aligned}
$$

Energy consumption of self-cleaning operation of gas oven

$$
\begin{aligned}
& E_{S}=\text { Direct measurement of gas consumption } \\
& E_{S}=45.2 \times 10^{3} \mathrm{Btu} \\
&
\end{aligned}
$$

Annual energy consumption of self-cleaning operation for conventional gas oven

$$
\begin{aligned}
& E_{S C}=E_{S} \times E_{S S}, E_{S S}=7 \\
& E_{s c}=317 \times 10^{3} B t w / y r
\end{aligned}
$$

$92.8 \mathrm{kWh} / \mathrm{yr}$
Annual secondary energy consumption for self-cleaning gas oven

$$
\begin{aligned}
& E_{S S}=E_{s s} \times S_{g} \times C \\
& E_{s S}=7.26 \mathrm{kWh} / y r
\end{aligned}
$$

Annual clock energy consumption

$$
\begin{aligned}
& \mathrm{E}_{\mathrm{CL}}=\mathrm{P}_{\mathrm{CL}} \times \mathrm{H}_{\mathrm{k}} \times \mathrm{C} \\
& \mathrm{E}_{\mathrm{CL}}=29.5 \mathrm{kWh} / \mathrm{yr}
\end{aligned}
$$

Total annual energy consumption of single conventional gas oven

$$
\begin{aligned}
& \mathrm{E}_{\mathrm{AOG}}=\mathrm{E}_{\mathrm{CO}}+\mathrm{E}_{\mathrm{SC}} \\
& \mathrm{E}_{\mathrm{AOG}}=2.12 \times 10^{6} \mathrm{Btu} / \mathrm{yr} \quad 620.8 \mathrm{kWh} / \mathrm{yr}
\end{aligned}
$$

Total annual electrical energy consumption of gas oven

$$
\begin{aligned}
& E_{A O E}=E_{S O}+E_{S S}+E_{C L} \\
& E_{A O E}=73.6 \mathrm{kWh} / \mathrm{yr}
\end{aligned}
$$

Annual conventional oven cooking efficiency

$$
\begin{aligned}
& \operatorname{Eff}_{A O}=\left(W_{1} \times C_{p} \times T\right) /\left(E_{O} \times\left(E_{1 O} \times H_{e}\right)\right) \\
& \operatorname{Eff}_{A O}=6.4 \%
\end{aligned}
$$

Energy factor

$$
\begin{aligned}
& R_{O}=O_{\sigma} / E_{A O} \\
& R_{O}=0.052
\end{aligned}
$$




\section{Summary of Gas Oven Test \#3}

\begin{tabular}{|l|l|l|l|l|l|l|l|l|l|l|l|}
\hline \multicolumn{2}{|c|}{ Temperature } & \multicolumn{3}{c|}{$\begin{array}{c}\text { Energy } \\
\text { Consumption }\end{array}$} & \multicolumn{3}{c|}{ Gas Volume } & \multicolumn{3}{c|}{ Constants, and Initial Values } \\
\hline \multicolumn{2}{|c|}{$\left({ }^{\circ} \mathrm{F}\right)$} & $\left({ }^{\circ} \mathrm{C}\right)$ & \multicolumn{2}{|c|}{$(\mathrm{Btu})$} & $(\mathrm{Wh})$ & \multicolumn{3}{c|}{$\left(\mathrm{ft}^{3}\right)$} & $(\mathrm{L})$ & \multicolumn{2}{|l}{} \\
\hline $\mathrm{T}_{\mathrm{A}}$ & 267.5 & 130.8 & $\mathrm{E}_{\mathrm{A}}$ & 5471 & 1603 & $\mathrm{~V}_{\mathrm{A}}$ & 5.33 & 150.9 & $\mathrm{P}_{\mathrm{CL}}$ & $0.9 \mathrm{Btu}$ & $3.1 \mathrm{~W}$ \\
$\mathrm{~T}_{\mathrm{B}}$ & 277.1 & 136.2 & $\mathrm{E}_{\mathrm{B}}$ & 5471 & 1603 & $\mathrm{~V}_{\mathrm{B}}$ & 5.33 & 150.9 & $\mathrm{O}_{0}$ & $124,200 \mathrm{Btu} / \mathrm{yr}$ & $36.4 \mathrm{Kwh} / \mathrm{yr}$ \\
$\mathrm{T}_{\mathrm{C}}$ & 280.2 & 137.9 & $\mathrm{E}_{\mathrm{C}}$ & 5834 & 1710 & $\mathrm{~V}_{\mathrm{C}}$ & 5.68 & 160.9 & $\mathrm{~W}_{1}$ & $8.38 \mathrm{lb}$ & $3.81 \mathrm{~kg}$ \\
$\mathrm{~T}_{\mathrm{D}}$ & 289.2 & 142.9 & $\mathrm{E}_{\mathrm{D}}$ & 5834 & 1710 & $\mathrm{~V}_{\mathrm{D}}$ & 5.68 & 160.9 & $\mathrm{C}_{\mathrm{p}}$ & $0.23 \mathrm{Btu} / \mathrm{b}^{\circ} \mathrm{F}$ & $0.96 \mathrm{~kJ} / \mathrm{kg}^{\circ} \mathrm{C}$ \\
& & & & & & & & $\mathrm{T}$ & $202.0{ }^{\circ} \mathrm{F}$ & $112.2{ }^{\circ} \mathrm{C}$ \\
$\mathrm{T}_{\mathrm{AB}}$ & 272.3 & 133.5 & $\mathrm{E}_{\mathrm{AB}}$ & 5471 & 1603 & $\mathrm{~V}_{\mathrm{AB}}$ & 5.33 & 150.9 & $\mathrm{H}_{\mathrm{c}}$ & $3.41 \mathrm{Btu} / \mathrm{Wh}$ & $3.6 \mathrm{KJ} / \mathrm{Wh}$ \\
$\mathrm{T}_{\mathrm{CD}}$ & 284.7 & 140.4 & $\mathrm{E}_{\mathrm{CD}}$ & 5834 & 1710 & $\mathrm{~V}_{\mathrm{CD}}$ & 5.68 & 160.9 & $\mathrm{H}_{\mathrm{n}}$ & $1027 \mathrm{Btu} / \mathrm{ft}^{3}$ & $10.6 \mathrm{Wh} / \mathrm{L}$ \\
$\mathrm{T}_{\mathrm{O}}$ & 276.6 & 135.9 & & & & & & & $\mathrm{H}_{\mathrm{k}}$ & $8760 \mathrm{hr} / \mathrm{yr}$ & $\mathrm{C}=0.001 \mathrm{~kW} / \mathrm{W}$ \\
\hline
\end{tabular}

Conventional gas oven test energy consumption

$$
\begin{array}{lc}
E_{O}=E_{A B}+\left[\left(\left(T_{O}-T_{A B}\right) /\left(T_{C D}=T_{A B}\right)\right) \times\left(E_{C D}-E_{A B}\right)\right] \\
E_{O}=5,597 \mathrm{Btu} & 1.640 \mathrm{kWh} / \mathrm{yr}
\end{array}
$$

Energy consumption of electrical components required for operation of gas oven

$\mathrm{E}_{\mathrm{TO}}=$ Direct measurement of gas ignition device $\mathrm{E}_{\mathrm{IO}}=116.9 \mathrm{Wh}$

Annual primary energy consumption

$$
\begin{aligned}
& \left.\mathrm{E}_{\mathrm{CO}}=\left(\mathrm{E}_{\mathrm{O}} \times \mathrm{O}_{\mathrm{O}}\right) / \mathrm{W}_{1} \times \mathrm{C}_{\mathrm{p}} \times \mathrm{T}\right) \\
& \mathrm{E}_{\mathrm{CO}}=1.78 \times 10^{6} \mathrm{Btu} / \mathrm{yr}
\end{aligned} \quad 523.0 \mathrm{kWh} / \mathrm{yr}
$$

Annual secondary energy for gas ovens (from glow plug)

$$
\begin{aligned}
& \mathrm{E}_{\mathrm{So}}=\left(\mathrm{E}_{10} \times \mathrm{H}_{\mathrm{e}} \times \mathrm{O}_{\mathrm{o}}\right) /\left(\mathrm{W}_{1} \times \mathrm{C}_{\mathrm{P}} \times \mathrm{T}\right) \\
& \mathrm{E}_{\mathrm{so}}=36.3 \mathrm{kWh} / \mathrm{yr}
\end{aligned}
$$

Energy consumption of self-cleaning operation of gas oven

$\mathrm{E}_{\mathrm{S}}=$ Direct measurement of gas consumption

$$
\mathrm{E}_{\mathrm{S}}=47.1 \times 10^{3} \mathrm{Btu} \quad 13.8 \mathrm{kWh} / \mathrm{yr}
$$

Annual energy consumption of self-cleaning operation for conventional gas oven

$$
\begin{aligned}
& E_{S C}=E_{S} \times E_{S s}, E_{S S}=7 \\
& E_{S C}=330 \times 10^{3} \mathrm{Btu} / \mathrm{yr}
\end{aligned}
$$

$96.7 \mathrm{kWh} / \mathrm{yr}$
Annual secondary energy consumption for self-cleaning gas oven

$$
\begin{aligned}
& E_{S S}=E_{1 s} \times S_{g} \times C \\
& E_{S S}=7.20 \mathrm{kWh} / y r
\end{aligned}
$$

Annual clock energy consumption

$$
\begin{aligned}
& E_{C L}=P_{C L} \times H_{k} \times C \\
& E_{C L}=27.1 \mathrm{kWh} / \mathrm{yr}
\end{aligned}
$$

Total annual energy consumption of single conventional gas oven

$$
\begin{aligned}
& \mathrm{E}_{\mathrm{AOG}}=\mathrm{E}_{\mathrm{CO}}+\mathrm{E}_{\mathrm{SC}} \\
& \mathrm{E}_{\mathrm{AOG}}=2.11 \times 10^{6} \mathrm{Btu} / \mathrm{yr} \quad 619.7 \mathrm{kWh} / \mathrm{yr}
\end{aligned}
$$

Total annual electrical energy consumption of gas oven

$$
\begin{aligned}
& E_{A O E}=E_{S O}+E_{S S}+E_{C L} \\
& E_{A O E}=70.6 \mathrm{kWh} / \mathrm{yI}
\end{aligned}
$$

Annual conventional oven cooking efficiency

$$
\begin{aligned}
& \operatorname{Eff}_{A O}=\left(W_{1} \times C_{p} \times T\right) /\left(E_{O} \times\left(E_{I O} \times H_{e}\right)\right) \\
& \operatorname{Eff}_{A O}=6.5 \%
\end{aligned}
$$

Energy factor

$$
\begin{aligned}
& R_{O}=O_{d} / E_{A O} \\
& R_{O}=0.053
\end{aligned}
$$




\section{Summary of Gas Oven Test \#4}

\begin{tabular}{|c|c|c|c|c|c|c|c|c|c|c|c|}
\hline \multicolumn{3}{|c|}{ Temperature } & \multicolumn{3}{|c|}{$\begin{array}{c}\text { Energy } \\
\text { Consumption }\end{array}$} & \multicolumn{3}{|c|}{ Gas Volume } & \multicolumn{3}{|c|}{ Constants, and Initial Values } \\
\hline & $\left({ }^{\circ} \mathrm{F}\right)$ & $\left({ }^{\circ} \mathrm{C}\right)$ & & (Btu) & (Wh) & & $\left(\mathrm{ft}^{3}\right)$ & $(\mathrm{L})$ & & & \\
\hline $\mathrm{T}_{\mathrm{A}}$ & 272.0 & 133.4 & $\mathrm{E}_{\mathrm{A}}$ & 5546 & 1625 & $\mathrm{~V}_{\mathrm{A}}$ & 5.40 & 152.9 & $\mathrm{P}_{\mathrm{CL}}$ & $0.9 \mathrm{Btu}$ & $3.1 \mathrm{~W}$ \\
\hline $\mathrm{T}_{\mathrm{B}}$ & 281.0 & 138.3 & $E_{B}$ & 5546 & 1625 & $\mathrm{~V}_{\mathrm{B}}$ & 5.40 & 152.9 & $\mathrm{O}_{\mathrm{o}}$ & $124,200 \mathrm{Btu} / \mathrm{yr}$ & $36.4 \mathrm{Kwh} / \mathrm{yr}$ \\
\hline $\mathrm{T}_{\mathrm{C}}$ & 284.3 & 140.1 & $\mathrm{E}_{\mathrm{C}}$ & 5910 & 1732 & $\mathrm{~V}_{\mathrm{C}}$ & 5.76 & 163.0 & $\mathrm{~W}_{1}$ & $8.38 \mathrm{lb}$ & $3.81 \mathrm{~kg}$ \\
\hline $\mathrm{T}_{\mathrm{D}}$ & 293.0 & 145.0 & $\mathrm{E}_{\mathrm{D}}$ & 5910 & 1732 & $V_{D}$ & 5.76 & 163.0 & $\mathrm{C}_{\mathrm{p}}$ & $0.23 \mathrm{Btu} / \mathrm{lb}^{\circ} \mathrm{F}$ & $0.96 \mathrm{~kJ} / \mathrm{kg}^{\circ} \mathrm{C}$ \\
\hline & & & & & & & & & $\mathrm{T}$ & $202.0^{\circ} \mathrm{F}$ & $112.2^{\circ} \mathrm{C}$ \\
\hline $\mathrm{T}_{\mathrm{AB}}$ & 276.5 & 135.8 & $E_{A B}$ & 5546 & 1625 & $\mathrm{~V}_{\mathrm{AB}}$ & 5.40 & 152.9 & $\mathrm{H}_{\mathrm{c}}$ & $3.41 \mathrm{Btu} / \mathrm{Wh}$ & $3.6 \mathrm{KJ} / \mathrm{Wh}$ \\
\hline $\mathrm{T}_{\mathrm{CD}}$ & 288.6 & 142.6 & $\mathrm{E}_{\mathrm{CD}}$ & 5910 & 1732 & $V_{C D}$ & 5.76 & 163.0 & $\mathrm{H}_{\mathrm{n}}$ & $1027 \mathrm{Btu} / \mathrm{ft}^{3}$ & $10.6 \mathrm{Wh} / \mathrm{L}$ \\
\hline $\mathrm{T}_{0}$ & 276.6 & 135.9 & & & & & & & $\mathrm{H}_{\mathrm{k}}$ & $8760 \mathrm{hr} / \mathrm{yr}$ & $\mathrm{C}=0.001 \mathrm{~kW} / \mathrm{W}$ \\
\hline
\end{tabular}

Conventional gas oven test energy consumption

$$
\begin{aligned}
& \mathrm{E}_{\mathrm{O}}=\mathrm{E}_{\mathrm{AB}}+\left[\left(\left(\mathrm{T}_{\mathrm{O}}-\mathrm{T}_{\mathrm{AB}}\right) /\left(\mathrm{T}_{\mathrm{CD}}=\mathrm{T}_{\mathrm{AB}}\right)\right) \times\left(\mathrm{E}_{\mathrm{CD}}-\mathrm{E}_{\mathrm{AB}}\right)\right] \\
& \mathrm{E}_{\mathrm{O}}=5,549 \mathrm{Btu} \\
& 1.626 \mathrm{kWh} / \mathrm{yr}
\end{aligned}
$$

Energy consumption of electrical components required for operation of gas oven

$\mathrm{E}_{\mathrm{TO}}=$ Direct measurement of gas ignition device

$\mathrm{E}_{\mathrm{IO}}=119.3 \mathrm{Wh}$

Annual primary energy consumption

$$
\begin{aligned}
& \left.E_{\mathrm{Co}}=\left(\mathrm{E}_{\mathrm{o}} \times \mathrm{O}_{\mathrm{o}}\right) / \mathrm{W}_{1} \times \mathrm{C}_{\mathrm{p}} \times \mathrm{T}\right) \quad 518.5 \mathrm{kWh} / \mathrm{yr} \\
& \mathrm{E}_{\mathrm{CO}}=1.77 \times 10^{6} \mathrm{Btu} / \mathrm{yr}
\end{aligned}
$$

Annual secondary energy for gas ovens

(from glow plug)

$$
\begin{aligned}
& E_{\text {so }}=\left(E_{10} \times H_{e} \times O_{O}\right) /\left(W_{1} \times C_{P} \times T\right) \\
& E_{\text {So }}=37.1 \mathrm{kWh} / \mathrm{yr}
\end{aligned}
$$

Energy consumption of self-cleaning operation of gas oven

$$
\mathrm{E}_{\mathrm{S}}=\text { Direct measurement of gas consumption }
$$$$
\mathrm{E}_{\mathrm{s}}=46.3 \times 10^{3} \mathrm{Btu} \quad 13.6 \mathrm{kWh} / \mathrm{yr}
$$

Annual energy consumption of self-cleaning operation for conventional gas oven

$$
\begin{aligned}
& E_{S C}=E_{S} \times E_{S S}, E_{S S}=7 \\
& E_{S C}=324 \times 10^{3} \mathrm{Btw} / \mathrm{yr}
\end{aligned} \quad 95.0 \mathrm{kWh} / \mathrm{yr}
$$

Annual secondary energy consumption for self-cleaning

$$
\begin{aligned}
\text { gas oven } & \\
E_{\mathrm{SS}} & =E_{\mathrm{IS}} \times \mathrm{S}_{\mathrm{g}} \times \mathrm{C} \\
\mathrm{E}_{\mathrm{SS}} & =6.99 \mathrm{kWh} / \mathrm{yr}
\end{aligned}
$$

Annual clock cnergy consumption

$$
\begin{aligned}
& E_{\mathrm{CL}}=\mathrm{P}_{\mathrm{CL}} \times \mathrm{H}_{\mathrm{k}} \times \mathrm{C} \\
& \mathrm{E}_{\mathrm{CL}}=27.2 \mathrm{kWh} / \mathrm{yr}
\end{aligned}
$$

Total annual energy consumption of single conventional gas oven

$$
\begin{aligned}
& E_{\mathrm{AOG}}=\mathrm{E}_{\mathrm{CO}}+\mathrm{E}_{\mathrm{SC}} \\
& \mathrm{E}_{\mathrm{AOG}}=2.09 \times 10^{6} \mathrm{Btu} / \mathrm{yr} \quad 613.4 \mathrm{kWh} / \mathrm{yr}
\end{aligned}
$$

Total annual electrical energy consumption of gas oven

$$
\begin{aligned}
& E_{A O E}=E_{S O}+E_{S S}+E_{C L} \\
& E_{A O E}=71.3 \mathrm{kWh} / \mathrm{yr}
\end{aligned}
$$

Annual conventional oven cooking efficiency

$$
\begin{aligned}
& \operatorname{Eff}_{A O}=\left(W_{1} \times C_{p} \times T\right) /\left(E_{o} \times\left(E_{1 O} \times H_{e}\right)\right) \\
& \operatorname{Eff}_{A O}=6.5 \%
\end{aligned}
$$

Energy factor

$$
\begin{aligned}
& R_{O}=O_{O} / E_{A O} \\
& R_{O}=0.053
\end{aligned}
$$




\section{Summary of Gas Oven Test \#5}

\begin{tabular}{|c|c|c|c|c|c|c|c|c|c|c|c|}
\hline \multicolumn{3}{|c|}{ Temperature } & \multicolumn{3}{|c|}{$\begin{array}{c}\text { Energy } \\
\text { Consumption }\end{array}$} & \multicolumn{3}{|c|}{ Gas Volume } & \multicolumn{3}{|c|}{ Constants, and Initial Values } \\
\hline & $\left({ }^{\circ} \mathrm{F}\right)$ & $\left({ }^{\circ} \mathrm{C}\right)$ & & (Btu) & $(\mathrm{Wh})$ & & $\left(\mathrm{ft}^{3}\right)$ & $(\mathrm{L})$ & & & \\
\hline $\mathrm{T}_{\mathrm{A}}$ & 268.3 & 131.3 & $\mathrm{E}_{\mathrm{A}}$ & 5505 & 1614 & $\mathrm{~V}_{\mathrm{A}}$ & 5.36 & 151.8 & $\mathrm{P}_{\mathrm{CL}}$ & $0.9 \mathrm{Btu}$ & $3.1 \mathrm{~W}$ \\
\hline $\mathrm{T}_{\mathrm{B}}$ & 278.4 & 136.9 & $\mathrm{E}_{\mathrm{B}}$ & 5505 & 1614 & $\mathrm{~V}_{\mathrm{B}}$ & 5.36 & 151.8 & $\mathrm{O}_{\mathrm{O}}$ & $131,038 \mathrm{Btu} / \mathrm{yr}$ & $38.4 \mathrm{Kwh} / \mathrm{yr}$ \\
\hline $\mathrm{T}_{\mathrm{C}}$ & 281.8 & 138.8 & $\mathrm{E}_{\mathrm{C}}$ & 5876 & 1722 & $\mathrm{~V}_{\mathrm{C}}$ & 5.72 & 162.0 & $\mathrm{~W}_{1}$ & $8.38 \mathrm{lb}$ & $3.81 \mathrm{~kg}$ \\
\hline $\mathrm{T}_{\mathrm{D}}$ & 291.2 & 144.0 & $\mathrm{E}_{\mathrm{D}}$ & 5876 & 1722 & $\mathrm{~V}_{\mathrm{D}}$ & 5.72 & 162.0 & $\mathrm{C}_{\mathrm{p}}$ & $0.23 \mathrm{Btu} / \mathrm{lb}^{\circ} \mathrm{F}$ & $0.96 \mathrm{~kJ} / \mathrm{kg}^{\circ} \mathrm{C}$ \\
\hline & & & & & & & & & $\mathrm{T}$ & $202.0^{\circ} \mathrm{F}$ & $112.2^{\circ} \mathrm{C}$ \\
\hline $\mathrm{T}_{\mathrm{AB}}$ & 273.3 & 134.1 & $\mathrm{E}_{\mathrm{AB}}$ & 5505 & 1614 & $\mathrm{~V}_{\mathrm{AB}}$ & 5.36 & 151.8 & $\mathrm{H}_{\mathrm{e}}$ & $3.41 \mathrm{Btu} / \mathrm{Wh}$ & $3.6 \mathrm{KJ} / \mathrm{Wh}$ \\
\hline $\mathrm{T}_{\mathrm{CD}}$ & 286.5 & 141.4 & $\mathrm{E}_{\mathrm{CD}}$ & 5876 & 1722 & $\mathrm{~V}_{\mathrm{CD}}$ & 5.72 & 162.0 & $\mathrm{H}_{\mathrm{n}}$ & $1027 \mathrm{Btu} / \mathrm{ft}^{3}$ & $10.6 \mathrm{Wh} / \mathrm{L}$ \\
\hline $\mathrm{T}_{\mathrm{O}}$ & 276.6 & 135.9 & & & & & & & $\mathrm{H}_{\mathrm{k}}$ & $8760 \mathrm{hr} / \mathrm{sr}$ & $\mathrm{C}=0.001 \mathrm{~kW} / \mathrm{W}$ \\
\hline
\end{tabular}

Conventional gas oven test energy consumption

$$
\begin{aligned}
& \mathrm{E}_{\mathrm{O}}=\mathrm{E}_{\mathrm{AB}}+\left[\left(\left(\mathrm{T}_{\mathrm{O}}-\mathrm{T}_{\mathrm{AB}}\right) /\left(\mathrm{T}_{\mathrm{CD}}=\mathrm{T}_{\mathrm{AB}}\right)\right) \times\left(\mathrm{E}_{\mathrm{CD}}-\mathrm{E}_{\mathrm{AB}}\right)\right] \\
& \mathrm{E}_{\mathrm{O}}=5,598 \mathrm{Btu} \\
& 1.641 \mathrm{kWh} / \mathrm{yr}
\end{aligned}
$$

Energy consumption of electrical components required for operation of gas oven

$\mathrm{E}_{\mathrm{TO}}=$ Direct measurement of gas ignition device

$\mathrm{E}_{\mathrm{TO}}=115.6 \mathrm{Wh}$

Annual primary energy consumption

$$
\begin{aligned}
& \left.\mathrm{E}_{\mathrm{CO}}=\left(\mathrm{E}_{\mathrm{O}} \times \mathrm{O}_{\mathrm{O}}\right) / \mathrm{W}_{1} \times \mathrm{C}_{\mathrm{p}} \times \mathrm{T}\right) \\
& \mathrm{E}_{\mathrm{CO}}=1.78 \times 10^{6} \mathrm{Btu} / \mathrm{yr}
\end{aligned} \quad 522.6 \mathrm{KWh} / \mathrm{yr}
$$

Annual secondary energy for gas ovens (from glow plug)

$$
\begin{aligned}
& E_{\text {so }}=\left(E_{10} \times H_{c} \times O_{o}\right) /\left(W_{1} \times C_{p} \times T\right) \\
& E_{\text {so }}=35.9 \mathrm{kWh} / \mathrm{yr}
\end{aligned}
$$

Energy consumption of self-cleaning operation of gas oven

$$
\begin{aligned}
& E_{\mathrm{S}}=\text { Direct measurement of gas consumption } \\
& \mathrm{E}_{\mathrm{S}}=45.7 \times 10^{3} \mathrm{Btu} \\
& 13.4 \mathrm{kWh} / \mathrm{yr}
\end{aligned}
$$

Annual energy consumption of self-cleaning opcration for conventional gas oven

$$
\begin{aligned}
& E_{S C}=E_{S} \times E_{S S}, E_{S S}=7 \\
& E_{S C}=320 \times 10^{3} \mathrm{Btu} / \mathrm{yr}
\end{aligned} \quad 93.8 \mathrm{kWh} / \mathrm{yr}
$$

Annual secondary energy consumption for self-cleaning gas oven

$$
\begin{aligned}
& E_{s s}=E_{1 s} \times S_{g} \times C \\
& E_{s s}=7.28 \mathrm{kWh} / y r
\end{aligned}
$$

Annual clock energy consumption

$$
\begin{aligned}
& E_{C L}=P_{C L} \times H_{k} \times C \\
& E_{C L}=28.3 \mathrm{kWh} / \mathrm{yr}
\end{aligned}
$$

Total annual energy consumption of single conventional gas oven

$$
\begin{aligned}
& E_{A O G}=E_{C O}+E_{S C} \\
& E_{A O G}=2.10 \times 10^{6} \mathrm{Btu} / \mathrm{yr} \quad 616.4 \mathrm{kWh} / \mathrm{yr}
\end{aligned}
$$

Total annual electrical energy consumption of gas oven

$$
\begin{aligned}
& E_{A O E}=E_{S O}+E_{S S}+E_{C L} \\
& E_{A O E}=71.5 \mathrm{kWh} / \mathrm{yr}
\end{aligned}
$$

Annual conventional oven cooking efficiency

$$
\begin{aligned}
& \operatorname{Eff}_{A O}=\left(W_{1} \times C_{p} \times T\right) /\left(E_{O} \times\left(E_{\text {IO }} \times H_{e}\right)\right) \\
& \operatorname{Eff}_{A O}=6.5 \%
\end{aligned}
$$

Energy factor

$$
\begin{aligned}
& \mathrm{R}_{\mathrm{o}}=\mathrm{O}_{\mathrm{O}} / \mathrm{E}_{\mathrm{AO}} \\
& \mathrm{R}_{\mathrm{O}}=0.053
\end{aligned}
$$

